\title{
Development of Whole-Building
}

Energy Design Targets for

Commercial Buildings

Phase 1 Planning

Volume 1: Final Report
D. B. Crawley
J. E. Kaufman
R. S. Briggs
J. J. Deringer
J. W. Jones
E. W. Kennett
w. W. Seaton

April 1987

Prepared for the U.S. Department of Energy under Contract DE-AC06-76RLO 1830

Pacific Northwest Laboratory

Operated for the U.S. Department of Energy

by Battelle Memorial Institute 


\title{
DISCLAIMER
}

This report was prepared as an account of work sponsored by an agency of the United States Government. Neither the United States Government nor any agency thereof, nor Battelle Memorial Institute, nor any of their employees, makes any warranty, expressed or implied, or assumes any legal liability or responsibility for the accuracy, completeness, or usefulness of any information, apparatus, product, or process disclosed, or represents that its use would not infringe privately owned rights. Reference herein to any specific commercial product, process, or service by trade name, trademark, manufacturer, or otherwise, does not necessarily constitute or imply its endorsement, recommendation, or favoring by the United States Government of any agency thereof, or Battelle Memorial Institute. The views and opinions of authors expressed herein do not necessarly state or reflect those of the United States Government or any agency thereof, or Battelle Memorial Institute.

\author{
PACIFIC NORTHWEST LABORATORY \\ operated by \\ BATTELLE MEMORIAL INSTITUTE \\ for the \\ UNITED STATES DEPARTMENT OF ENERGY \\ under Contract DE-AC06-76RLO 1830
}

\begin{tabular}{|c|c|}
\hline \multicolumn{2}{|c|}{ Printed in the United States of America } \\
\hline \multicolumn{2}{|c|}{ Available from } \\
\hline \multirow{4}{*}{\multicolumn{2}{|c|}{$\begin{array}{c}\text { National Technical Information Service } \\
\text { United States Department of Commerce } \\
5285 \text { Port Royal Road } \\
\text { Springfield, Virginia } 22161\end{array}$}} \\
\hline & \\
\hline & \\
\hline & \\
\hline \multirow{2}{*}{\multicolumn{2}{|c|}{$\begin{array}{l}\text { NTIS Price Codes } \\
\text { Microfiche A01 }\end{array}$}} \\
\hline & \\
\hline \multicolumn{2}{|c|}{ Printed Copy } \\
\hline & Price \\
\hline Pages & Codes \\
\hline $001-025$ & $\mathrm{~A} 02$ \\
\hline $026-050$ & $\mathrm{~A} 03$ \\
\hline $051-075$ & $\mathrm{~A} 04$ \\
\hline $076-100$ & A05 \\
\hline $101-125$ & A06 \\
\hline $126-150$ & $\mathrm{~A} 07$ \\
\hline $151-175$ & $\mathrm{~A} 08$ \\
\hline $176-200$ & A09 \\
\hline $201-225$ & A010 \\
\hline $226-250$ & A011 \\
\hline $251-275$ & A012 \\
\hline $276-300$ & $\mathrm{~A} 013$ \\
\hline
\end{tabular}




\author{
DEVELOPMENT OF WHOLE-BUILDING ENERGY \\ DESIGN TARGETS FOR COMMERCIAL BUILDINGS-- \\ PHASE I PLANNING \\ VOLUME 1: FINAL REPORT
}

D. B. Crawley

R. S. Briggs

Pacific Northwest Laboratory

J. W. Jones

W. W. Seaton

American Society of Heating, Refrigerating, and Air Conditioning Engineers, Inc.

J. F. Kaufman

Illuminating Engineering

Snciety of North America

J. J. Deringer

E. W. Kennett American Institute of

Architects Foundation

Apri1 1987

Prepared for

the U.S. Department of Energy

under Contract DE-AC06-76RLO 1830

Pacific Northwest Laboratory

Richland, Washington 99352 

FOREWORD

This report is one in a series of reports describing research activities in support of the Department of Energy (DOE), Commercial Building Systems Integration Research Program. The goal of the program is to develop the scientific and technical basis for improving integrated decision making during design and construction. Improved decision making could reduce buildings' energy use $40 \%$ to $60 \%$ by the year 2010 .

The objectives of the Commercial Building Systems Integration Research Program are to:

- identify and quantify the most significant energy-related interactions among building subsystems (for example, walls, roofs, windows, HVAC systems and equipment, lighting, power, etc.)

- develop the scientific and technical basis for improving energyrelated interactions in building subsystems

- provide guidance to designers, owners and builders for improving the integration of building subsystems for energy efficiency.

This report describes background research for preparation of a plan for development of whole-building energy targets for new commercial buildings. The lead laboratory for this program is the Pacific Northwest Laboratory. A wide variety of expertise and resources from industry, academia, other government entities, and other DOE laboratories are used in planning, reviewing and conducting research activities. Cooperative and complementary research, development, and technology transfer activities with other interested organizations are actively pursued.

Comments about the work described in this report will be appreciated by the authors or program managers. The research reports prepared for the program are listed in the back of this report.

Drury B. Crawley, Program Manager Building Systems Integration Pacific Northwest Laboratory
Jean J. Boulin, Group Leader Architectural and Engineering Systems Building Systems Division U.S. Department of Energy 



\section{ACKNOWLEDGMENTS}

The authors wish to thank all of the individuals and organizations who provided assistance and guidance through liaison with the project team and by responding to survey questionnaires and providing building data. The authors wish to recognize the many contributions of the Technical Core Team members listed below.

American Society of Heating, Refrigerating, and Air Conditioning Engineers, Inc.

Lynn G. Rellenger, P.E.

David L. Grumman, P.E.

Nei1 R. Patterson, P.E.

Illuminating Engineering Society of North America

Gilbert H. Reiling

Jerry W. White, P.E.

American Institute of Architects Foundation

Charles Eley, AIA

Harrison Fraker, AIA

Thomas Vonier, AIA

Recognition should also be made of the efforts of the subcontractor personnel: John Holton and Judy Klein of Burt Hill Kosar Rittelmann Associates; and Bruce Hunn, John Peterson, and Scott Silver of the University of Texas Center for Energy Studies.

Appreciation is also expressed to Richard Kutina of the American Gas Association and Michael McGrath of the Edison Electric Institute for their counsel and to Ted Kurkowsk $i$ and Jean Boulin of the U. S. Department of Energy for their support. 



\section{SUMMARY}

This Phase 1 report discusses a proposed methodology for setting targets for energy performance in new commercial buildings. The targets would be used as voluntary guidelines for the buildings industry. The building targets project is being conducted at Pacific Northwest Laboratory (PNL) for the U.S. Department of Energy (DOE) to encourage the construction of energy-efficient buildings by informing designers and owners about cost-effective goals for energy use in new commercial buildings. The outcome of this research will be a flexible methodology for setting such targets.

The proposed plan is to develop a Targets Model which would use computer analysis tools to determine building targets. The Targets Model itself would be based on a concept of space functions, that is, a building is a collection of spaces that can be categorized by function. Categories of space functions include lobbies, private offices, and kitchens, all of which can occur in a number of building types. In essence, the building target would then be the floor-area-weighted average of targets for the space functions it contains. A key advantage of this approach when used with computer analys is tools is that the model can produce both example targets for various building types and custom targets for a specific building. This approach is expected to be more flexible and accurate overall than an alternative building-type approach and simpler to use than a building-specific procedure in Section 10 of ASHRAE/IES Standard 90-75. Included in the proposed model are a cost model containing situation-specific costs for energy and construction and the concept of three target levels--typical, good, and the technical/cost-effective limit.

In general, the proposed Targets Model would use design requirements for building functions as input. Examples of requirements are a building's relationship to its surroundings, occupancy levels, desired thermal comfort, and illumination needs. Based on the requirements, space-function characteristics would be determined. Example characteristics include the envelope design, the scheduled use and loads, the temperature and humidity, and the lighting system. Characteristics that are constrained by requirements would need to be separated from those that are not so constrained. In the case of unconstrained 
characteristics, options affecting energy efficiency could be considered. The appropriate characteristics would be fed into the space-function energy model to determine the energy impacts of the characteristics. These results would be input to an energy-cost and building-cost model to calculate the energy-related costs. The results from the energy-cost and building-cost model would be fed through the characteristic selection procedure to select the options that are reasonably balanced between energy use and cost effectiveness, setting the target for that space function. The final step would be to sum the targets for each function on the basis of the area for that function to obtain a target for the building.

The complete Phase 1 reporting is in two volumes. This volume is the final report and describes the Targets Model, the development and testing of key concepts, and the planned Phase 2 tasks. Volume 2 contains supporting technical detail. A review by representatives of the buildings industry of Phase 1 work and proposed Phase 2 tasks, is planned for March 4-5, 1987 in Washington, DC. Phase 2 will develop the Targets Model based on this review. 


\section{CONTENTS}

FOREWORD

$i j i$

ACKNOWLEDGMENTS $\ldots \ldots \ldots \ldots \ldots \ldots \ldots \ldots \ldots \ldots \ldots \ldots \ldots \ldots \ldots \ldots \ldots$

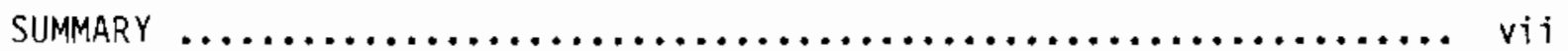

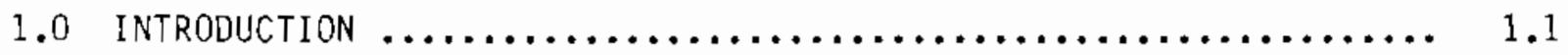

1.1 PROJECT ORGANIZATION $\ldots \ldots \ldots \ldots \ldots \ldots \ldots \ldots \ldots \ldots \ldots \ldots \ldots \ldots \ldots \ldots$

1.2 PROJECT OVERVIEW $\ldots \ldots \ldots \ldots \ldots \ldots \ldots \ldots \ldots \ldots \ldots \ldots \ldots \ldots \ldots \ldots$

1.3 DESIRABLE ATTRIBUTES OF WHOLE-BUILDING ENERGY TARGETS $\ldots \ldots$.

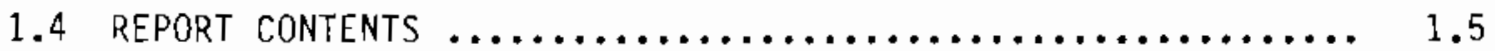

2.0 PROPOSED APPROACH TO DEVELOPING TARGETS $\ldots \ldots \ldots \ldots \ldots \ldots \ldots \ldots \ldots \ldots . . \ldots \ldots$

2.1 APPROACH TO TARGETS-MODEL DEVELOPMENT $\ldots \ldots \ldots \ldots \ldots \ldots \ldots \ldots .2 .6$

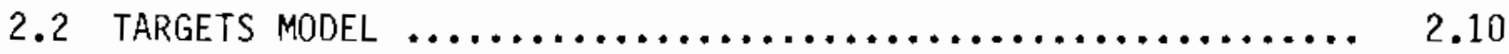

2.2.1 Space-Function Characteristics $\ldots \ldots \ldots \ldots \ldots \ldots \ldots \ldots .2 .12$

2.2.2 Space-Function Energy Mode1 ................ 2.16

2.2.3 Energy-Cost and Building-Cost Model ........... 2.18

2.2.4 Energy-Characteristic Selection Procedure ......... 2.20

2.3 USING TARGETS FOR BUILDING DESIGN $\ldots \ldots \ldots \ldots \ldots \ldots \ldots \ldots \ldots \ldots .2 .23$

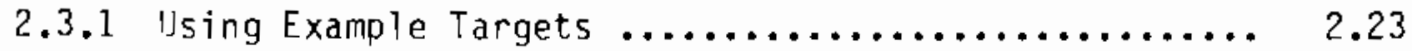

2.3.2 Using Custom, Building-Specific Targets ......... 2.24

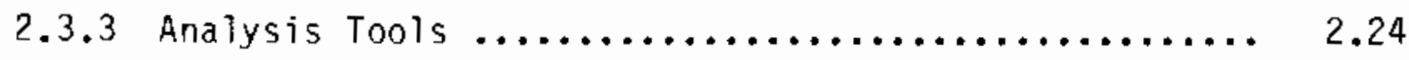

3.0 SUMMARIES OF MAJOR PHASE 1 EFFORTS $\ldots \ldots \ldots \ldots \ldots \ldots \ldots \ldots \ldots \ldots \ldots \ldots \ldots \ldots$

3.1 SPACE-FUnCTION ENERGY MODEL $\ldots \ldots \ldots \ldots \ldots \ldots \ldots \ldots \ldots \ldots \ldots \ldots \ldots \ldots$

3.1 .1 Space Loads $\ldots \ldots \ldots \ldots \ldots \ldots \ldots \ldots \ldots \ldots \ldots \ldots \ldots \ldots . . \ldots \ldots$

3.1.2 Schedule of Operation and 0ccupancy ............ 3.4

3.1.3 HVAC System/Equipment Performance Model ......... 3.5 
3.1.4 Energy Analysis Proof-of-Concept Tests ......... 3.6

3.2 CHARACTERISTIC SELECTION PROCEDURE PROOF-OF-CONCEPT

TESTING

3.11

3.2.1 Description of Proof-of-Concept Test ........... 3.12

3.2 .3 Summary of Results $\ldots \ldots \ldots \ldots \ldots \ldots \ldots \ldots \ldots \ldots \ldots . \ldots \ldots \ldots$

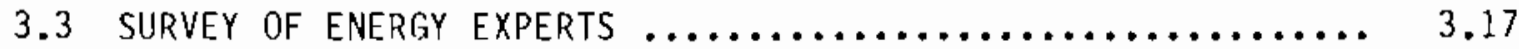

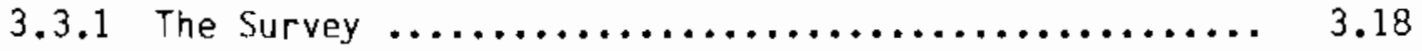

3.3 .2 Nature of Response $\ldots \ldots \ldots \ldots \ldots \ldots \ldots \ldots \ldots \ldots \ldots \ldots . \ldots \ldots$

3.3.3 Summary of Energy Estimate Results ............. 3.19

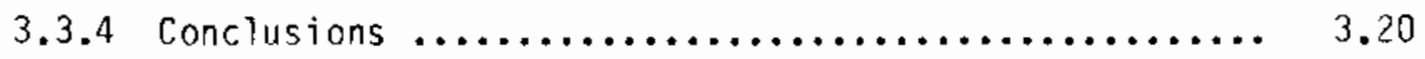

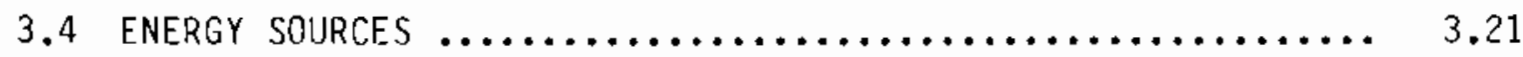

3.4 .1 Background $\ldots \ldots \ldots \ldots \ldots \ldots \ldots \ldots \ldots \ldots \ldots \ldots \ldots \ldots \ldots . .21$

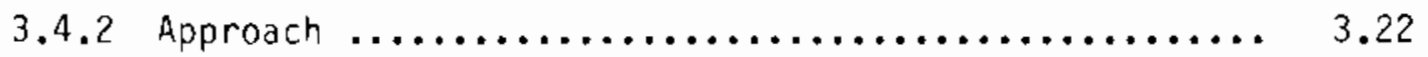

3.4.3 Summary of Evaluation of Alternative
Methodologies $\ldots \ldots \ldots \ldots \ldots \ldots \ldots \ldots \ldots \ldots \ldots \ldots \ldots \ldots \ldots \ldots$

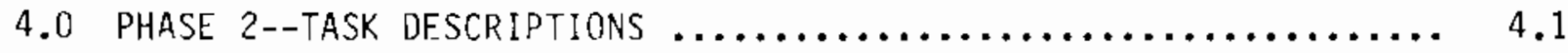

4.1 TASK 1 --PROJECT INTEGRATION $\ldots \ldots \ldots \ldots \ldots \ldots \ldots \ldots \ldots \ldots \ldots \ldots . \ldots \ldots \ldots$

4.1.1 Task 1.1--Refine Project Goals and Objectives ...... 4.1

4.1.2 Task 1.2--Define Objectives for the Targets

Model ............................... 4.2

4.1.3 Task 1.3 Define the Structure of the Targets

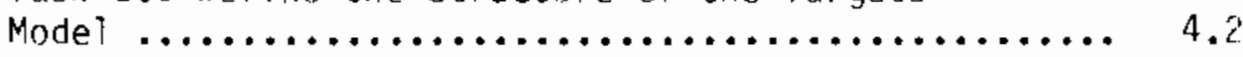

4.1.4 Task 1.4--Define the Target Format and

Presentation ........................... 4.2

4.1.5 Task 1.5--Define Project Documentation Standards ... 4.4

4.1.6 Task 1.6--Prepare Project Executive Summary for Phase 2

4.4

4.2 TASK $2-$-BUILDINGS-INDUSTRY REVIEW $\ldots \ldots \ldots \ldots \ldots \ldots \ldots \ldots \ldots . \ldots \ldots$

4.2.1 Buildings-Industry Review Panel .............. 4.5 
4.2 .2 Technical Review Panel $\ldots \ldots \ldots \ldots \ldots \ldots \ldots \ldots \ldots \ldots . . . .4 .6$

4.2.3 Task 2.1--Project Review Workshop of Phase 2

Work Plan ................................ 4.6

4.2.4 Task 2.2--0ngoing Buildings-Industry Review ....... 4.6

4.3 TASK 3--HARDWARE SYSTEM SELECTION/SOFTWARE DEVELOPMENT $\ldots . . .4 .7$

4.3.1 Task 3.1--Define Project Standard Software ........ 4.7

4.3.2 Task 3.2--Define Attributes of User Interface ..... 4.8

4.3.3 Task 3.3--Investigate hardware 0ptions/Initial

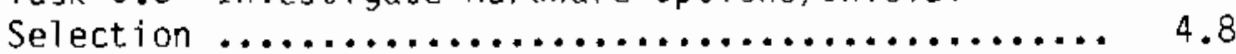

4.3.4 Task 3.4--Develop Project Research Software ....... 4.8

4.3.5 Task 3.5--Select Final Hardware System ........... 4.8

4.4 TASK 4 --ENERGY MODEL DEVELOPMENT $\ldots \ldots \ldots \ldots \ldots \ldots \ldots \ldots \ldots \ldots .4 .8$

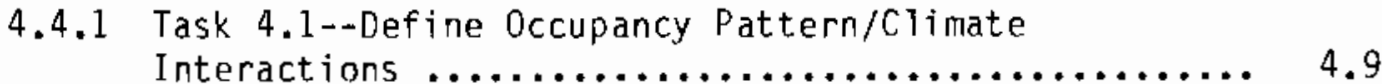

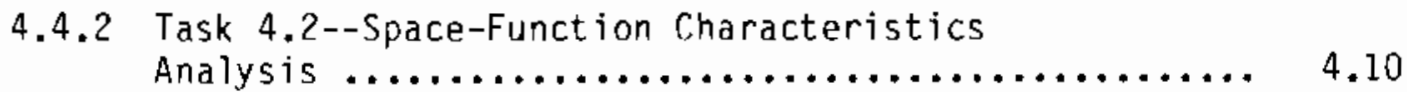

4.4.3 Task 4.3--Develop Space-Function Loads Model ...... 4.11

4.4.4 Task 4.4--Develop System/Equipment/Plant

Energy Model ............................ 4.16

4.5 TASK 5--DEVELOP ENERGY-COST AND BUILDING-COST MODEL $\ldots \ldots \ldots .4 .20$

4.5.1 Task 5.1--Develop Building System and Component

Cost Expressions ......................... 4.21

4.5.2 Task 5.2--Develop Energy-Cost Procedure ......... 4.21

4.5.3 Task 5.3--Test Energy-Cost and Building-Cost

Model ................................. 4.22

4.6 TASK 6--DEVELOP CHARACTERISTICS-SELECTION PROCEDURE $\ldots \ldots \ldots .4 .23$

4.6.1 Task 6.1--Develop Economic Criteria ............ 4.23

4.6.2 Task 6.2--Devel op Characteristics-Selection

Procedure Model ................................ 4.24 
4.6.3 Task 6.3--Test and Verify Target-Selection

Procedure Model ........................... 4.25

4.7 TASK 7--DEVELOP EXAMPLE WHOLE-BUILDING ENERGY TARGETS $\ldots \ldots .4 .25$

4.7.1 Task 7.1--Define Target Levels ................ 4.26

4.7.2 Task 7.2--Develop Example Space-Function Target Characteristics ......................... 4.27

4.7.3 Task 7.3--Test and Refine Space-Function Characteristics and Assumptions .............. 4.27

4.7.4 Task 7.4--Aggregate Space-Function Targets into Demonstration Case Study Whole-Building Energy Targets ............................... 4.27

4.7.5 Task 7.5--Using Targets in Building Design ........ 4.2E

REFERENCES $\ldots \ldots \ldots \ldots \ldots \ldots \ldots \ldots \ldots \ldots \ldots \ldots \ldots \ldots \ldots \ldots \ldots \ldots \ldots \ldots \ldots \ldots \ldots \ldots \ldots$

APPENDIX A List of Building System Integration Research Reports ..... A.I 


\section{FIGURES}

2.1 Sources of Information Affecting Targets Development ........ 2.6

2.2 Targets Model--Procedure for Developing Targets ........... 2.7

2.3 Relationships Between Space-Function Requirements, Characteristics and Energy Mode1 ........................ 2.14

2.4 Energy-Cost and Building-Cost Model $\ldots \ldots \ldots \ldots \ldots \ldots \ldots \ldots \ldots \ldots$

2.5 Selection Procedure Search Routine $\ldots \ldots \ldots \ldots \ldots \ldots \ldots \ldots \ldots \ldots \ldots . \ldots 2$

2.6 Generic Process for Using Ruilding-Specific Targets for a Building Design ............................. 2.25

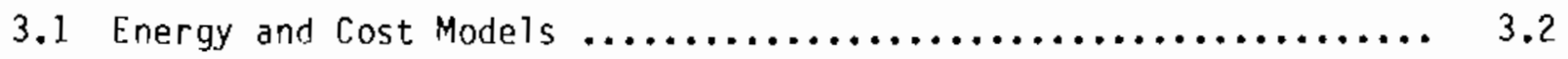

3.2 Comparison of Energy for Individual Zones and Five-Zone

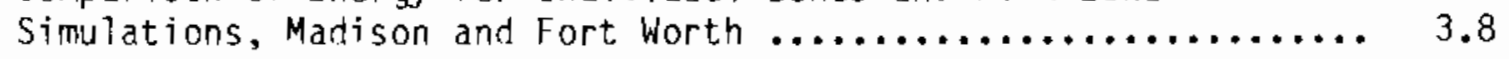

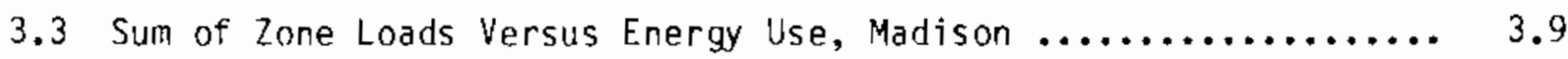

3.4 Sum of Zone Loads Versus Energy Use, Forth Worth ............ 3.10

3.5 Selection Procedure Iterative Search Process ............. 3.13

3.6 Example Heating Fuel Specific Targets ................. 3.16

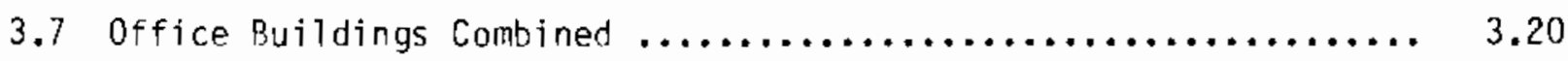




\section{TARLES}

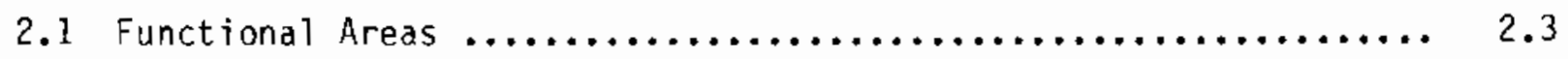

2.2 Building Types $\ldots \ldots \ldots \ldots \ldots \ldots \ldots \ldots \ldots \ldots \ldots \ldots \ldots \ldots \ldots \ldots \ldots \ldots \ldots$

2.3 Steps to Derive a Whole-Building Energy Target Using the Targets Mode1 .................................. 2.11

2.4 Summary Description of Space-Function Requirements ........... 2.13

3.1 Example Configurations and Results Generated Using Proof-ofConcept Program ................................... 3.15

3.2 Estimates for Five Building Types ..................... 3.19

3.3 Methods Grouped by Generic Approach $\ldots \ldots \ldots \ldots \ldots \ldots \ldots \ldots \ldots . \ldots \ldots$

3.4 Evaluation Matrix for Rating Methodologies ............... 3.25 


\subsection{INTRODUCTION}

The objective of the building-targets project is to encourage the design of energy-efficient buildings by developing voluntary, performance-based guidelines for energy use in new commercial buildings. These guidelines are referred to as whole-building energy design targets, and the intent of setting these targets is to inform new-building designers and owners of energy-use goals that can be achieved cost-effectively without interfering with other design goals. This Volume I: Final Report presents the planning effort completed in Phase 1 of the research on a proposed methodology for setting such targets. Volume 2: Technical Report presents additional technical detail.

Whole-building energy design targets are indices or yardsticks to measure the annual energy performance of building designs. Architects and engineers can achieve the targets through careful design and integration of building systems and components. The targets do not specify performance criteria for building components, or methods, materials, or processes that must be used. The intent is to provide flexibility for innovative responses in designing energy-efficient and cost-effective new commercial designs.

The primary focus of this project is to develop a flexible methodology for setting target guidelines, rather than to determine numerical target values. The need at this time is for a well-defined target-setting methodology that is easy to apply. However, some target values are being generated as part of the project to demonstrate the use of the methodology and to illustrate energyefficient solutions for typical economic perspectives. The proposed methodology, which is called a "Targets Model," has several innovative features:

- Targets are based upon space functions. Buildings can be seen as collections of spaces designed for specific functions, such as office space, storage space, or lobby space. The proposed targets procedure will be based upon space functions that are common to a wide variety of buildings. For example, a kitchen is a space function that could occur in a restaurant, hotel, or office building. Whole-building 
targets can then be developed for specific building designs as the area-weighted sum of targets for individual space functions.

- Economics is integrar to the targets process. Situation-specific costs for energy and construction factors can be used as input to the basic methodology for establishing targets, so that the targets reflect an appropriate balance of energy and economic considerations.

- Custom, building-specific targets are feasible. Besides target values based on average conditions, the Targets Model is structured so that building designers can generate targets appropriate to a specific building design. These custom targets reflect building internal load levels, hours and patterns of occupancy, as well as site and other design constraints.

- Multiple levels of targets are planned. The concept of target levels was introduced to avoid setting a single target that, in some cases, may be too low or too high. The levels of targets proposed include a typical design level, a good design level, and a level representing the technical/cost-effective limit. Multiple levels should provide designers with the flexibility to address the different energy conservation priorities and economic perspectives of various owners.

The proposed methodology is intended to provide an opportunity for an industry-wide consensus to be developed on appropriate levels of energy consumption for new building designs. One step was taken toward such a consensus through establishing liaison with several buildings-industry groups to obtain input during the development process from those who would be the ultimate users of the targets. During Phase 2, a workshop will be held to review Phase 1 research and to obtain the input of buildings-industry attendees on the Statement of Work for Phase 2. Two project review panels will also be established at the beginning of Phase 2: a Buildings Industry Review Panel (BIRP) consisting primarily of building owners, developers, and contractors; and occupant representatives; and a Technical Review Panel (TRP) consisting of representatives--architects, engineers, and other designers--from various related building design professions. 


\subsection{PROJECT ORGANIZATION}

The U.S. Department of Energy (DOE), Assistant Secretary for Conservation and Renewable Energy, Office of Buildings and Community Systems, Building Systems Division, is providing the funding for this project through the Commercial Building Systems Integration Program (BSIP) at Pacific Northwest Laboratory (PNL). The BSIP comprises a number of research projects dealing with issues of whole-building energy use and systems integration.

The project is being conducted in two phases: Phase 1, Planning, and Phase 2, Development. An interim period will be allowed between the two phases to allow a buildings-industry review of the Phase 1 plan. Appropriate revisions will be incorporated into the plan before the start of Phase 2.

A project team of design professionals from various segments of the industry has been established to conduct the research necessary for targets development. The project team comprises members of the following professional organizations: the American Society of Heating, Refrigerating, and AirConditioning Engineers, Inc. (ASHRAE), the American Institute of Architects Foundation (AIAF), and the Illuminating Engineering Society of North America (IESNA). Pacific Northwest Laboratory is actively involved in the technical work and manages the project for the DOE.

\subsection{PROJECT OVERVIEW}

The potential advantages of performance-based design guidelines or targets have been recognized for some time. However, a number of obstacles frustrated previous development efforts and prevented acceptance of performance targets by the buildings industry. Resistance to previous performance-based guidelines grew primarily either from concern over the equity of proposed procedures or from the difficulty of applying them to design practice.

To meet the objectives of this project, the proposed approach must effectively overcome these obstacles. The proposed approach provides a creative response to each concern and a basis for developing industry-wide support for the targets. This approach to developing whole-building targets is intended to provide information pertinent to specific projects at appropriate stages in the 
design process, without undue effort. The design targets are intended to provide a positive contribution, rather than an added burden, to the design process.

The DOE has expressed an interest in using the results of this research project as input to its development of whole-building design standards for federal nonresidential buildings. This project will not develop such standards; it will develop a research basis for technically sound energy performance targets.

\subsection{DESIRABLE ATTRIBUTES OF WHOLE-BUILDING ENERGY TARGETS}

A list of attributes was developed for targets in this project. Any targets that result from procedures developed in this project must have these attributes, if the targets produced are to be useful to and accepted by the buildings industry. The targets need to be:

- Comprehensive - The targets should be applicable to all commercial building types, to all locations within the nation, and to all sources of energy used in these buildings.

- Technically sound - The targets must be based on reasoned professional judgment and on analytical procedures that are technically sound and defensible.

- Economically sound - The targets must be economically beneficial for building owners and operators.

- Neutral with respect to energy sources - The targets should provide information to users about energy-related costs in a form useful for market-based decisions, but they must be free from biases toward different energy sources.

- Acceptable to buildings industry - The target formats and procedures must be acceptable to the major organizations of design professionals, building owners, and building operators. 
- Easy to use and understand - The presentation formats for the targets must be simple enough to be readily understood and used by building owners, operators, developers, and designers.

- Usefur to client and designer - Target levels should be achievable and advantageous to both designer and client. They must not be set at levels so stringent that only a few highly skilled experts can achieve them.

- Useful to both architects and engineers - The targets must be useful to each discipline involved in decisions affecting building design and energy performance.

- Educational - The targets must be educationat for the user, conveying what a given target level means in terms of design and construction practices.

- Easy to update - It is expected that building technologies and energy and building costs will change sufficiently to warrant periodic revision of the targets. The target-setting methodology must provide a means of easily accommodating these changes.

\subsection{REPORT CONTENTS}

Section 2 of this report describes the major features of the proposed Targets Model, including how targets generated by the model might be used during the design of a specific building. Section 3 discusses several Phase 1 tasks that received major emphas is and effort. Section 4 summarizes the proposed Phase 2 work plan for developing the Targets Model and for generating demonstration target values. All the above topics are discussed in detail in Volume 2: Technical Report. 



\subsection{PROPOSED APPROACH TO DEVELOPING TARGETS}

At the beginning of this project, five approaches for developing targets for energy use were considered; these approaches are described briefly below. The fifth approach is the one proposed for target development in Phase 2 . It is called a space-function approach because it examines a building's energy use in terms of the uses of its various parts (e.g. office space, storage space, services) and is discussed in greater detail. The first two approaches listed will be used to gather data for use in checking the results of the spacefunction approach. The disadvantages of the third and fourth approaches were considered when creating the space-function approach. The five approaches considered were:

1. Gather metered energy-use data. Gather existing energy-use data to serve as a basis for establishing appropriate target levels for new building design. This information can be used to check the results of the proposed space function approach.

2. Survey expert opinion. Conduct a survey of experts in the buildingenergy field to determine their opinions on appropriate target levels. This information can be used as an additional check on the proposed space-function approach.

3. Analyze building prototypes. Expand the building-type approach used in the Building Energy Performance Standard (BEPS) project, which developed operating conditions for 16 building types, to a larger combination of building types and climates in order to account for variations in operation patterns and schedules. This approach was not proposed for further research because it does not appear to be sufficiently flexible.

4. Use ASHRAE Section 10 procedure (ASHRAE/IES 90-75). Use the procedure in Section 10 of ASHRAE/IES Standard 90-75. In that procedure an energy budget is defined on a building-specific basis through redesigning the building to meet the component criteria in Sections 5 to 9 of Standard 90-75. This approach was not proposed because it is more complex than the space function approach. 
5. Analyze space functions. This approach is based on the hypothesis that the energy use of a whole building can be defined as the sum of the energy needed for human activities (functions) in specific parts of a building (spaces). Needs may include thermal comfort, ventilation, fllumination, and services. The energy needed for a particular activity can be defined in terms of characteristics of the space and the function. These characteristics can be defined independently for various spaces and functions within the same building. Therefore, the basic units of analysis in this approach are space functions rather than buildings. For example, space functions would include office space, Tobby space, retail space, and space for services rather than an office building, or a hardware store. Energy requirements for the same space function can be defined and used to analyze energy use in many different buildings. As an example of a typical space function, a kitchen could be located in any building type--office, restaurant, or hotel. Therefore, space-function energy targets must be developed without consideration of building type. Each function will be described in terms of the characteristics that specify its energy requirements independently of the characteristics of other functions.

Each of the first four approaches has advantages and has been used in previous attempts to develop building-energy performance criteria. However, each approach by itself has disadvantages for developing a whole-building performance approach acceptable to the buildings industry. Therefore, the space-function approach was designed to be more flexible, more comprehensive, and more manageable than the other approaches. It is the central element of an overall model for developing building-energy targets. It is supported by cost information and additional concepts, as explained later in this chapter.

Thirteen major space function categories were identified in Phase 1. These are 1 isted in Table 2.1, along with a number of subcategories that resu't from variation in function characteristics with each category. This list wil? be further refined in Phase 2 to provide a basic list of building blocks for the Targets Model. Table 2.2 provides examples of how these space functions might be aggregated in several building types. 
TABLE 2.1. Functional Areas

I. Lobbies

1. Office lobbies

2. Hotel/apartment lobbies

3. Reception areas

II. Offices

4. Private

5. Open

6. Executive

7. Drafting rooms

III. Retail

8. Jewelry store

9. Fine merchandising

10. Mass merchandising

11. General merchandising

12. Food

IV. Living/Sleeping Areas

13. Housekeeping

14. Nonhousekeeping

v. Hospitality

15. Lounge

16. Dining

VI. Assembly

17. Auditorium

18. Theater

19. Classroom

20. Conference room

21. Gymnasium

VII. Production

22. Kitchen

23. As sembly spaces

24. Manufacturing

25. Handiing
VIII. Medical

26. Autopsy

27. Emergency

28. Examination/treatment

29. Laboratories

30. Patient rooms

31. Recovery

32. Surgery

Ix. Special Areas

33. Book stacks

34. Reading areas

35. Museum/display

36. Laboratory

37. Laundry

38. Computer

39. Sanctuary

40. Detention

$x$. Storage

41. Active dry storage

42. Active refrigerated storage

43. Inactive dry storage

44. Materials handling

45. Lockers/small storage

XI. Circulation

46. Corridors

47. Stairways

48. Vertical circulation

49. Atrium

XIl. Services

50. Toilets

51. Mechanical/electrical

XIII. Garages

52. Service garages

53. Parking garages 
TABLE 2.2. Building Types

\begin{tabular}{|c|c|}
\hline Office Buildings & Retail Stores \\
\hline $\begin{array}{l}\text { lobby } \\
\text { Reception areas } \\
\text { Private urfices } \\
\text { Open offices } \\
\text { Executive offices } \\
\text { Drafting roons } \\
\text { tenference rooms } \\
\text { Conputer rooms } \\
\text { lockers/small storage } \\
\text { Retall-jewelry } \\
\text { Retail-fine merchandising } \\
\text { Retail-general merchandising } \\
\text { Oining } \\
\text { Kitchen } \\
\text { Corridurs } \\
\text { Stairways } \\
\text { Atrium } \\
\text { Joilcts } \\
\text { Mechanlcal/electrical spaces } \\
\text { Vertical transportation } \\
\text { Parking garages }\end{array}$ & $\begin{array}{l}\text { Lobby } \\
\text { Retail-jeweiry } \\
\text { Retall-fine merchandizing } \\
\text { Retail-mass merchandizing } \\
\text { Retal-generdl merchandizing } \\
\text { Retai-fuod } \\
\text { Private offices } \\
\text { Open offices } \\
\text { Executive offices } \\
\text { Active dry storage } \\
\text { Active refrigerated storage } \\
\text { Lockers/small storage } \\
\text { Corridors } \\
\text { Stairways } \\
\text { Atrium } \\
\text { Toilets } \\
\text { Mechanicalelectrical spaces } \\
\text { Vertical transportation } \\
\text { Parking garages }\end{array}$ \\
\hline lodging & Apartment Buildings \\
\hline $\begin{array}{l}\text { Lobby } \\
\text { Private office } \\
\text { Sleeping areas } \\
\text { Lounges } \\
\text { Dining } \\
\text { Kitchen } \\
\text { Conference roalls } \\
\text { íliditorium } \\
\text { Laundry } \\
\text { lockers/sinall storage } \\
\text { Corridors } \\
\text { Stairways } \\
\text { Atrium } \\
\text { loilets } \\
\text { Mechanical/electrical spaces } \\
\text { Vertical transportation } \\
\text { Parking garages }\end{array}$ & $\begin{array}{l}\text { Lobby } \\
\text { Living areas } \\
\text { Private offlces } \\
\text { Retail-jewelry } \\
\text { Retall-fine nierchandising } \\
\text { Retail-food } \\
\text { Inactive dry storage } \\
\text { Corridors } \\
\text { stairways } \\
\text { Tollets } \\
\text { Mechanlcalelectrical spaces } \\
\text { Vertlcal transjurtation } \\
\text { Parking garages }\end{array}$ \\
\hline
\end{tabular}

\begin{tabular}{|c|c|}
\hline Schools & Warehouses \\
\hline $\begin{array}{l}\text { Private offlces } \\
\text { Open offices } \\
\text { Executive offices } \\
\text { Classrooms } \\
\text { Auditorium } \\
\text { Gymasium } \\
\text { laboratory } \\
\text { Dining } \\
\text { Production-assembly } \\
\text { kitchen } \\
\text { Retail-general } \\
\text { Active dry storage } \\
\text { Corridors } \\
\text { Stairways } \\
\text { Toilets } \\
\text { Mechanical/electrical spaces } \\
\text { Vertical transportation }\end{array}$ & $\begin{array}{l}\text { Private of fices } \\
\text { Open offices } \\
\text { Executive offlces } \\
\text { Active dry storage } \\
\text { Active refrigerated storage } \\
\text { Indctive ory storage } \\
\text { Materials handling } \\
\text { Corridors } \\
\text { Stairways } \\
\text { Toilets } \\
\text { Mechanical/electrical spaces } \\
\text { Verilcal transportation }\end{array}$ \\
\hline Assembly & Restaurants \\
\hline $\begin{array}{l}\text { Iobby } \\
\text { Private offlces } \\
\text { open offices } \\
\text { Executive offices } \\
\text { Auditorium } \\
\text { Theater } \\
\text { Conference rooms } \\
\text { lockers/small storage } \\
\text { Corridors } \\
\text { Stairways } \\
\text { Toilets } \\
\text { Mechanical/electrical spaces } \\
\text { Vertical transportation } \\
\text { Parking garages }\end{array}$ & $\begin{array}{l}\text { Private offices } \\
\text { Dining } \\
\text { kitchen } \\
\text { Active dry storage } \\
\text { Actlve refriguraled storage } \\
\text { Toilets } \\
\text { Mechanicalelectrical spaces }\end{array}$ \\
\hline Churches & Museum/Gallery \\
\hline $\begin{array}{l}\text { Private offices } \\
\text { Classrooms } \\
\text { Dining } \\
\text { Kitchen } \\
\text { Lockers/small storage } \\
\text { Sanctuary } \\
\text { Corridors } \\
\text { Toilets } \\
\text { Mechanical/electrical spaces }\end{array}$ & $\begin{array}{l}\text { Private offices } \\
\text { Open offices } \\
\text { Executive offices } \\
\text { Reception area } \\
\text { Museum display } \\
\text { Inspection/Restoration } \\
\text { Active dry storage } \\
\text { Hechanical/electrical spaces } \\
\text { Corridors } \\
\text { Stafrways } \\
\text { Toilets }\end{array}$ \\
\hline
\end{tabular}


The space-function approach to developing targets for energy use in commercial buildings has advantages; it is:

- simpler to develop because fewer separate functions are encountered in commercial buildings (perhaps as few as 20 to 30 ) than are probable combinations of these functions

- more accurate because the energy-use characteristics of each function can be defined more precisely than the energy-use characteristics of generic building types

- more flexible because evaluating the energy needs of each function provides a way to deal with the diverse uses and schedules that typically exist in buildings

- a more direct way to establish whole-building energy targets than that provided by the other approaches.

Because of these advantages, which were confirmed by analysis and proofof-concept testing in Phase 1, the space-function model was proposed as the key element of the Targets Model procedure in Phase 2. The model will be supported by energy-cost and building-cost information.

Figure 2.1 shows the major information sources for developing the Targets Model and target values. A review of existing energy-consumption data and a survey of expert opinion will support the development of the space function procedure and verify the reasonableness of the target values produced. $A$ detailed collection of data on space function and building characteristics and the development of economic data are also necessary to provide input for the energy-cost and building-cost model and for establishing the targets procedure.

The space-function model and the energy-cost and building-cost model are two major components of the proposed targets model. However, Phase 1 identified several other concepts important in resolving the various problems encountered in past efforts to establish whole-building energy targets. These concepts include the following: 


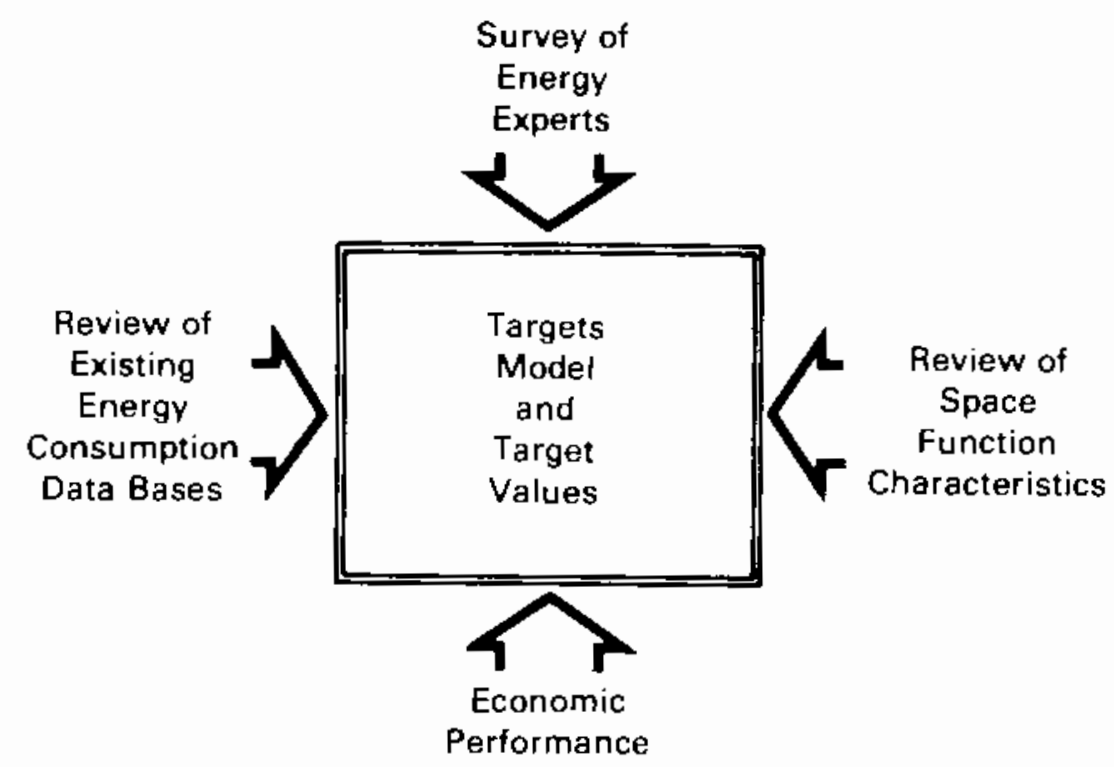

FIGURE 2.1. Sources of Information Affecting Targets Development

- providing a mechanism for developing custom, building-specific targets that reflect the wide range of design and operations constraints encountered in commercial buildings

- developing multiple levels of targets, instead of a single leve1, to address issues of quality and economic perspective

- integrating economic evaluation into the procedure for selecting target levels

- developing a target-setting procedure that will easily accommodate variation in design constraints, and energy and economic criteria and conditions.

The features of this Targets Model are discussed in the following sections.

\subsection{APPROACH TO TARGETS-MODEL DEVELOPMENT}

The proposed Targets Model is shown in Figure 2.2. For input, the Targets Model uses descriptions of space function requirements constrained by nonenergy design considerations, orientation, climate, energy costs, and economic perspective. As the figure shows, the requirements enter the targets model, function energy model, energy-cost and building-cost model, and characteristic 


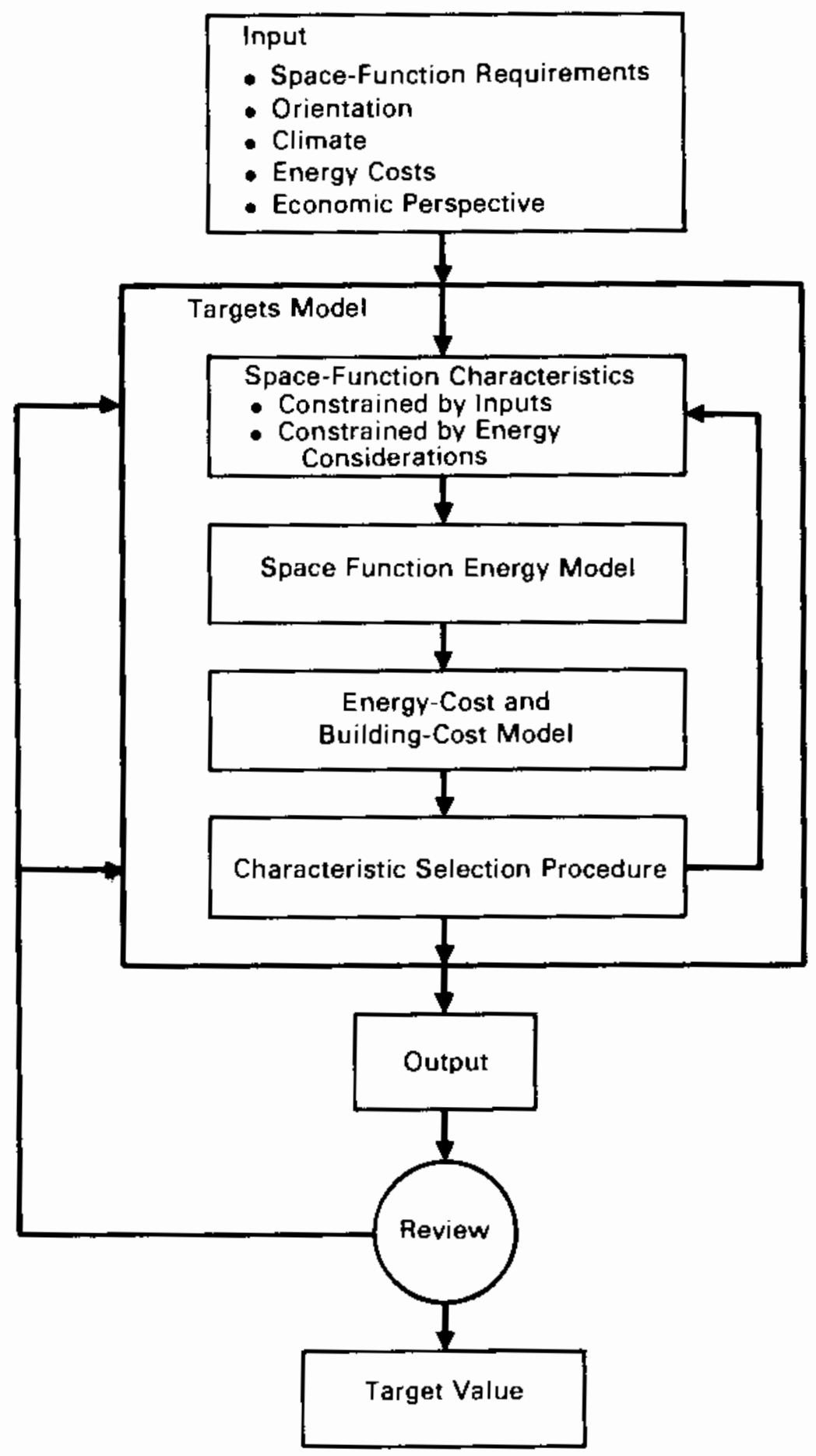

FIGURE 2.2. Targets Model--Procedure for Developing Targets 
selection procedure. From the inputs, the model selects space-function characteristics that meet the input requirements and a set of energy-related. cost-effective physical characteristics appropriate for the specific space function. (These are characteristics not dictated or constrained by other design considerations). These two sets of characteristics serve as input to the space-function energy model, which in turn provides estimates of energy use. The space-function characteristics and energy-use results are then processed through the energy-cost and building-cost model to determine the economic consequences of the characteristics selected within the Targets Model.

The results from the energy-cost and building-cost model are reviewed and fed through the characteristic selection procedure to refine the selection of unconstrained space-function characteristics in an iterative process unti? a reasonable balance of energy use and cost-effectiveness is achieved. Once this balance has been achieved, a target for the space function is set. The final step is to sum the targets for each function (on the basis of the area associated with each function) to obtain a whole-building energy design target.

Thus, the end product of the Targets Model is a whole-building energy performance target tailored to a specific building, rather than to a generic building that may or may not be a suitable reference point for the specific building. This approach directly resolves several of the problems that have hampered previous efforts. However, this approach also creates the need to develop a straightforward way to define energy needs on a function-by-function basis. Initially, it might appear that this can only be achieved by full-scale energy analysis for each set of circumstances that may be encountered in the design of commercial buildings. However, research conducted in support of the revision of ANSI/ASHRAE/IES Standard 90A-1980 (PNL 1983; ANSI/ASHRAE/IES 90.1P $1986)^{(a)}$ has shown that generalized relationships can be derived that provide reasonable estimates of annual space heating and cooling loads as a function of

(a) Forty voiumes of research were published by Pacific Northwest Laboratory as PNL-4870 (PNL 1983). This work is also commoniy referred to as Specia) Project (SP) 41 research, which was its designation by ASHRAE, the major subcontractor. 
design parameters influenced by solar gain, internal loads, thermal transmission and operating schedule. Internal loads can be directly linked to the function of the space, and a reasonable correlation exists between the space function and envelope characteristics that have greatest impact on annual loads.

With this approach, there was some expectation that interaction between major energy systems [e.g. heating, ventilation, and air conditioning (HVAC), and 1 ighting] and the space and its environment would preclude considering space functions separately. Specific areas of concern included interspace heat transfer, economizer cycle operation, deadband thermostats and other control features, and the part-load characteristics of heating and cooling equipment. However, a preliminary evaluation of building-energy performance simulations carried out in Phase 1 has shown that annual energy use for heating and cooling varies with space load in a predictable way for both single and multiple space systems. Thus, the interaction of the system, the space, and the environment do not lead to significant differences in estimates of annual energy use whether the energy use of each space function is estimated separately and summed or defined by a multiple space system simulation. Therefore, for a given system selection, a reasonably direct relationship appears to exist between annual space loads and annual energy performance.

During development of an overall target methodology, the concept of spacefunction targets evolved from static tables of values to an interactive procedure. The proposed procedure will use a set of mathematical relationships or algorithms that allow design parameters to be constrained by considerations other than energy. A balance between energy and nonenergy considerations is necessary because a design that simply minimizes energy use may not be compatible with other design requirements and thus would be unacceptable to the owner or occupant.

Careful consideration determined that an extended approach that would explicitly incorporate economic efficiency into the target relationships needs to be developed. The criteria for setting energy performance targets would then he a balance of energy concerns with design constraints and cost effectiveness. Including economic considerations explicitly in the process adds some 
complexity. However, the feasibility of including economic considerations in the target procedure was tested in a proof-of-concept economics model with encouraging results. This model included cost data, a preliminary building energy model, and economic optimization routines. Each of these components is described in Volume 2: Technical Report.

The proposed Phase 2 targets development effort will create a fina? Targets Model that will be validated through detailed testing. This testing will consist of using the Targets Model to generate energy-use estimates for each space function. Another product of Phase 2 development will be sets of demonstration target values that will show energy-efficient solutions for typical economic perspectives. These demonstration target values will be a result of the model testing and will include target values both for individual space functions and for typical combinations of space functions (whole buildings). The energy-related features of each space function used in testing the Targets Model will serve as case-study examples of design solutions that meet the demonstration targets. The demonstration target values will also be compared with appropriate data on energy use.

\subsection{TARGETS MODFL}

The process for deriving a whole-building energy target, using the Targets Model procedure, is shown in Table 2.3. To accomplish the listed tasks, several components of the Targets Model must be developed, including the following:

- identifying and classifying function characteristics

- developing algorithms to predict the extent that each characteristic affects space-environment interactions (and thus the heating and cooling loads) and defining system and equipment factors (expressed in terms of HVAC system and control characteristics) that translate the space loads into equipment energy use.

- developing mathematical relationshios that integrate cost considerations to the target selection procedure to provide the rationale for specifying unconstrained function characteristics. 
TABLE 2.3. Steps to Derive a Whole-Building Energy Target Using the Targets Model

- Specify building functions

- Identify function characteristics that infiuence energy use and are dictated or constrained by non-energy design considerations.

- Specify function characteristics that influence energy use and are not constrained by design considerations other than energy efficiency.

- Define configuration (size, volume, location - perimeter or interior) characteristics of enclosing surfaces (fenestration, orientation and thermal mass) for each function.

- Define themal comfort, 111 umination and ventilation requirements for each function.

- Define energy requirements to meet comfort, illumination and ventilation needs (Btus/ft ${ }^{2}$ ) for each function. The steps in estimating the energy requirements are:

- Define the heating and cooling loads in terms of surface and function characteristics and operating schedule (annual space loads).

ANNUAL LOAD = (TRANSMISSION + SOLAR GAIN + INTERNAL, GAIN) - (SCHEDULE FACTOR)

- Define HVAC and illumination system performance characteristics for each system (annual system factor)

- Cefine equipment performance characteristics (annual equipment factor). For example for the cooling component of the target:

Cooling $=$ (Annual Load) $\cdot$ (Systems Factor) $\cdot$ (Equipment Factor)

where the annual cooling loads include consideration of all configuration, envelope and schedule characteristics.

- Multiply the energy used per square foot for each function by the floor area associated with that function.

- Evaluate the energy cost and building cost consequences of the selected characteristics for each function. Based on erergy costs and building costs, revise the space function characteristics that are not constrained by other design factors to mininize cosis. Repeat the process as necessary to achieve a balance between energy use and cost.

- Sum the energy use-area products for each of the various functions to obtain the whole-building target. 
Rudimentary versions of both the energy model and the energy-cost and building-cost model have been developed and tested in Phase 1. Of the two models, the energy model has been more fully developed and tested. Both models will be completed in Phase 2 and carefully tested over a wide range of conditions. The mathematical expressions that make up the energy-cost and buildingcost model will be refined, and estimates of the costs of selected building features and systems will be developed.

The remainder of this chapter briefly describes each of the major elements of the proposed Targets Mode1. Chapter 3 describes the Phase 1 tasks undertaken to identify appropriate space functions, their energy-use characteristics, and the energy and cost models developed in Phase 1. These descriptions provide important background information for the proposed Phase 2 development of a complete Targets Model.

\subsubsection{Space-Function Characteristics}

The selection of space-function characteristics is the first of the four components of the Targets Model. Space-function characteristics include the envelope (type and features), the size and shape of the building, the schedule for use and loads, the required thermal comfort level, the lighting systems, and the equipment. These characteristics are generated by the inputs to the Targets Mode1, shown in Figure 2.2. The five inputs are space function requirements, orientation, climate, energy costs, and economic perspective.

The space-function requirements directly influence several space-function characteristics and the energy required to accommodate human activities within the space. The space-function requirements are space needs, relationship to surroundings, illumination, occupancy, schedules, thermal comfort requirements, connected equipment, and other considerations. Table 2.4 summarizes each of these space function requirements.

Figure 2.3 indicates how the space-function requirements, together with orientation and climate, generate a wide range of space-function characteristics and how these characteristics in turn affect the loads that are considered 
TABLE 2.4. Summary Description of Space-Function Requirements

Space Needs Characteristics associated with space needs

include the size, volume, and configuration of the space.

Relationship to Surroundings

Designing a space to meet a specific function may require exposure to the exterior of a building, either for light access, or view.

Illumination Level, type, and quality of illumination required for human comfort, productivity, and aesthetics are important characteristics of a function that directly affects energy use.

Occupancy

Schedule

Thermal Comfort Requi rements

Connected

Equipment

Other Considerations
Density of occupancy.

Schedule or pattern of use.

The level of thermal comfort required within the space to serve the intended function during the occupied period also directly influences the level of energy use.

This includes receptacle loads, compunications equipment, and special equipment such as computers and copy machines. Some functions, such as food preparation, have unusually high loads. Two additional factors may have an impact on energy use to serve some functions or in some buildings: service water heating requirements, and conveyance needs. For each of these factors, a characteristic value will be identified, or an allowed range of variation will be specified.

Geographic location and space orientation have not been included in the list of characteristics but have significant impacts on energy-use characteristics of a space, particularly in terms of its impact on heating and cooling loads. The proposed space-function energy model, however, does treat climate and orientation impact explicitly. These parameters are handled as direct, unconstrained, input variables in the Targets Model rather than as space-function characteristics. 


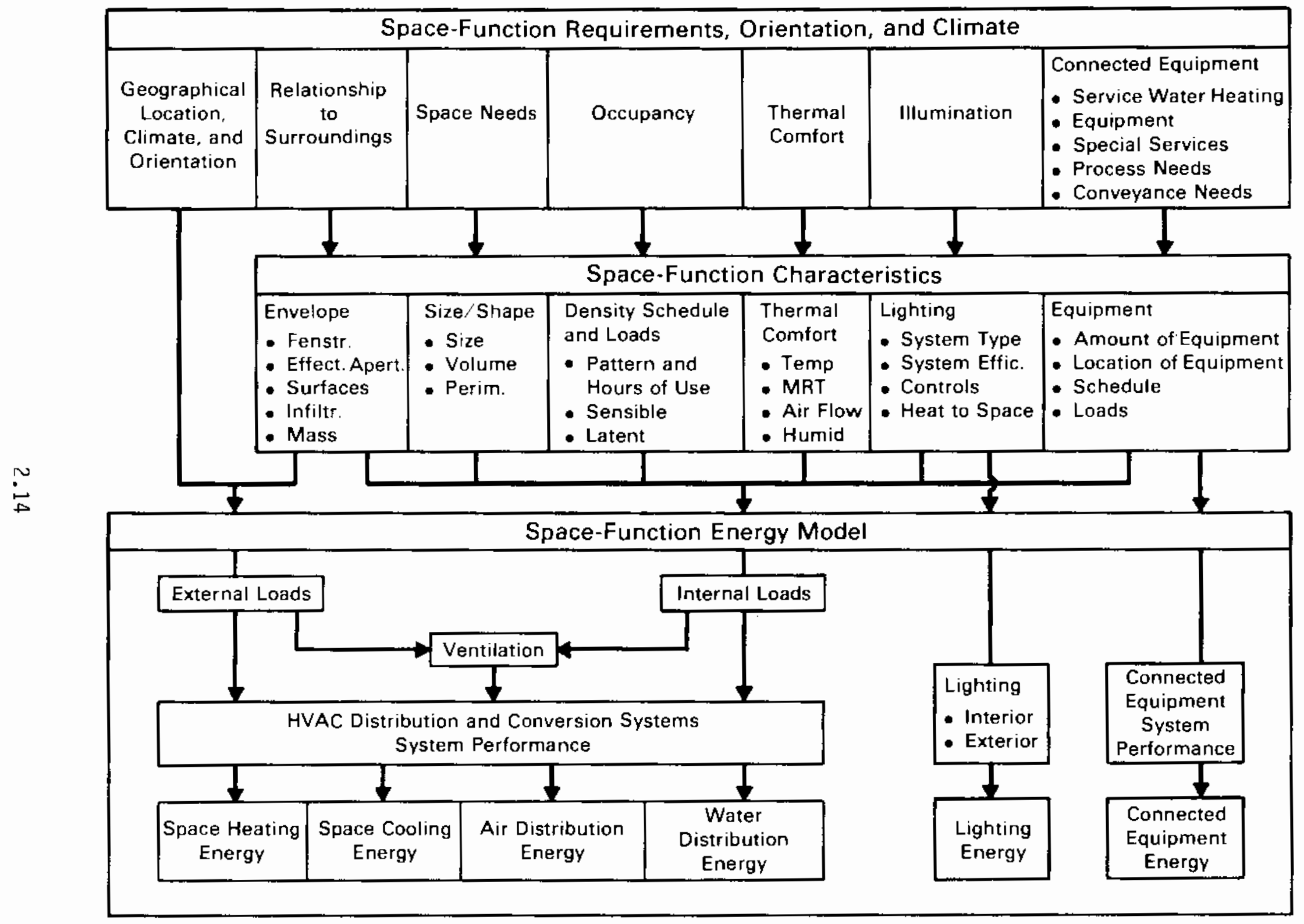

FIGURE 2.3. Relationships Betweer Space-Function Requirements, Characteristics and Energy Model 
in the space-function energy model. Three of the five inputs to the Targets Model, the space-function requirements, orientation, and climate, are shown in the top row of the figure.

Climate provides an example of how these inputs will be used in the Targets Mode1. The approach proposed to incorporate climate considerations into the model will expand upon the approach used to develop the envelope criteria of the Standard 90 support research (PNL 1983; ANSI/ASHRAE/IES 90.1P 1986). The procedure for selecting envelope characteristics will be defined in terms of general climate variables, such as heating degree days, cooling degree days, cooling degree hours, daily temperature range and measures of incident solar radiation. Additional work on the impact of variation of climate parameters on space-load relationships will be carried out in Phase 2 .

The second row of Figure 2.3 shows the space-function characteristics that are generated in response to the first-row input requirements. For example, the requirement for a certain level of illumination, color rendition, contrast, etc., lead to the selection of the lighting system with an associated installed-power requirement as indicated in the second row. Likewise, the occupancy requirements generate the second-row space-function characteristics of occupancy density, schedule of operation, and internal loads. Several attempts to provide a reasonable means of dealing with occupancy and operating schedule have been made.

In the BEPS Program, a set of standard building operating conditions (SBOC) was established for each of 16 building classifications. The disadvantage of this approach is that these operating conditions do not account for the large variation in the operation patterns and schedules in buildings within a single-building classification. Therefore, the BEPS budgets did not always reflect the energy-use patterns of the buildings being designed. Designers were uncomfortable using one schedule to judge building-energy performance when actual operation differed significantly among buildings.

In Phase 1, the Special Project (SP) 41 (PNL 1983) analysis of schedule effects was extended to the point of examining schedule variations at the system level, rather than at the space-load level. These results indicated that a linear relationship still exists between schedule-modified space loads 
and energy use and that the use of schedule factors might provide an appropriate means of dealing with these issues in the Targets Model. This approach will be developed further in Phase 2. Schedule effects will be defined for several factors, including lighting, occupancy, miscellaneous equipment, ventilation, indoor temperature, heating and cooling system availability, and fan and pump operation.

The space-function characteristics, which are described at greater length in Chapter 3, in turn directly affect the space loads and the energy used by various building systems. Each of the space-function characteristics directly affects the space loads. In addition, some characteristics such as lighting and connected equipment also consume energy in providing service. This is shown in the bottom part of the space-function energy model in Figure 2.3 .

\subsubsection{Space-Function Energy Model}

The second major element of the Targets Model is the space-function energy mode1, which determines the energy impacts of the space-function characteristics defined above. The bottom of Figure 2.3 describes this model.

The space-function energy model is a simplified procedure for estimating annual energy requirements for each space function in order to set targets. It is simplified in that it operates using sets of regression coefficients in simple arithmetic expressions to approximate the results of complex simulations. However, it is reasonably comprehensive in its modeling of factors that contribute to energy use and energy-related costs because the regression coefficients were derived from several thousand simulations using the analysis program DOE-2.1B. These simulations were designed to specifically cover the range of building parameters and climate conditions encountered in the design of new commercial buildings in the United States. The following subsections briefly describe two major subelements of the space-function energy model: space loads, and HVAC system/equipment performance.

\section{Space Loads}

Annual space load interactions that will be used in developing the targets were developed in conjunction with research conducted in support of revising ANSI/ASHRAE/IES Standard 90A-1980 (PNL 1983; ANSI/ASHRAE/IES 90.1P 1986). This 
research has provided algorithms that define variation of annual space loads in terms of a building's thermal envelope and mass characteristics, solar gain, lighting and equipment power density, occupant density and ventilation requirements. The algorithms take the following general form:

$$
\begin{aligned}
\text { Load = } & F(\text { Transmission + Solar Gain + Internal Gain) for } \\
& \text { each orientation and corrected for mass effects }
\end{aligned}
$$

Regression analyses of both heating and cooling loads, from DOE-2.1B, simulations defined the coefficients for thermal characteristics, solar gains, and internal loads as a function of basic climate parameters. The mass correction term was defined through a separate regression-based correlation. Chapter 3 provides a brief technical description of the space-loads model.

The equation used to define the coefficients needs to be refined before this procedure can be used in the space-function energy model. However, the refinements are related to the accuracy of equations used to define the regression coefficients, not to the appropriateness of the algorithm as a component of the target-setting methodology. The Standard 90 loads research and the proof-of-concept tests examining the relationship of loads and energy use, completed during Phase 1 , have provided ample evidence that annual space-load algorithms can be applied as a component of a target-setting methodology.

\section{HVAC System/Equipment Performance Model}

The second element of the space-function energy model is the development of HVAC system and equipment factors that translate annual space loads into energy performance estimates. The Phase 1 proof-of-concept effort indicates that it is possible to define systems and equipment factors such that, for example, the cooling component of the target could be defined as:

$$
\text { Cooling }=B+(\text { Space Load }) \cdot\left(F_{\text {systen }}\right) \cdot\left(F_{\text {equipment }}\right)
$$

where $B=$ a constant for a given climate and system selection

$\mathrm{F}_{\text {system }}=\mathrm{a}$ factor which varies with systern type and climate $F_{\text {equipment }}=$ an annual energy-use efficiency for the equipment selected. 
This concept will be developed in detail in Phase 2 for both heating and cooling. Also, a similar format will be developed in Phase 2 for illumination and auxiliary-device energy use.

\subsubsection{Energy-Cost and Building-Cost Model}

The energy-cost and building-cost model, the third major component of the Targets Model, calculates the important energy-related costs. The subelements of this model are shown in Figure 2.4. The model's role is to deal with cost considerations in the overall target selection process. This is accomplished by applying a basic set of cost criteria to guide the selection of the spacefunction characteristics shown in Figure 2.3, used in defining target levels and not dictated or constrained by the input characteristics. Both first cost and costs over time are considered. Each is discussed below, along with other annual costs.

\section{First Costs}

The model will estimate first costs of building features that affect energy use and will use generalized information about the costs of energyrelated building features, such as building insulation, glazing systems, and lighting systems. This information will be developed from published sources of building cost information. The first cost associated with changing a building component that affects energy use may increase or decrease as an energy conservation strategy is implemented. For example, space loads may be decreased by using high-performance glass, increasing envelope cost. But this same decrease in load may allow the HVAC equipment to be down-sized--more than offsetting increased glazing costs, and resulting in a net decrease in overall costs. The first element of the energy-cost and building-cost model will track this series of cost impacts for each change in space and/or operating characteristics examined.

Because the building-cost data will be used primarity to evaluate the relative costs and benefits of competing design solutions, performance of the model will depend on the accuracy of relative building costs and not absolute costs. Developing procedures that estimate the change in costs as various 


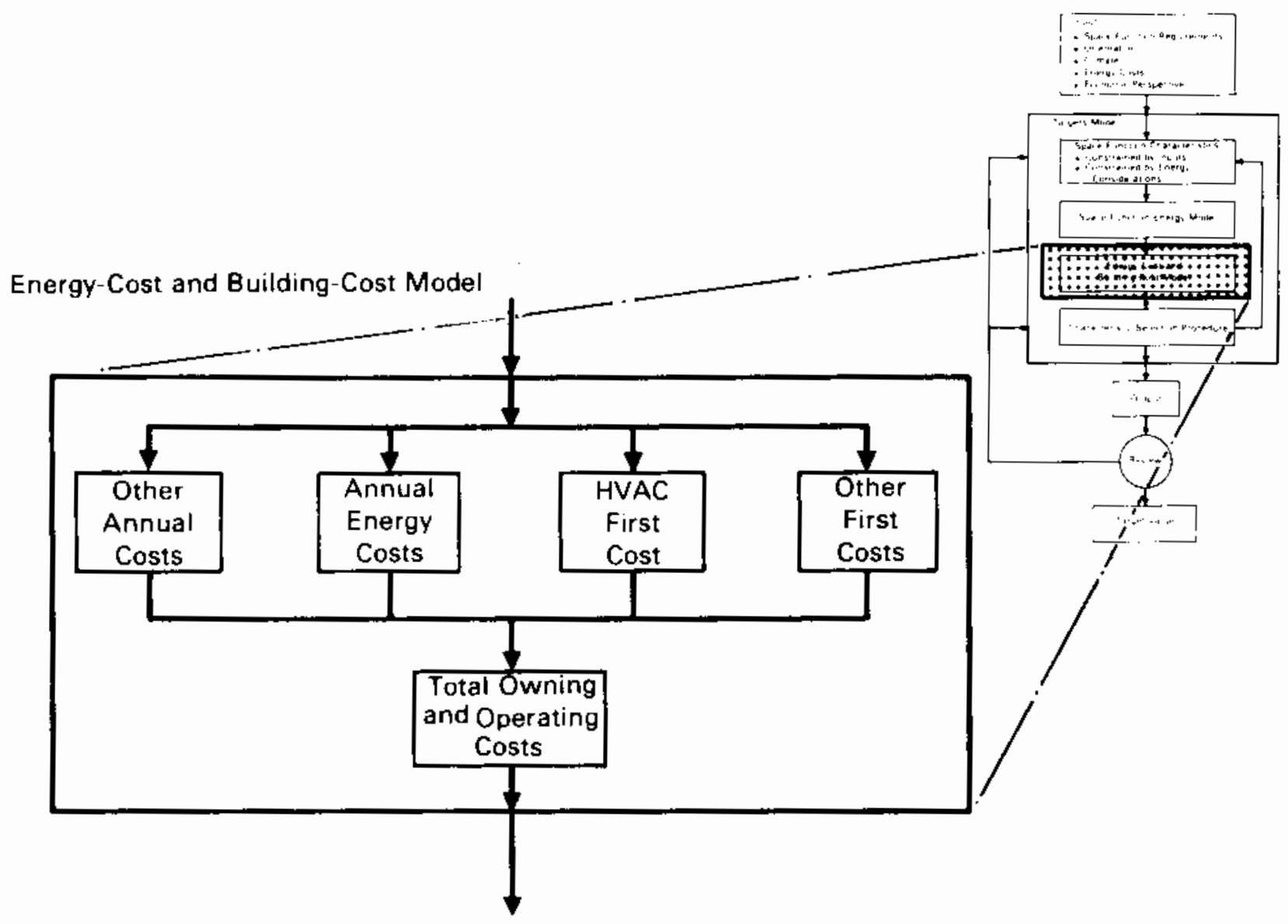

(To Selection Procedure)

FIGURE 2.4. Energy-Cost and Building-Cost Model

methods of improving the energy performance of building components are implemented is a much more manageable task than is estimating total building costs.

Those changes in cost will be estimated by developing general cost expressions that treat the relationship between building costs and building parameters as continuous functions rather than as discrete values. Although actual building materials and systems components are available only in discrete sizes, discrete thicknesses, etc., they will be treated as continuously variable in the cost model portion of the Targets Model. The continuous cost expressions will describe underlying relationships driving building subsystem costs rather than representing specific costs that might be observed in a particular situation. 
One example of the use of continuous-cost expressions is the relationship between design load and HVAC system sizing. That relationship will probably be treated as a continuous function as it is in the DoE-2 systems model, rather than in discrete size and cost intervals. On the other hand, it may be necessary to treat the relationship between design loads and HVAC sizing as a stairstep function. Modifications of the general concept of continuous cost functions may be desirable in some cases to account for major discontinuities such as switching from 4-lamp to 3-lamp fluorescent 1ighting fixtures. Tradeoffs associated with these choices will be explored in the development of a detailed cost model in Phase 2.

The cost data used by the cost expressions will be based on appropriate building costs and will be separated in the cost model from the generalized cost expressions. This will make it easy to update costs as they change over time without changing the cost expressions in the model.

\section{Annual Energy Costs}

The annual energy-cost model will be based on local energy costs as reflected in local utility rate structures. Final decisions on the method for treating energy costs will be made during Phase 2 after two local cost-ofservice procedures selected in Phase 1 are thoroughly reviewed. The proposed methods for handling energy costs are discussed in more detail in Chapter 3 and in the Volume 2: Technical Report.

Other Annual Costs

The other annual costs category includes maintenance or replacement costs, such as routine servicing of HVAC components or replacement of light bulbs. Costs that occur on a nonuniform basis are expected to be annualized (averaged over each year) in the model.

\subsubsection{Energy-Characteristic Selection Procedure}

The selection procedure for choosing the unconstrained space function characteristics is the fourth major component of the Targets Model. A rudimentary proof-of-concept version of the procedure was developed and tested 
during Phase 1. A revised version will be developed during Phase 2. This computer-based model will automatically select appropriate sets of energyrelated space features.

The range of characteristic values available to the selection process will be constrained to ensure that the energy-related physical characteristics selected are appropriate, given considerations affecting design decisions. Some constraints are associated with the input parameters, others with energy, cost or economic considerations. Those associated with input parameters are fixed, once specified by the input, for the entire analysis. Those associated with energy, cost, and economic considerations are balanced, within an allowed range of variation, by the characteristic selection procedure and the other components of the Targets Model.

The energy and cost impacts of features selected will define energy target levels in response to the criteria and constraints defined as input. Several possible approaches are being considered. For example, one approach is to determine achievable levels of total owning and operating costs (TOOC) for various economic perspectives. Another possible approach is to establish targets based upon local utility costs. The TOOC approach is discussed in more detail below.

Total Owning and Operating Costs

The TOOC are the sum of the first cost, annual energy cost, and other annual cost components described above. Because some costs occur only once while others recur periodically, standard economic methods that account for the time value of money will be used when combining these costs to determine the TOOC. If the minimum TOOC were selected as the criteria, the characteristic selection procedure would, in effect, select sets of physical characteristics for a function using standard methods of engineering and economic analysis along with program logic that emulates techniques commonly used by building energy analysts to define cost-effective building design solutions.

Figure 2.5 iliustrates a general relationship between initial cost and energy savings that is often observed when opportunities for energy conservation in new buildings are evaluated. (Note that larger present values of 


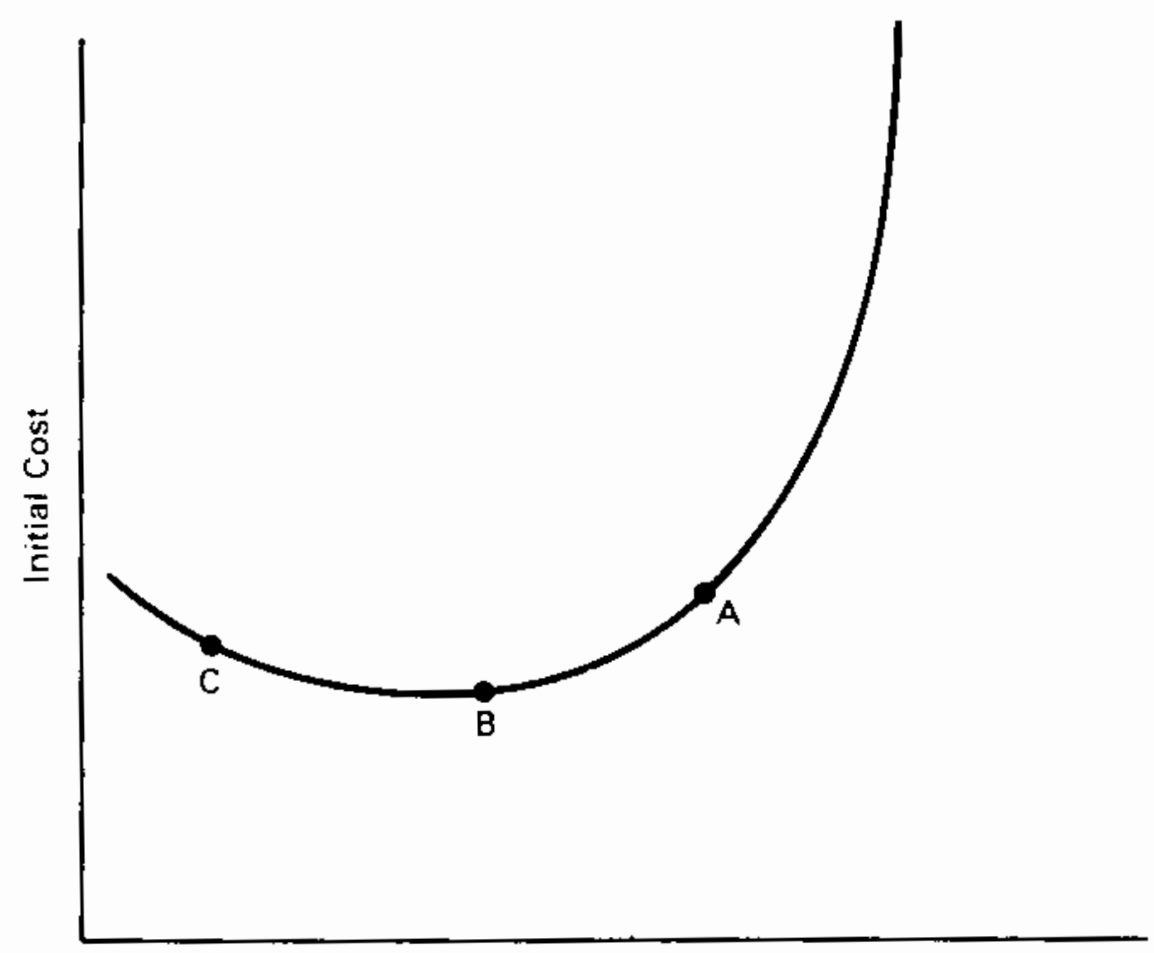

Present Value of Energy Savings

FIGURE 2.5. Selection Procedure Search Routine

energy savings are desirable). When features are added to reduce the heating and cooling loads in an energy inefficient design (point $\mathrm{C}$ ), initial cost usually decilines because of savings in mechanical system first costs. As energy-conserving features are evaluated beyond the minimum first-cost configuration (point $B$ ), the initial cost begins to rise.

In general, beyond point $B$ smaller and smaller units of energy savings result from each additional unit of first cost spent on energy-conserving features. The least-cost solution, when both first costs and energy savings over time are considered, occurs at point $A$. Beyond this point, the value of energy saved would not offset the additional first cost.

The proof-of-concept version of the energy characteristic selection procedure in Phase 1 used this approach. It searched for energy-related space function characteristics that correspond with point $A$, where first costs and energy savings are in an appropriate balance. The selection procedure used search routines and various methods of comparing energy and cost performance using the 
space-function energy model in order to arrive at sets of appropriate space function characteristics that could then be used in generating targets.

\subsection{USING TARGETS FOR BUILDING DESIGN}

The previous section has described the basic features of the four major components of the Targets Model to be developed in Phase 2 of this project. The proposed targets procedure may be used to provide example targets for evaluating design alternatives and custom targets for a specific building being designed.

The primary use of the Targets Model is in the target-setting mode, in which voluntary space-function targets would be generated to provide example solutions as guidance for design professionals. In such a mode it is expected that seasoned professional judgment would be used to select the inputs, criteria and constraints used by the Targets Model and to review and revise the Targets Model resu1ts. Design professionals can then combine these spacefunction targets to produce custom whole-building targets that accommodate the mix of space functions encountered in a particular design project.

The Targets Model also could be used during a building design to generate custom space-function and whole-building targets that reflect the specific design constraints of that project. The two primary uses, as well as use of the model as an analysis tool, are discussed in more detail below.

\subsubsection{Using Example Targets}

The demonstration target solutions that would be generated in developing the targets procedures may be used as general references for typical buildingand space-function situations, presented in a case-study format. These examples would be structured and detailed to give the reader a feeling for the stringency of the target leveis, as well as an indication of the design features that might be used in typical situations to meet the target levels. Thus, the demonstration targets will provide general guidance about levels of energy and economic effectiveness. 


\subsubsection{Using Custom, Building-Specific Targets}

Two major steps are involved in using the customized, building-specific targets for building design:

- Generate a building-specific target. Information needed to generate the target is available very early in the building planning and design process. Also, a preliminary building-specific energy target could be developed much earlier, before the building programining phase, by using reasonable estimates about the anticipated building functions.

- Calculate if the building design meets the target. The designer uses his/her preferred energy and economics tools to evaluate energy use and costs of the building design. Results from these tools are then compared with the target to determine if the energy design target was met.

Figure 2.6 shows schematically how the Targets Model procedure might be used for custom, building-specific targets during a specific building-design project.

\subsubsection{Analysis Tools}

The proposed procedure will use computer-based approaches for generating building-specific targets. This procedure is based upon the assumption that building-specific targets would be used on projects for which energy analyses will he conducted, and that virtually all energy analyses will be computerbased. Several criteria are considered especially important in developing procedures for using the building-specific energy targets during a building design process:

- The targets procedures should be very easy to use. Ease of use is vital to the acceptance and use of voluntary guidelines. For example, the procedures should minimize duplication of effort in generating a target and in determining if a building design meets a target. 


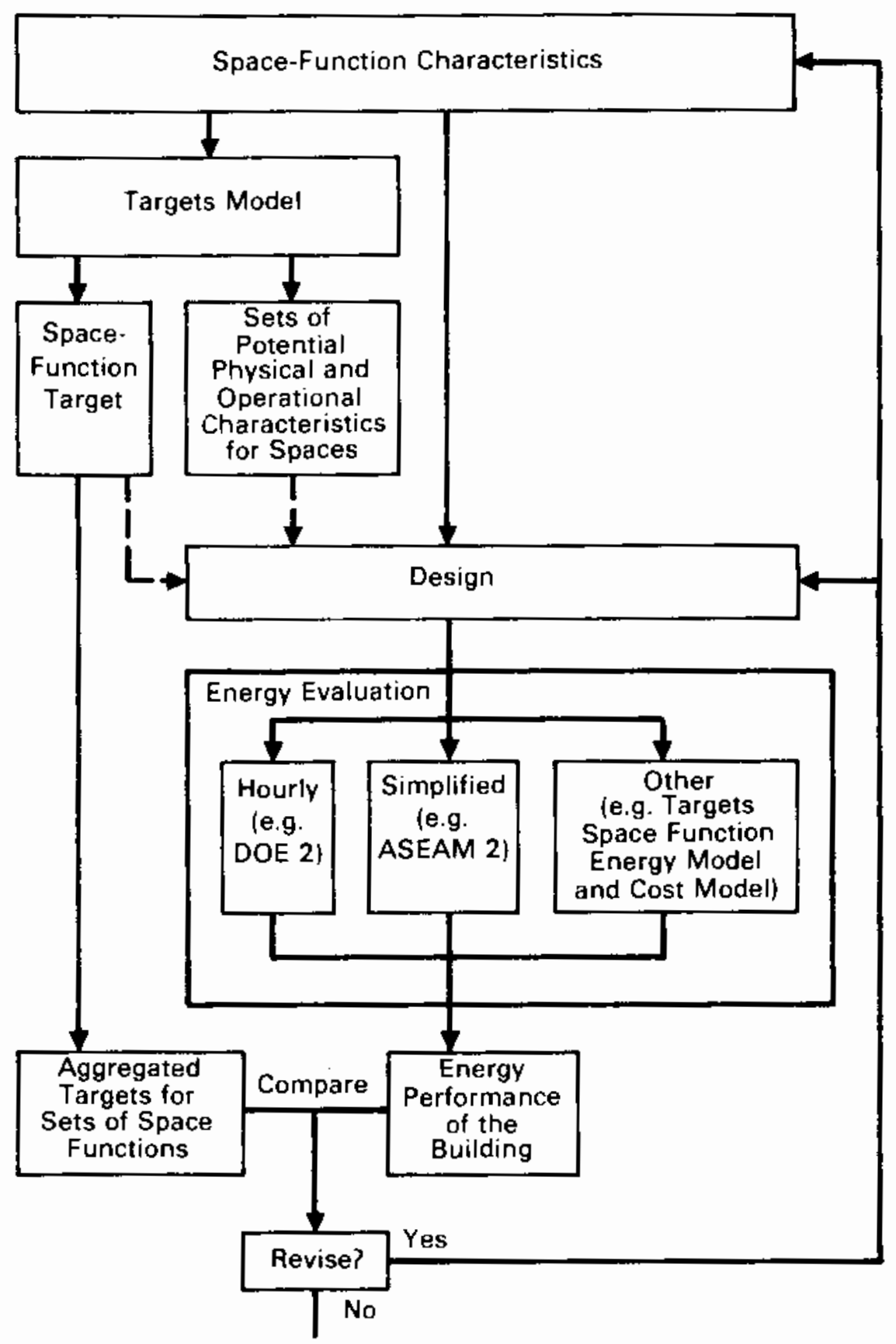

FIGURE 2.6. Generic Process for Using Building-Specific Targets for a Building Design 
- The targets procedures should be reasonably accurate. There is unavoidable variation among analysis tools; different programs will give different results for the same building design. The procedures will need to address this.

- The targets procedures need to be flexible enough to be useful with different design tools and for different applications. Hourly simulations are inappropriate for many small projects, while simplified procedures may not be capable of providing credible guidance for large and complex ones. The procedures need to be useful to a wide range of practitioners regardless of the procedure that they choose to use.

Phase 2 of this project will explore the possibility of using at least three different computer software tools for energy-analys is to determine if a building design meets a building-specific target:

- hourly simulation tools, such as DOE-2 and BLAST

- bin-based analysis tools, such as ASEAM2, that perform monthly temperature-bin calculations based on the ASHRAE Technical Committee (TC) 4.7 method

- a version of the energy and cost calculation procedures to be developed for the Targets Model.

These three energy analysis tools differ in their capabilities to model various building features and in their speed and accuracy. Both the targets energy model and the simplified simulation tools are likely to be used with microcomputers. Hourly simulation tools might be used with a variety of computers, from micros to mainframes. The proposed procedure will not require certification or approval of specific tools. Rather, the intent in this project is to develop sets of minimum, desirable attributes for tools to be used in conjunction with the targets.

A number of options will be examined in Phase 2 for relating buildingspecific target procedures with the various analysis tools. The final form of the implementation will depend upon several factors to be examined in Phase 2. The options to be considered and their advantages and disadvantages are discussed in the Volume 2: Technical Report. 


\subsection{SUMMARIES OF MAJOR PHASE 1 EFFORTS}

This section summarizes the efforts to develop and test key concepts for the targets methodology. These concepts include the space-function energy model and its major elements and the concept of incorporating economic considerations into the characteristic selection procedure of the Targets Model so that custom targets can be generated for a particular building. Also summarized are a survey of energy experts that was designed to provide a point of reference in developing targets and an approach to evaluate energy sources and costs in an objective way.

\subsection{SPACE-FUNCTION ENERGY MODEL}

As discussed in Section 2, space functions have been proposed as the basic unit for developing energy targets. Each function will be described in terms of the characteristics that specify its energy requirements independently of the characteristics of other functions. Energy targets for buildings will be the area-weighted sums of targets for all the space functions that make up the building.

Figure 3.1 describes the space-function energy model. The figure also indicates the types of information used as input to the model. The model operates using sets of regression coefficients and specified physical characteristics of the space to provide estimates of annual energy use that normally require the use of complex hour-by-hour simulations. However, the Standard 90 research and the proof-of-concept tests of Phase 1 have demonstrated that this model works reasonably well. The regression coefficients, the principle element of this model, were derived from several thousand DOE-2.1B computer simulations designed to specifically cover the range of building parameters and climate conditions encountered in the design of new commercial buildings in the United States. The following sections briefly describe the key elements of the model: space loads, schedule of operation and occupancy, and HVAC system/ equipment performance model. 


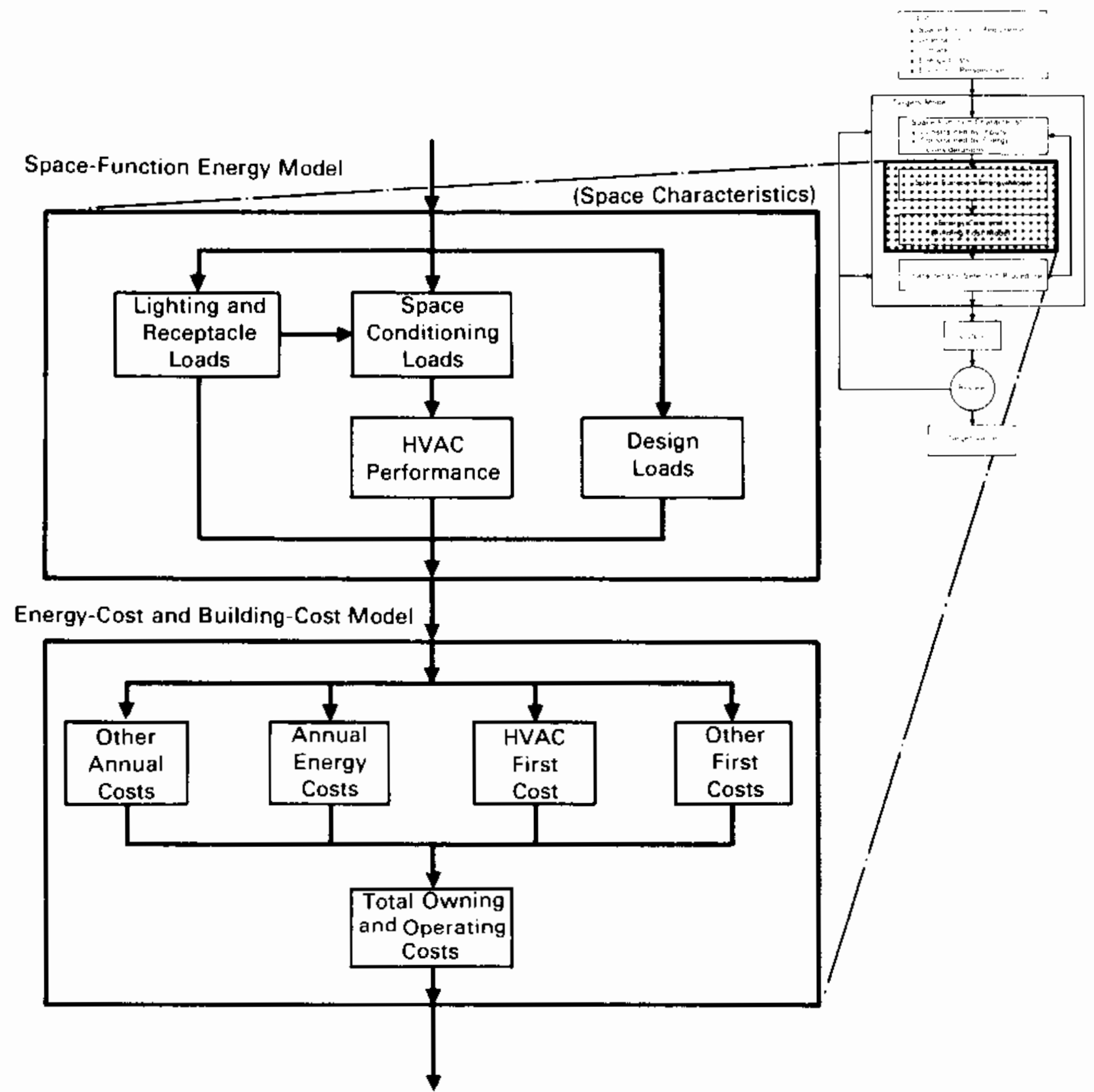

(To Selection Procedure)

FIGURE 3.1. Energy and Cost Models 


\subsubsection{Space Loads}

The first element in the space-function energy model is a space-loads model, which was initially developed in the Standard 90 revision effort (PNL 1983; ANSI/ASHRAE/IES Standard 90.1P 1986). In its initial SP 41 form (PNL 1983) the cooling-load algorithm was stated as follows:

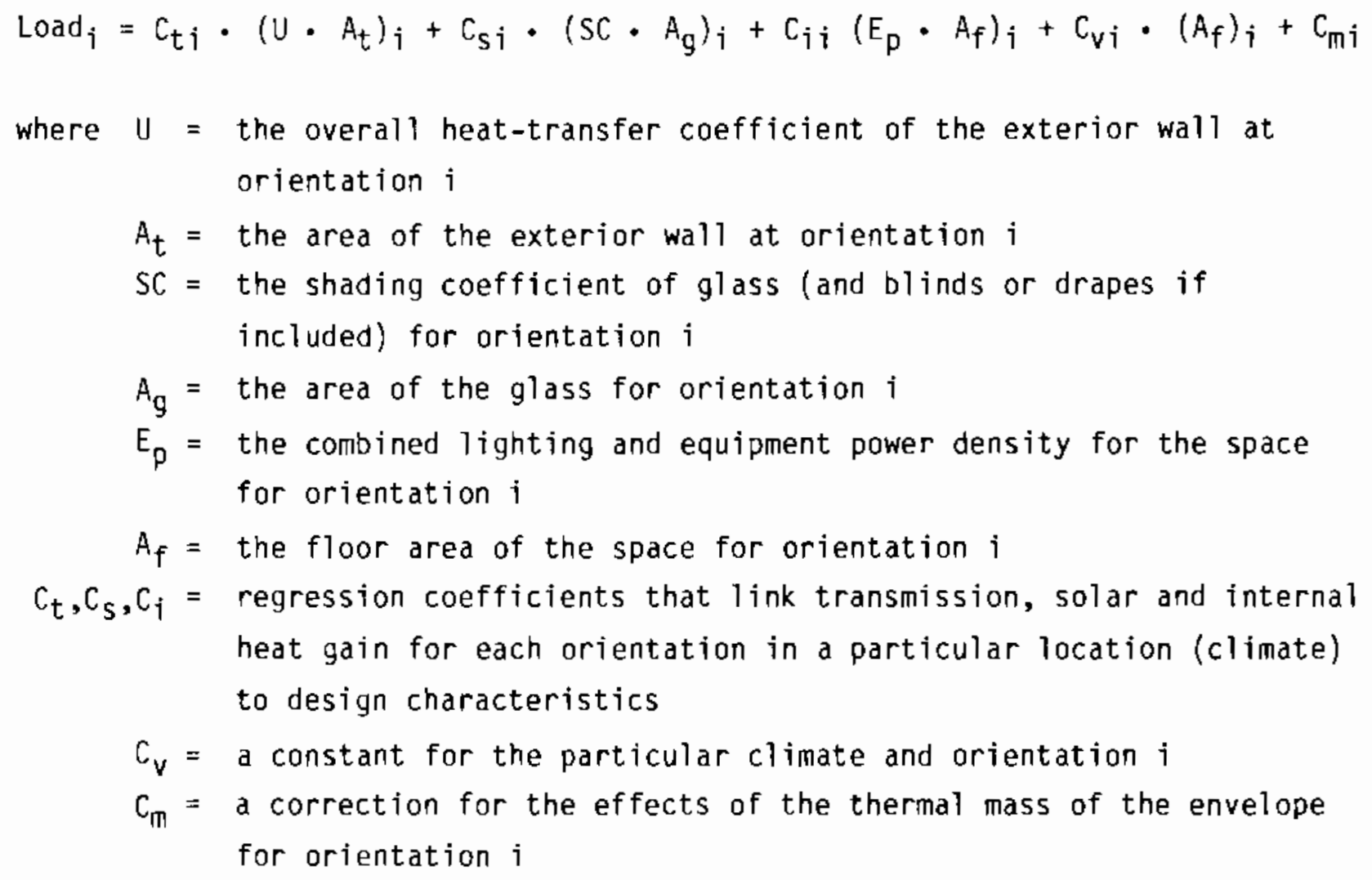

The SP 41 regression analysis, using DOE-2.1B computer simulation results, defined coefficients $\left(C_{t}, C_{s}, C_{j}\right.$, and $\left.C_{v}\right)$ for the thermal characteristic, solar gain, and internal loads terms in the equation as functions of cooling degree days $(\mathrm{CDD})$ or cooling degree hours $(\mathrm{CDH})$. The mass correction tem $\left(\mathrm{C}_{\mathrm{m}}\right)$ was defined through a separate regression-based correlation. A similar algorithm was derived for the heating loads in which coefficients were defined as a function of heating degree days (HDD).

This environment/annual space load relationship was included in the first public review draft of ANSI/ASHRAE/IES Standard 90.1P, dated June 10, 1985. One comment received during that review indicated that the regression 
coefficients did not appear to be sufficiently responsive to variations in energy use at extremes in the range of envelope parameter variation and $\mathrm{cli}$ matic conditions. Further research under the auspices of the Standard 90 revision effort is in progress to correct this deficiency and to provide a more accurate procedure. This work has provided a new set of regression coefficient relationships that incorporate additional climate parameters and the complex interaction of physical characteristic. The new coefficients provide results that track the DOE-2.1B simulation more closely. However, because they were derived through regression analysis and cannot be easily related to physical principles, other approaches will also be examined in developing the space loads model in Phase 2.

Although several problems are yet to be resolved before a final space-load model can be selected, the problems are primarily related to refinement of the equations used to define the coefficients, not to the appropriateness of the algorithm as a component of a Target Model. The Standard 90 research and the proof-of-concept tests completed as part of this project have provided ample evidence that environment/annual space load algorithrns can be developed.

\subsubsection{Schedu?e of Operation and Occupancy}

In the SP 41 research, three sets of operation profiles, corresponding to 10-, 16-, and 24-hour operations were exanined. Energy analyses were conducted to provide a basis for defining the $C_{t}, C_{s}$, and $C_{i}$ regression coefficients with the different schedules for these uses. As the operation schedules changed, energy use changed, following a reasonably consistent pattern for the range of climates examined. These results indicated that varying occupancy, lighting and HVAC operating schedules could be accommodated by modifying each annual load regression coefficient with a schedule factor. For example, for the transmission coefficient:

$$
c_{t i}=c_{t i} \cdot\left(F_{\text {schedule }}\right)_{t i}
$$

A similar form can be used for each of the other regression coefficients. The space-load characteristics that are related to or may be closely approximated with a schedule, lighting, occupancy, miscellaneous equipment, outside 
air with and without economizer use, indoor temperature, fan and pump operation, and heating and cooling system availability.

The Phase 1 targets research extended the SP 41 analysis (PNL 1983) to the point of examining the effects of variable schedules at the system level, rather than at the space-load level. These results indicated that a linear relationship exists between the schedule modifications for space loads and energy use. It will therefore be possible to develop schedule factors ( $\left.F_{\text {schedule }}\right)$ as part of the Targets Model. Issues related to operating schedules, however, will be examined in more detail in Phase 2.

\subsubsection{HVAC System/Equipment Performance Model}

The next step in the process of developing the space-function energy model was to identify appropriate HVAC system factors that could translate annual space loads into estimates of energy consumption. The Phase 1 effort indicated that it was possible to define systems and equipment factors such that the cooling component of the target could be defined as:

$$
\text { Component Load }=B+(\text { Space } \operatorname{Load}) \cdot\left(F_{\text {system }}\right) \cdot\left(F_{\text {equipment }}\right)
$$

where: $B$ is a constant for a given climate and system selection, $F_{\text {system }}$ is a factor that varies with system type and climate, and Fequipment is an annual energy-use efficiency for the equipment selected. Separate factors were deve?oped for heating, cooling, and each of the systems examined. The Phase 2 research will develop a means of relating the system and equipment factors to basic control and operating characteristics that are constrained by design considerations other than energy efficiency. This element of the Targets Model must be flexible enough to accommodate limitations in equipment availability in some size ranges, building size or configuration variations, and overriding economic concerns. However, it is not necessary to attempt to characterize all HVAC system types. The target setting procedure will onty require a carefully selected and limited set of system and equipment factors. 


\subsubsection{Energy Analysis Proof-of-Concept Tests}

In Phase 1, the space-function concept had to be tested before the proposed procedure could be recommended for developing energy targets. Key issues were:

- What are the implications of estimating annual building-energy use as the sum of energy use for independent functions (spaces) served by individual systems versus estimating energy use for a building made up of the same function spaces but served by a single system?

- How does annual energy use for heating and cooling vary as the annual space loads vary both in magnitude and in distribution over time?

- How does the relationship between the annual space loads and annua? energy use for heating and cooling vary for differing HVAC systems?

These issues were explored by undertaking a proof-of-concept test consisting of a series of DOE-2.1C computer simulations.

The first task in setting up the D0E-2. IC computer simulations in Phase 1 was to select a building configuration for the tests. The base building configuration used in the SP 41 research (PNL 1983) was selected for use. It is a simple five-zone model of an intermediate floor of a building, comprising four perimeter zones and one core zone. For the initial series of tests, occupancy schedules and latent loads were typical for an office building. Zones were defined so that exterior exposure was oriented in one of the cardinal directions (north, south, east or west). Both the space heating and sensible cooling loads were varied by changing the glazing from single pane to double pane and then to triple pane with varying shading coefficients. The simulation of the HVAC systems used the standard DOE-2.1C models with minor modifications.

Three generic HVAC system types were selected for examination: 1) a variable air volume system (VAV) with a water-cooled centrifugal chiller, zone reheat, and an electric boiler; 2) a constant-volume, packaged-single-zone (PSZ) system with air-cooled direct expansion cooling and electric resistance subzone reheat; and 3) a package-terminal-air-conditioning (PTAC) systern with electric resistance heating cycling on as needed to maintain space conditions. The VAV system is typical of systems used in large buildings with 
site-assembled centralized equipment and an extensive distribution system. The PSZ system, generally a factory-assembled unit, is typical of systems selected for smaller buildings with much shorter distribution runs. The PTAC, a through-the-wall unit, is typically used for conditioning small spaces with independent schedules and has no associated distribution system.

Systems ( $F_{\text {system }}$ ) and equipment ( $F_{\text {equipment }}$ ) factors were determined for each system in two locations for the proof-of-concept tests in Phase 1: Fort Worth, Texas, predominantly a cooling climate; and Madison, Wisconsin, predominantly a heating climate. The resulting space-function model and the results of the simulations are described in greater detail in the Volume 2: Technical Report.

Each HVAC system was simulated for the building with three sensible load levels for both the multiple zone (five-zone) and independent zone system configurations in the two climates. The independent zone analysis for each system was also repeated at one sensible load, the intermediate level, for increased hours of operation at each location.

The major issues relating to the space function approach are discussed in the following sections.

\section{Aggregating Space-Energy Use}

The first issue addressed was the difference in energy use predicted for a building simulated as a collection of zones and a building where the individual zones were simulated separately and building-energy use defined as the sum of individual-zone-energy use. The energy use for each of the three systems for a simultaneous analysis (five-zone simulation with inter-zone heat transfer and system diversity) were compared with the results of the sum of the separate zone analyses (individual-zone simulations without any inter-zone heat transfer or consideration of system or equipment diversity) for Madison and Fort Worth. The comparison indicates that little difference exists between the total annual energy use for heating, cooling and fans for the five-zone and individual zone simulations. These results are illustrated in Figure 3.2 for Madison and Fort Worth. 

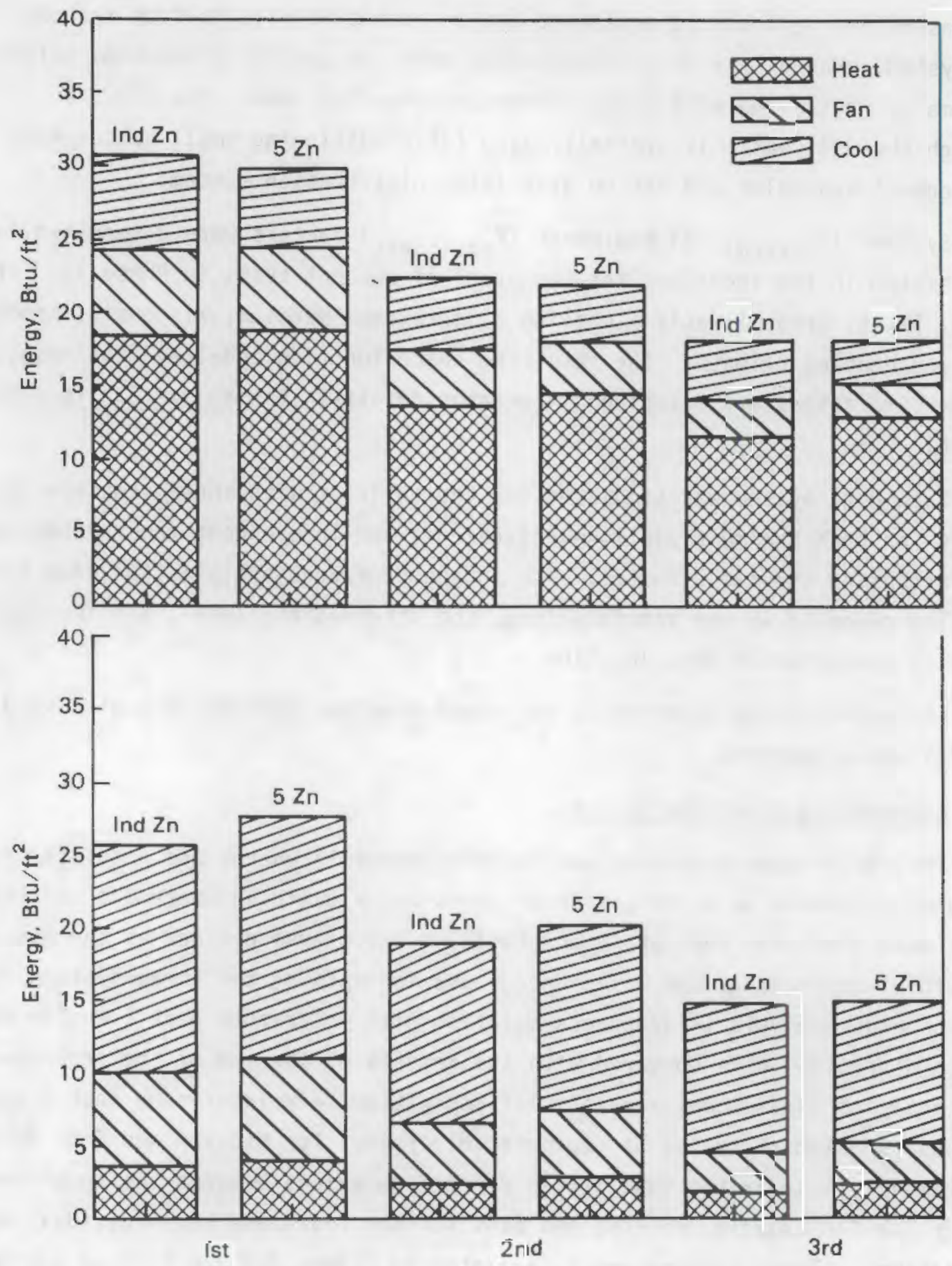

FIGURE 3.2. Comparison of Energy for Individual Zones and Five-Zone Simulations, Madison (top) and Fort Worth (bottom) 


\section{Space Loads Versus Energy Use}

The second issue is the effect of varying loads on the relationship between loads and energy use. The use of an economizer, varying control strategies and part-load performance of heating and cooling equipment was expected to affect the relationship between space loads and energy use. From this analysis, it appears an essentially linear relationship exists between annual space load and annual energy use. This trend is illustrated in Figures 3.3 and 3.4 for the south zones of Madison and Fort Worth, respectively. The nonlinear effects observed when hourly loads and hourly energy use are examined are not apparent in the annual comparisons. The intercept and slope of the annual space load/energy-use relationship varies by system type as expected, but the correlations remain linear over the tested variation in sensible load.

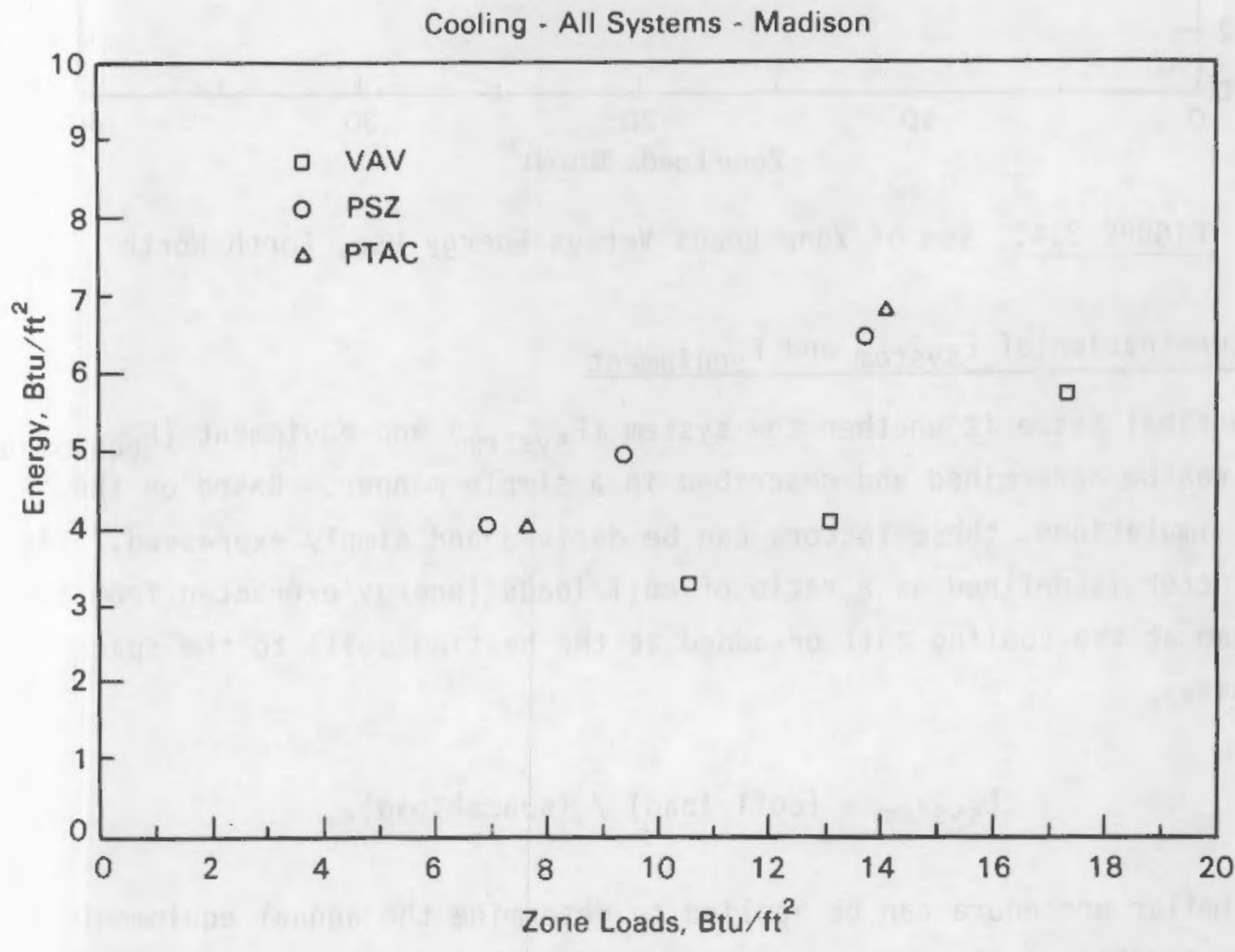

FIGURE 3.3. Sum of Zone Loads Versus Energy Use, Madison 


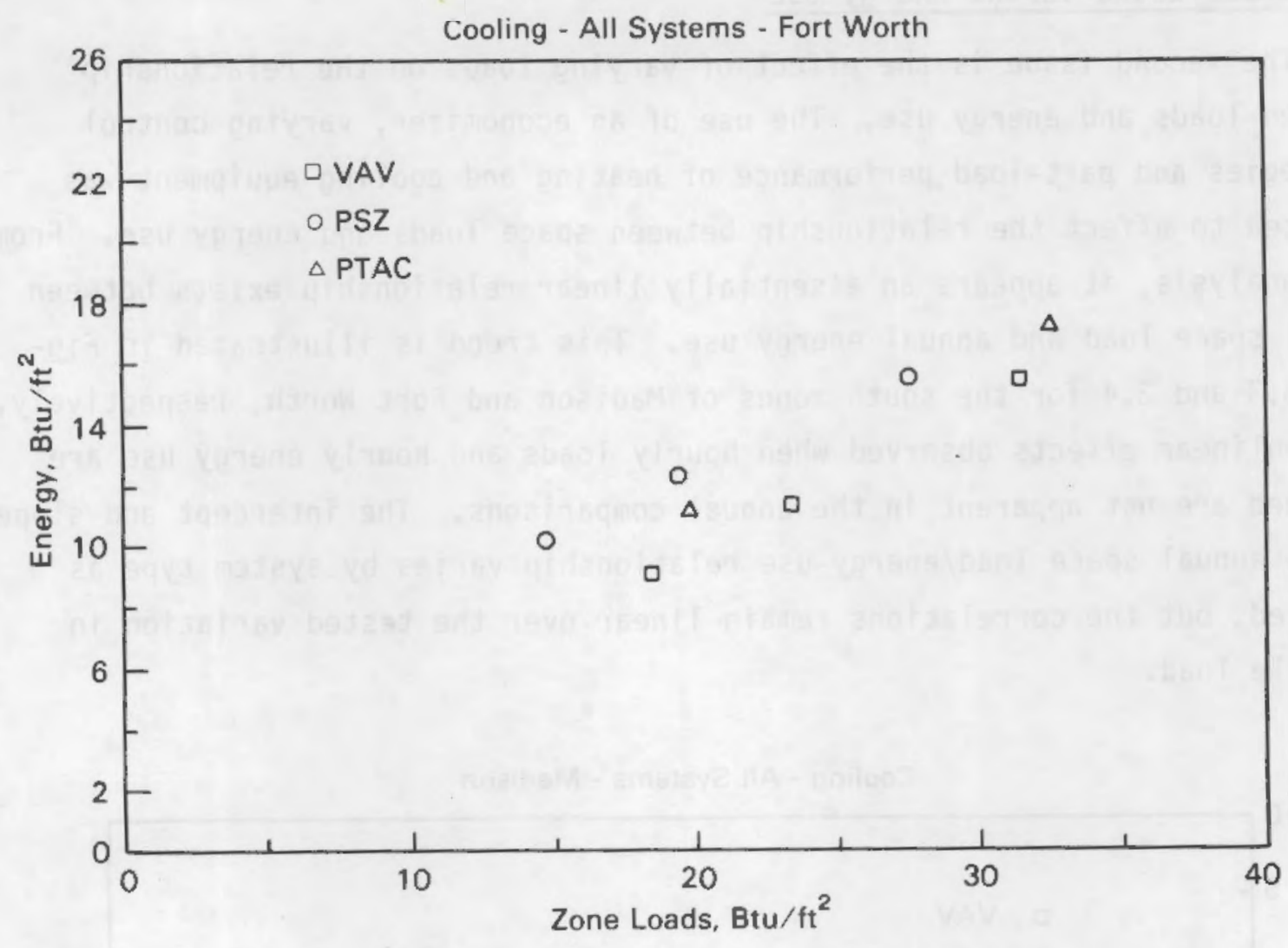

FIGURE 3.4. Sum of Zone Loads Versus Energy Use, Forth Worth

\section{Determination of $F_{\text {system }}$ and $F_{\text {equipment }}$}

The final issue is whether the system ( $F_{\text {system }}$ ) and equipment ( $F_{\text {equipment }}$ ) factors can be determined and described in a simple manner. Based on the Phase 1 simulations, these factors can be derived and simply expressed. The system factor is defined as a ratio of coil loads (energy extracted from the air stream at the cooling coil or added at the heating coil) to the space energy use.

$$
F_{\text {system }}=(\text { coil load }) /(\text { space load }) \text {. }
$$

A similar procedure can be applied to determine the annual equipment factor as a ratio of the energy use to the coil loads: 


$$
F_{\text {equipment }}=\text { (energy use) } /(\text { coil load) } \text {. }
$$

The $F_{\text {system }}$ and $F_{\text {equipment }}$ values derived in this proof-of-concept analysis are shown in detail in the Volume 2: Technical Report.

\section{Summary of Energy Model Proof-of-Concept Results}

This preliminary proof-of-concept analysis has indicated that the spacefunction approach is a viable alternative to the BEPS and ASHRAE Standard 90 , Section 10 approaches (ASHRAE/IES 90-75). Also, it has the distinct advantage of greater flexibility in the case of the BEPS procedures and greater ease of performance in the case of Standard 90. The results obtained in Phase 1 show that it is possible to consider functions individually and that a linear relationship exists between annual space loads and annual energy use for three basic and inherently different HVAC systems. This remains true even when energy use differs markedly from one system to another. Several factors must still be considered, but the present research provides clear rationale for continuing development of this concept in Phase 2 of the Targets Project. The

Volume 2: Technical Report contains a more complete discussion of the Phase 1 proof-of-concept results.

\subsection{CHARACTERISTIC SELECTION PROCEDURE PROOF-OF-CONCEPT TESTING}

A proposal was advanced during Phase 1 to integrate economic considerations into the process for selecting building characteristics, from which energy targets would be generated. An approach was proposed that would automate the selection of certain space characteristics in response to the characteristics of the particular space in question. The approach was appealing in concept as it would enable the generation of "custom targets" at the same time that it established the cost-effectiveness of the targets.

However, significant questions existed regarding the feasibility of the approach. It was not clear to the project team that such an approach would be feasible, given the complexity of building system interactions and their impact on energy performance. A proof-of-concept test was devised to determine whether such a procedure could make reasonable selections that were consistent 
with sound engineering judgment. In addition, it was necessary to examine the implications of such an approach for the nature and performance of the resulting targets.

\subsubsection{Description of Proof-of-Concept Test}

The general feasibility of the approach was explored through a proof-ofconcept computer model developed during Phase 1. This model was developed as a spreadsheet program using very rudimentary versions of the basic elements proposed for a complete Targets Model, namely:

- space-function energy model

- building-cost and energy-cost model

- characteristic selection procedure.

Because the space function energy model has not yet been developed, the energy use model in the spreadsheet was based on formulas and coefficients from Standard 90.1P and on a number of rules of thumb and best estimates. An effort was made to give the model many of the characteristics of the final model. However, it was the viability of the approach and not the accuracy of the resulting numbers that the spreadsheet was designed to demonstrate.

Characteristics were selected based on minimizing first costs, energy costs, and other annual costs over the selected time horizon. This was done by multiplying annual energy costs by the appropriate present-worth factor, adding the first cost of a set of energy-related features, and selecting the least expensive option.

Figure 3.5 illustrates the iterative search process that is used to find the value for certain parameters that will result in the lowest owning and operating costs. The procedure searches for the value of each parameter where the energy savings resulting from an incremental change exactly equals the additional cost.

There are three principal steps that the selection procedure employs as it executes. First, it eliminates options that are clearly not cost-effective by testing them under economically favorable conditions. The search routine continues to narrow the remaining options, by looking at extreme conditions that 


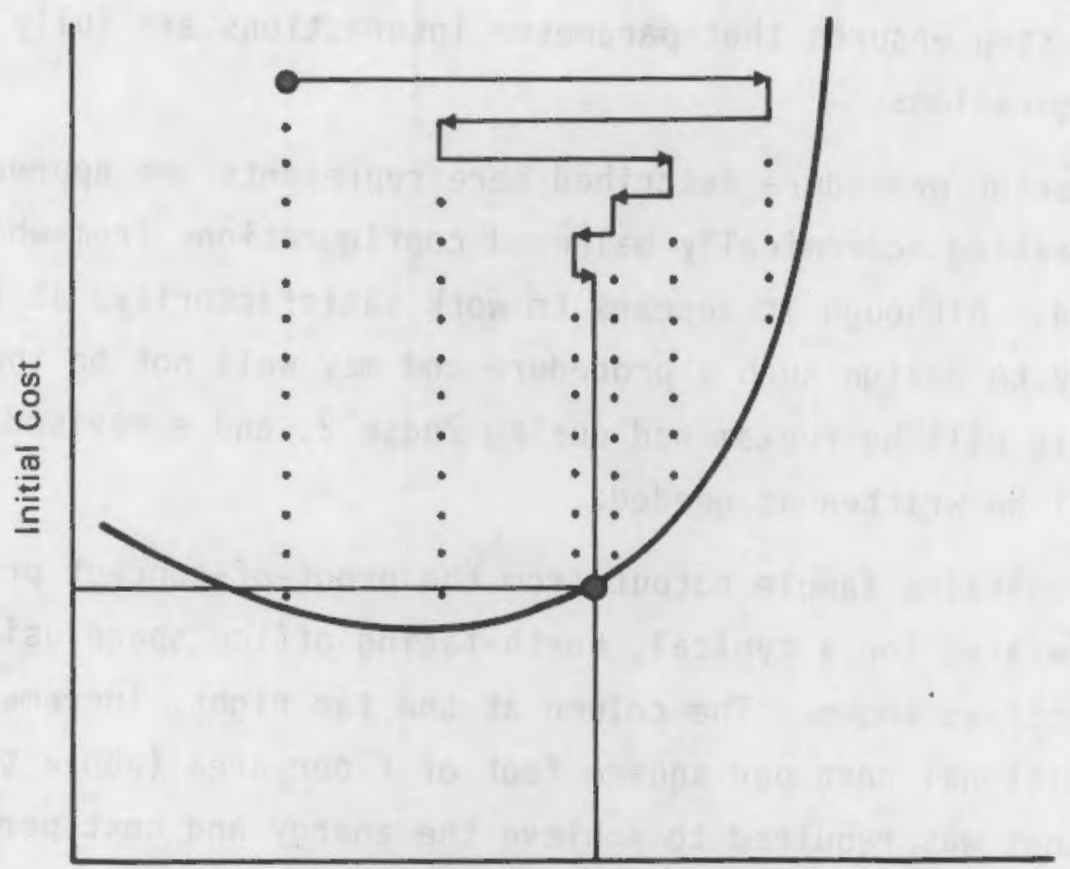

Present Value of Energy Savings

FIGURE 3.5. Selection Procedure Iterative Search Process

are either highly favorable or highly unfavorable to the parameter. The procedure uses the following order in considering the possibility of limiting or eliminating options: electric lighting, daylighting controls, cooling-system type, heating-system type, glazing type, shading coefficient, and wall-insulation level. For heating, cooling, and glazing systems, an option must be significantly outperformed before it will be abandoned. Since the sequence used to examine options for elimination could be important, this aspect of the procedure will be examined further in Phase 2.

The second step of the optimization procedure takes all possible combinations of the remaining options and optimizes electric lighting, shading coefficient, and wall insulation for each configuration at a moderate level of precision. The most cost-effective configuration is then selected.

The third and final step of the selection procedure takes the configuration that resulted from the second phase and optimizes electric-lighting level, 
glass-shading coefficient, and wall insulation at a high level of precision. This additional step ensures that parameter interactions are fully reflected in the final configurations.

The calculation procedure described here represents one approach to the problem of generating economically balanced configurations from which targets can be generated. Although it appears to work satisfactorily, it is certainly not the only way to design such a procedure and may well not be the best way. The program logic will be reexamined during Phase 2, and a revised version of the program will be written as needed.

Table 3.1 contains sample output from the proof-of-concept program. The values were generated for a typical, north-facing office space using the three economic perspectives shown. The column at the far right, incremental first cost is the additional cost per square foot of floor area (above the initialcost minimum) that was required to achieve the energy and cost performance.

Figure 3.6 was generated to illustrate how the targets model could be employed to deal equitably with different energy sources. Separate targets were generated for south-facing office space assuming either that natural gas or electricity were to be used for heating. Targets for each energy source reflect the same investment criteria for energy-conservation opportunities, and this is the basis on which the approach can be considered neutral or free from artificial bias with respect to competing energy sources. Where cost-effective opportunities for energy conservation exist, target values will be lower in response.

Notice that in Miami, where virtually no heating energy is used, the targets are almost identical. The difference between targets for natural gas and electricity are largest in Boston and Seattle, where electric heat pumps were found to be cost-effective under the given economic assumptions.

\subsubsection{Summary of Results}

The proof-of-concept test demonstrated that the approach was technically feasible. The selection procedure proved to be accurate, consistently selecting characteristics having the lowest total owning and operating costs as calculated by the simplified energy model. Since the characteristics that were 
TABLE 3.1. Example Configurations and Results Generated Using Proof-of-Concept Program

PERSPECTIVE 11 (INITIAL COST MINIMUM)

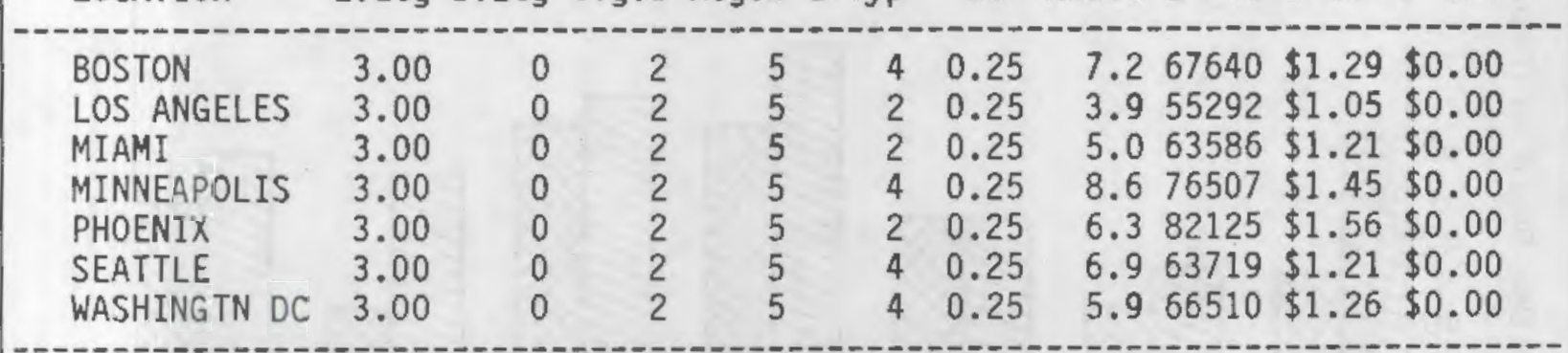

PERSPECTIVE $\$ 3$ (SHORT LIFE-CYCLE COST MINIMUM)

\begin{tabular}{|c|c|c|c|c|c|c|c|}
\hline BOSTON & 2.64 & 1 & 2 & 4 & 3 & 0.57 & $10.259123 \$ 0.78 \$ 2.11$ \\
\hline ELES & & 0 & 2 & 5 & 2 & 0. & $7.142324 \$ 0$ \\
\hline & & 0 & $\overline{1}$ & 5 & 2 & 0 . & $7.042617 \$ 0$ \\
\hline APOLIS & 2.6 & 1 & 2 & 4 & 3 & 0.57 & $11.671580 \$ 0$ \\
\hline & 1. & 0 & 1 & 5 & 2 & & $3 \$ 1$ \\
\hline & 2.6 & 1 & 2 & 4 & 3 & 0.57 & $9.5 \quad 55248 \quad \$ 0.73 \$ 2.10$ \\
\hline WASHINGTN DC & 2.58 & 1 & 2 & & 3 & 0.57 & $9.5 \quad 54790 \$ 0.78 \$ 2.15$ \\
\hline
\end{tabular}

PERSPECTIVE \#5 (SOCIETAL COST MINIMUM)

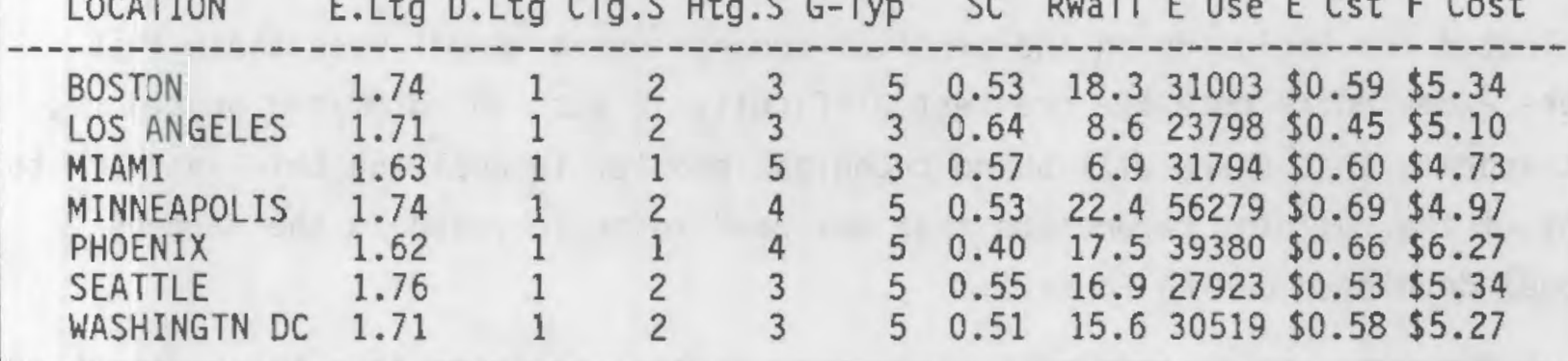

KEY TO TABLE 4-3:

E.Ltg - Electric Lighting (W/sf)

D.Ltg - $0=$ no daylighting controls, $1=$ automatic daylighting controls

Clg.S - 1=electric chiller and cooling tower, 2=direct expansion unit

Htg.S - $3=$ electric heat pump, $4=$ gas furnace or boiler, $5=$ electric furnace or boiler

G-Typ - 1=single tinted, 2=single reflective, $3=$ double tinted, $4=$ double reflective, $5=$ high performance

SC - glass shading coefficient

Rwall - R-value of exterior walls 


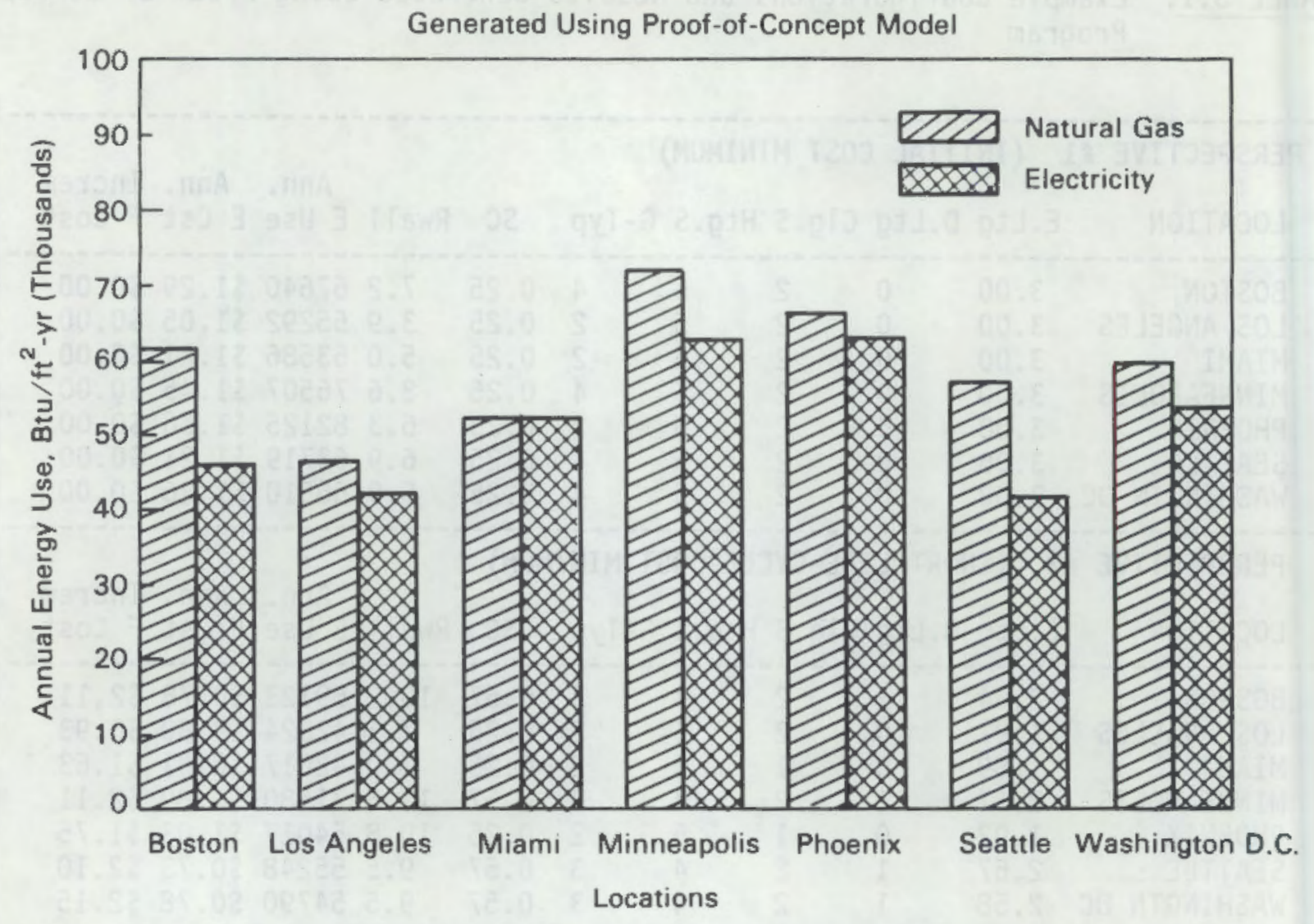

FIGURE 3.6. Example Heating Fuel Specific Targets

selected for inclusion in the proof-of-concept energy model were those that were expected to pose the greatest difficulty in such an automated procedure, it appears that there will be no technical problem in applying this approach to any of the building parameters that may need to be included in the Targets Model developed during Phase 2.

Moreover, apart from some minor aberrations resulting from the rudimentary nature of the energy and cost models, the selections appear reasonable based on an understanding of energy use in buildings. Characteristics are selected to represent technically and economically sound mixes of strategies, reflecting both the physical and economic interactions that are involved.

Execution times for the program, implemented in a spreadsheet program, were excessive, in view of some of the ways being considered for implementing 
the approach into the final procedures. However, because of a number of technical solutions available, involving improved logic and faster codes, execution speed is not viewed as a major constraint for the approach.

Preliminary analysis of the effects that such an approach would have on the resulting targets has been encouraging. Although a number of significant questions remain unresolved regarding the final form in which the methodology would be implemented, the approach appears to offer significant advantages related to target responsiveness and neutrality, issues that have plagued earlier efforts at developing performance-based standards and guidelines.

\subsection{SURVEY OF ENERGY EXPERTS}

The objective of this task was to develop estimates of several levels of whole-building energy performance, based on the combined professional judgment of a number of building energy experts. Another objective was to determine qualitatively the extent of agreement that exists today on different levels of whole-building energy performance. Expert judgment was sought primarily on two levels of energy performance: average energy design practice and good design practice for energy efficiency.

These two levels were bounded in the survey by asking the energy experts for their opinions on four ranges of energy-design practice: technical/costeffective limit, good practice, average practice, and energy-intensive design practice. This task has focused on obtaining estimates primarily for two building types-offices and motels/hotels, but estimates for other building types were also obtained.

The emphasis was on determining the judgment of the experts, not on data collection. To obtain information about important assumptions used in producing the estimates, a page of questions was developed to enable each respondent to define relevant assumptions used and to insert comments about any special qualifications or features that might affect the interpretation of the estimates.

The information obtained from this survey is intended to provide guidance to the project team in the development of other project activities, and to 
provide a useful qualitative reference for building designers and owners. The results of this survey are not intended to be used as the direct basis of energy targets developed in this project.

\subsubsection{The Survey}

The project team identified energy experts to provide experience across the range of climate conditions experienced in the continental United States, to provide experience with a variety of building types, concentrating on offices and hotels/motels, and to represent a range of buildings industry groups. No attempt was made to ensure that a statistically meaningful sample was obtained. About 125 sources were identified and responses were obtained from about $45 \%$ or 57 individuals. Some respondents gave estimates for more than one building type or region, for a total of 141 separate estimates.

\subsubsection{Nature of Responses}

Five building types accounted for $87 \%$ of the energy estimates provided. Almost half of the responses were for office buildings ( 60 responses, or 43\%). Education and hotel/motel came next with 24 and 19 responses respectively. There were 11 responses for apartments, and 8 responses for retail facilities.

Most respondents either indicated that their estimates covered all climates, a region, or specific locations. A greater proportion of responses was received from the more heavily populated regions of the country. For some building types, more responses came from the northern and eastern parts of the country.

The participants were asked to indicate whether their estimates were based on design calculations, actual consumption, or a combination of the two. The responses were about evenly split among these three categories. Virtually all responses were in terms of $\mathrm{Btu} /\left(\mathrm{y} \cdot \mathrm{ft}^{2}\right)$ or $\mathrm{KBtu} /\left(\mathrm{y} \cdot \mathrm{ft}^{2}\right)$ at the building site. In those few cases where another unit of measure was used, two sets of estimates were provided, one in Btu/(y•ft$\left.t^{2}\right)$ and another in a second unit of measurement. 


\subsubsection{Summary of Energy Estimate Results}

Table 3.2 summarizes the average energy estimates produced by the survey for the five building types with more than just a few responses. Some respondents provided estimates as ranges, while others provided average values. All estimates have been combined as an average for each building type. These averages are for the total number of responses received, without regard to differences in experience basis, estimate basis (design calculation or actual consumption), or region of the country. Thus, any use of these averages needs to be treated with great caution.

More detailed tabulations by building type are contained in Volume 2: Technical Report, with more statistical analysis of the estimates: maximum and minimum estimates, and standard deviation, presented graphically. For example, Figure 3.7 shows all combined estimates obtained for office buildings, for the four energy levels requested: technical limit, good, average, and energy intensive. For each level, the figure indicates the mean of the estimates, the

\section{TABLE 3.2. Estimates for Five Building Types}

\begin{tabular}{|c|c|c|c|c|c|c|c|c|}
\hline & \multicolumn{4}{|c|}{ OFFICE $(\mathrm{a})$} & \multirow{2}{*}{$\begin{array}{l}\text { HOTEL/ } \\
\text { MOTEL }\end{array}$} & \multirow[t]{2}{*}{ EDUC } & \multirow[t]{2}{*}{ APTS } & \multirow[t]{2}{*}{ RETAIL } \\
\hline & Design & Actual & Combined & All & & & & \\
\hline Technical Limit & 33 & 43 & 44 & 39 & 70 & 36 & 42 & 92 \\
\hline Good Practice & 46 & 61 & 66 & 57 & 90 & 55 & 58 & 105 \\
\hline Average Practice & 62 & 82 & 102 & 80 & 117 & 81 & 74 & 157 \\
\hline Energy Intensive & 103 & 122 & 127 & 116 & 166 & 99 & 117 & 265 \\
\hline
\end{tabular}

(a) KEY: Design = Estimates provided that were based on Design Calculations. Actual = Estimates provided that were based on Actual Consumption. Combined = Estimates provided that were based on a combination of Design Calculations and Actual Consumption.

All = All office building estimates combined, without regard to the basis used (Design + Actual + Combined). 


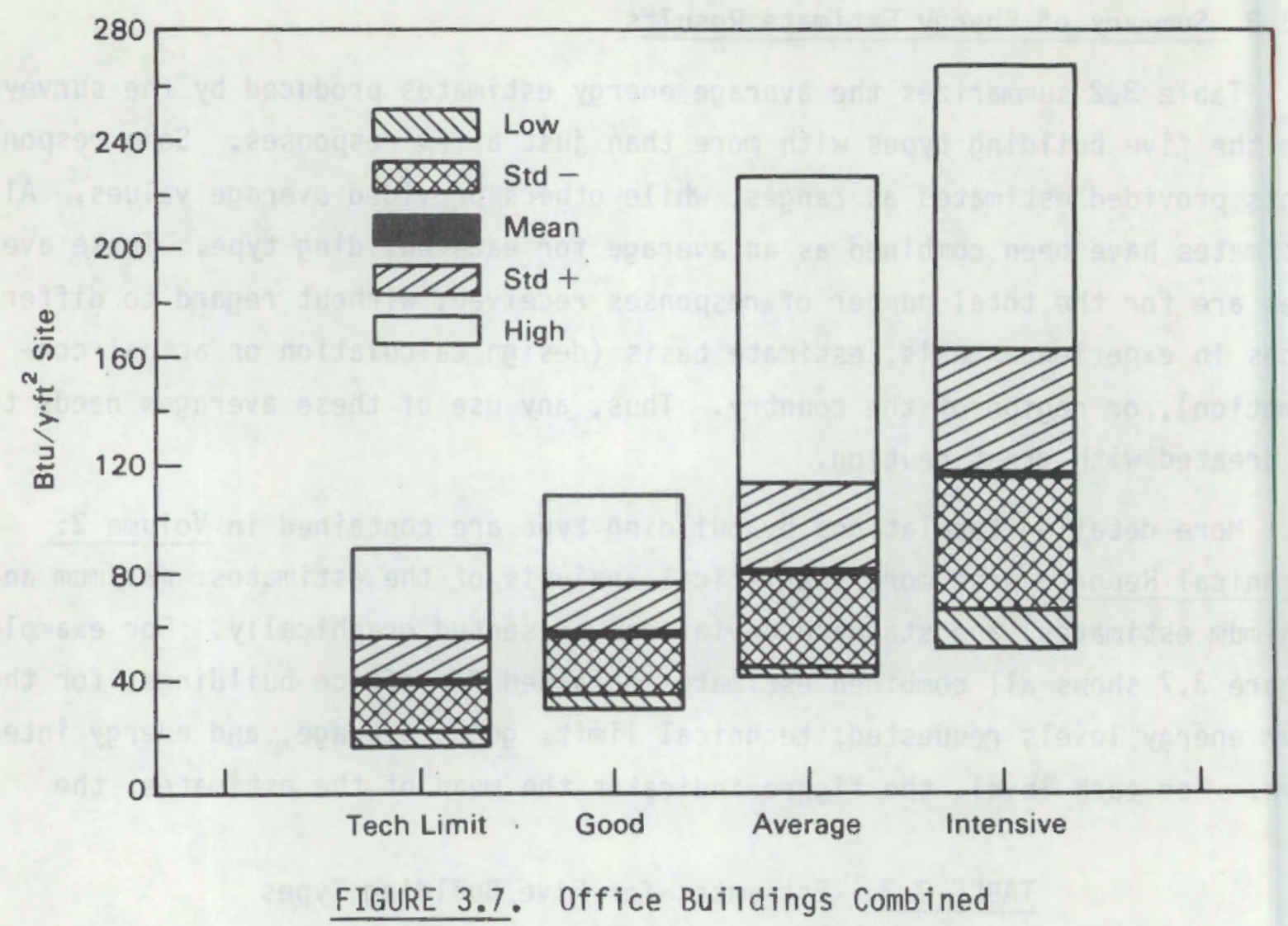

range of one standard deviation about the mean (about two thirds of the estimates involved), and the maximum and minimum estimates received. Similar figures for other building types are contained in Volume 2: Technical Report along with discussions of the results.

\subsubsection{Conclusions}

The results of this survey will be used by the project team as one point of reference in the further development of energy target methodologies and levels. The results should also prove useful as general reference information to building owners and designers on professional judgment about various levels of energy use for several building types.

The results have proved valuable not only for the average estimates obtained, but also for the variations in the estimates, and for the experience gained in collecting, tabulating, and interpreting the estimates. Because of numerous limitations in the survey and in the results, the energy estimates 
reported should be used with considerable care and judgment. This is especially important considering the consistently wide variation in the estimates. Phase 2 of this project will address directly many of the causes of variation in commercial building energy use that have surfaced both in this survey and elsewhere.

\subsection{ENERGY SOURCES}

This section is a summary description of the work conducted in Phase 1 to develop an approach for treating energy sources consistent with the project goais of 1) promoting economical levels of building-energy efficiency and 2) being acceptable to the energy-supply and buildings industries. The intent is to develop a treatment of energy sources that is free from artificial bias with respect to competing energy sources and huilding systems, and that will not introduce distortions that would undermine the economic appropriateness of the targets. A detailed discussion of this work is contained in the Volume 2: Technical Report.

\subsubsection{Background}

The treatment of different energy sources in past building-energyguideline projects has proven to be difficult. Different forms of energy used in buildings vary in the thermal efficiency of their production and end-use conversion, in their market prices, and in the social and environmental costs associated with their production and use. There is no simple or obvious common basis on which all energy sources can be compared. Moreover, it is technically difficult to devise a procedure for dealing with different energy sources that does not inadvertently introduce distortions and biases that artificially favor certain energy sources or building systems over others. Two issues that are particularly important in considering the approach for treating different energy sources are the method for measuring energy and the treatment of energy costs.

Energy use can be measured as a raw resource, at a building's site boundary, at a building's heating and cooling coils, or at a number of points in between. Energy targets based on each of these methods of measuring energy would result in significantly different incentives for the end user. For 
example, targets that measured energy use at the raw-resource level would place electricity at a great competitive disadvantage versus fossil fuels because of the inherent inefficiencies involved in generating electricity from thermal sources. The user of the targets would have no incentive to use electricity. On the other hand, if the targets used the site boundary as the point of measurement, fossil fuels would be put at a disadvantage because their conversion losses occur after delivery to the site rather than before. It can be argued that either of these approaches would result in artificial biases that would create incentives for the user to switch fuel types in order to more easily meet the target. Such artificial incentives for fuel switching form serious distortions that the energy sources approach employed in this project will attempt to eliminate.

Most performance-based building energy standards and guidelines in the past have been energy-based rather than cost-based; that is, they have not integrated energy costs into the methodology. The cost of utility-supplied energy varies by as much as a factor of ten across the country. Targets that ignore these cost differences would promote inadequate levels of performance in high-energy-cost areas while promoting unwarranted expenditures on energy efficiency in areas having low-cost energy resources.

\subsubsection{Approach}

The approach to dealing with energy sources was designed to ensure that the consideration of options would be done in an open, thorough, and objective way. Explicit criteria and a methodical approach to assessing alternative methods were used to provide a clear decision trail. Technical representatives of the gas and electric industries have contributed to all project team discussions and decisions regarding the treatment of energy sources.

The Phase 1 work on energy sources consisted of two major tasks. The first task was to develop a set of evaluation criteria for assessing the various methods for treating energy sources. The evaluation criteria grew directly out of the statement of project goals and desirable attributes for the targets, described in section 1 of this report. The criteria represent the team consensus as to the relative importance of each criterion to the ultimate success of 
the project. These evaluation criteria and weights assigned to each by the team were then used to rate each of the alternative methods.

The second task was to compile a list of possible methods for treating energy sources and to assess these methods in light of the evaluation criteria. Four generic approaches were identified for treating different energy sources as shown in Table 3.3 .

TABLE 3.3. Methods Grouped by Generic Approach

A. MEASURE THERMAL ENERGY AT THE SITE BOUNDARY

1. Site Boundary Conversion to Thermal Energy

2. ASHRAE/IES Standard g08-1975 (Section 10) Method

B. MEASURE THERMAL ENERGY AT SITE BOUNDARY, COIL FOR FOSSIL FUELS

3. Apply On-Site Post-Conversion Factor

4. Ornit On-Site Conversion Energy Losses

c. MEASURE ENERGY AT THE RESOURCES LEVEL

5. DOE's Institutional Grant Program (IGP) Factor

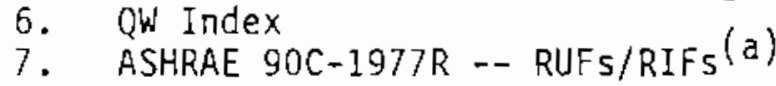

D. USE ENERGY COST AS BASIS FOR COMPARISON

B. Building Energy Performance Standards (BEPS) -Weighting Factors

9. National Average Unit Cost Per Energy Source

10. Regional Average Unit Cost Per Energy Source

11. Loca1 Cost (ASHRAE/IES Standard 90B-1975R)

12. Local Energy Source Cost (per Published Rate Schedule)

13. Marginal Cost

14. Total Owning and Operating cost

(a) This method actually goes beyond resource energy and is the only method that explicitly attempts to address societal and environmental impacts. 
Within the four generic approaches, 14 distinct methods have been identified, and Table 3.3 shows how the 14 methods group into the 4 generic approaches. Some methods are simply variations on others. This listing does not include all the methodologies that have ever been suggested or used. However, it does cover virtually all of the methods that have received widespread consideration and review. A detailed discussion of the advantages and disadvantages and the ranking for each method is contained in the Volume 2: Technical Report.

\subsubsection{Summary of Evaluation of A1ternative Methodologies}

All of the methods that have been reviewed are imperfect: none fully meet all of the evaluation criteria. Selecting methods for further development and use in Phase 2 has been a matter of determining which methods best match the project objectives.

An evaluation matrix, presented in Table 3.4, summarizes the performance of each of the 14 methods with respect to the evaluation criteria. Ratings in the evaluation matrix were developed by the project team using professional judgment. These ratings were combined using relative-weight factors for each of the four major categories of evaluation criteria as a whole yielding an overall numerical score for each method.

Based upon the evaluation, method 14, TOOC, was selected for primary consideration for development in Phase 2 of the project. The procedure will focus on energy costs as reflected by local market prices. Use of local prices is consistent with the voluntary nature of the targets and their reliance for acceptance on benefit to the individual user. Given that this method received a low evaluation score for complexity of use, attention needs to be given to developing simplified techniques for final implementation during Phase 2. The second and third ranked methods in Table 3.4 will also be considered during Phase 2, but not at the same priority level as the TOOC method. Extensive review of this work will take place before further final development of a selected approach is begun during Phase 2 . 
TABLE 3.4. Evaluation Matrix for Rating Methodologies

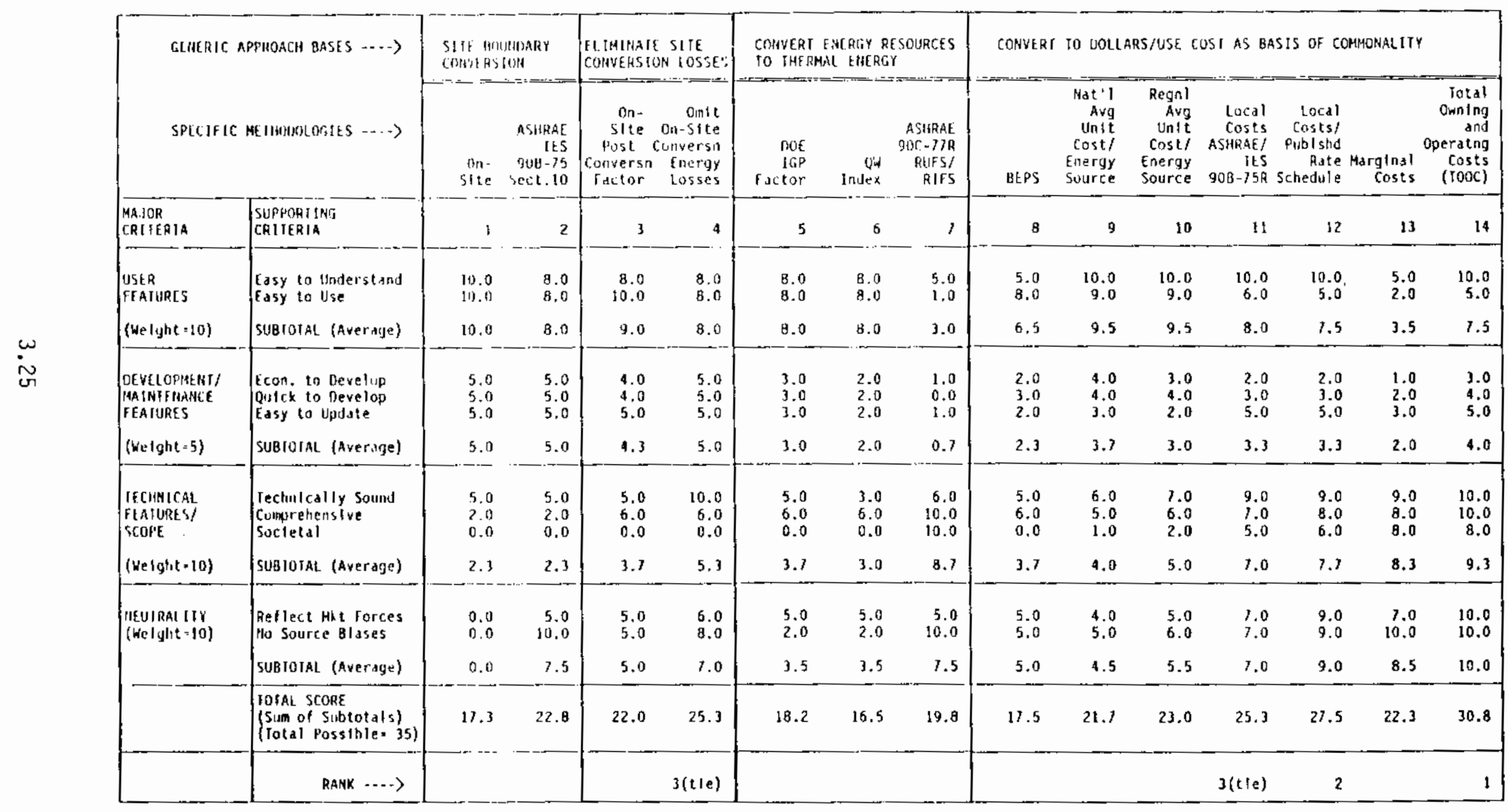





\subsection{PHASE 2--TASK DESCRIPTIONS}

Phase 1 Planning resulted in the proposed space-function approach to developing whole-building energy design targets. This approach, the Targets Model described in Section 2, provides a means of determining custom, buildingspecific targets.

Phase 2 of this project shall complete in detail the methodology outlined in Phase 1 through the development of a Targets Model. The Targets Model software and hardware system will be designed for ease of use. Each of the major tasks involved in Phase 2 target development is described below. The major tasks for Phase 2 target development are:

- Task 1--Project Integration

- Task 2--Buildings-Industry Review

- Task 3--Hardware Syster Selection/Software Developments

- Task 4--Energy-Model Development

- Task 5--Develop Energy-Cost and Building-Cost Mode 1

- Task 6--Develop Characteristics-Selection Procedure

- Task 7--Devel op Example Whole-Building Energy Targets.

\subsection{TASK 1--PROJECT INTEGRATION}

This task will ensure that all elements of the project research are integrated and properly controlled. The activities involved in Task 1 are:

- Task 1.1--Refine Project Goals and Objectives

- Task 1.2--Define Objectives for the Targets Moder

- Task 1.3--Define the Structure of the Targets Mode1

- Task 1.4--Define the Target Format and Presentation

- Task 1.5--Define Project Documentation Standards

- Task 1.6--Prepare Project Executive Summary for Phase 2.

\subsubsection{Task 1.1--Refine Project Goals and Objectives}

In Phase 1, a set of desirable attributes for whole-building energy targets were developed by the project team after lengthy review. These attributes along with the overall objective and goals for the project research will be reviewed at the beginning of Phase 2 . 


\subsubsection{Task 1.2--Define Objectives for the Targets Model}

In this task, the objectives to be achieved by the Targets Model will be defined by the project team working with the DOE. These objectives will provide direction for the research in the various elements of the model. 4.1.3 Task 1.3--Define the Structure of the Targets Model

The structure of the Targets Model will be defined based on the objectives set for the project and the Targets Mode1. Two alternative approaches are being considered for the energy portion of the Targets Model. One approach is to develop an integrated set of correlation models based on numerous computer simulations using DOE-2 or another state-of-the-art energy-analysis program. A second approach is to apply compaction techniques to an annual hourly energy simulation method on computer hardware that will be commonly available when the project is completed.

Both approaches have desirable characteristics and potential liabilities. For example, the correlation approach would likely be easier and faster to use once developed. However, it will be difficult to develop and update. A compacted simulation model will likely take longer to use (in machine time) but should be much easier to develop and update than would a correlation approach. Further, a compacted simulation model is likely to be more accurate and easier to verify than a correlation model.

This task will assess the benefits of both approaches. The major product of this task will be to recommend one or a combination of the two approaches for final development of the Targets Model. For example, there may be benefits in using elements of the correlation approach to define and focus efforts on the simulation approach.

\subsubsection{Task 1.4--Define the Target Format and Presentation}

The objective of this task is to identify a general approach to the format of the targets procedures and materials during Phase 2. In this task, the steps necessary to ensure effectiveness and consistency in the formats will be identified. Format in this context includes the content, methods, 
organization, and appearance of the targets procedures and materials--in short, all the packaging aspects of the research conducted for the Targets project that directly affect the end user.

The final form for the products of this targets project depends on the outcome of a large number of technical deliberations during Phase 2 . The final targets materials are expected to include:

- an overview describing the targets including their function

- a fully developed Targets Model, consisting of calculation procedures that use energy and economic criteria, constraints, and other parameters to generate energy targets levels or values

- case study sets of demonstration target values for selected typical space functions, space function characteristics, and building types.

- a well-defined procedure to determine whether a specific building design project meets a given target level or value

- a custom target determination calculation procedure usable with an hourly simulation program such as DOE-2.

Further, it is expected that in Phase 2:

- Example sets of space (building) characteristics that correspond with the demonstration-case-study targets to help make the target procedure and performance levels more understandable will be developed.

- Component information from the calculations and a graphics interface option for the Targets Model that would help to make the background information and calculations accessible to the user will be developed.

- Options that make calculation routines that are inherent in the Targets Model, such as optimization, available to the user to guide early design decisions will be developed.

- Instructions on how to use the products and procedures provided will be developed. 
- An appendix or supplementary volume to document the technical basis for all procedures contained in targets materials, especially the Targets Model, will be developed.

A workbook may be developed as a medium for communicating to the design community the value of the technical materials contained in the project. This workbook concept for the formulation of targets materials should be considered for use either as part of the primary vehicle for dissemination or as a followup document.

\subsubsection{Task 1.5--Define Project Documentation Standards}

A documentation standard for technical information and research results developed during Phase 2 will be established. This information will be compiled in supplementary volumes to document the technical basis for all procedures. A documentation standard is necessary to ensure that materials in the technical documentation are consistent and comprehensible. A written standard will encourage the documentation of work as it is produced, rather than at the end of the project when important details are likely to be overlooked.

\subsubsection{Task 1.6--Prepare Project Executive Summary for Phase 2}

The project team will prepare an executive summary that summarizes the findings of the research conducted during Phase 2. Task reports will be prepared to document research and findings for each task. These task reports will be used in preparing the overall executive summary.

\subsection{TASK 2--BUILDINGS-INDUSTRY REVIEH}

The objective of the buildings-industry review is to establish liaison with buildings-industry groups, especially owner associations to review and provide input to the targets-development process.

Two advisory groups will be estabiished to provide input to the targetsdevelopment process: a Buildings-Industry Review Panel for owner, managers, and operators; and a Technical Review Panel for design professionals. These advisory groups will meet periodically to provide feedback and review of ongoing research in the targets project. There are two activities involved in the buildings-industry review task: 
- Task 2.1--Project Review Workshop of Phase 2 Work Plan

- Task 2.2--Ongoing Buildings-Industry Review

These activities are described after a brief discussion of the two review groups.

\subsubsection{Buildings-Industry Review Panel}

Representatives of the following building-owner associations will be asked to participate in regular meetings of a Buildings-Industry Review Panel (BIRP), beginning with the Project Review Workshop in the winter of 1987:

- Office Buildings

- Building Owners and Managers Association

- Urban Land Institute

- Institute of Real Estate Management

- U.S. General Services Administration

- Education Facilities

- Association of Physical Plant Administration

- Council of Educational Facility Planners

- American Association of School Administration

- Apartment Buildings

- National Apartment Association

- Institute of Real Estate Management

- National Association of Home Builders

- U.S. Department of Housing/Urban Development

- U.S. Department of Defense

- Lodging Facilities

- American Hotel and Motel Association

- Urban Land Institute

- Warehouses

- Warehousing Education \& Research Council

- U.S. Department of Defense. 


\subsubsection{Technical Review Panel}

A Technical Review Panel (TRP) will be established to periodically review the technical approach and research conducted during Phase 2. Individuals from the following groups will be invited to participate:

- American Society of Heating, Refrigerating, and Air-Conditioning Engineers, Inc.

- Illuminating Engineering Society of North America

- American Institute of Architects

- American Consulting Engineering Council

- U.S. Government Agencies

- U.S. Department of Energy, Federal Energy Management Program (FEMP)

- U.S. Department of Defense

- U.S. Department of Housing and Urban Development

- U.S. Postal Service

- General Services Administration

- U.S. Department of Commerce, National Bureau of Standards (NBS)

- DOE National Laboratories.

\subsubsection{Task 2.1--Project Review Workshop of Phase 2 Work Plan}

A two day workshop will be held March 4-5, 1987 in Washington, D.C. Presentations will be made on the proof-of-concept research conducted in Phase 1 as well as the proposed methodology for developing targets in Phase 2. Participants in the workshop will provide review of the Phase 2 plan, with changes incorporated by the project team in the methodology proposed for target development.

\subsubsection{Task 2.2--0ngoing Buildings-Industry Review}

Regular meetings of the BIRP and the TRP will be held to obtain review of ongoing research for the project. 


\subsection{TASK 3--HARDWARE SYSTEM SELECTION/SOFTWARE DEVELOPMENT}

The selection of a computing and programming system for the targets model is important since the decision ultimately defines the way in which the targets interact with the user. "Hardware system" as used in this report means the computing equipment and its operating system that are used in developing targets model and the equipment that will be used by the end user to generate a project-specific target. "Software system" as used in this report means the programming language, specific software packages, etc., in which the targets model will be coded. Because pieces of the model may be developed by various individuals in different work locations, it will be necessary to take steps to actively coordinate this decision. There are five tasks involved in accomplishing this activity:

- Task 3.1--Define Project Standard Software

- Task 3.2--Define Attributes of User Interface

- Task 3.3--Investigate Hardware Options/Initial Selection

- Task 3.4--Develop Project Research Software

- Task 3.5--Select Final Hardware System.

Descriptions of the tasks to develop an appropriate format for presenting the Targets Model follow. Explicit criteria for the selection of hardware and software systems for the Targets Model will be established and selections will be made. Criteria to be considered include execution speed for the procedure, installed base among end users, ease of development, and graphics interface. The results of Task 1.3 will also provide an important input to the choice of hardware system, based upon the selection of either the correlation or compacted simulation approach to the energy model part of the Targets Model.

\subsubsection{Task 3.1--Define Project Standard Software}

Standardized software products for all project work will simplify data transfer and communication between team members. Because interrelated work will be conducted at various locations, it is necessary to ensure that data can be shared and that scarce project resources will not be expended overcoming data format and communication problems. Project standard software will include: communication software, word processing software, statistical software, calculation software, spreadsheet software, and graphics software. 


\subsubsection{Task 3.2--Define Attributes of User Interface}

The methods of user interface with the Targets Model will be defined. The interface should allow the user to quickly assess and compare alternatives and should also be a graphic-based input and output medium. The potential use of, or interface with, expert system shells should also be considered in developing a user interface.

\subsubsection{Task 3.3--Investigate Hardware Options/Initial Selection}

Hardware system options for use with the Targets Model, planning three to five years in the future will be investigated. An initial selection of the hardware system will be made to allow development of project research software in Task 3.4. Issues to be considered include speed, method of input/output, device configuration, and other related hardware system opportunities.

\subsubsection{Task 3.4--Develop Project Research Software}

Project research software will be developed and programmed for the following parts of the Targets Model: energy model, energy cost/building-cost model, characteristic selection procedure, and user interface. Software development will be conducted with the initial hardware system selected in Task 3.3 .

\subsubsection{Task 3.5--Select Final Hardware System}

The initial hardware system selected in Task 3.3 will be reviewed in this task. A final hardware system will be selected for use in developing the Targets Model software in Task 3.4. This task will be conducted after all model development and research has been completed near the end of the project.

\subsection{TASK 4--ENERGY MODEL DEVELOPMENT}

A primary objective of the present project is to develop a procedure for establishing whole-building performance targets which are comprehensive enough to cover all the building, HVAC, fuel types, climate regions, operating conditions and schedules that may be encountered in designing buildings. The Targets Model to be developed in this Phase 2 task is the major product of 
Phase 2, and is intended to provide a comprehensive and flexible target setting methodology. There are four major activities involved in developing the energy model portion of the Targets Model:

- Task 4.1--Define 0ccupancy Pattern/Climate Interactions

- Task 4.2--Space Function Characteristics Analysis

- Task 4.3--Develop Space Function Loads Model

- Task 4.4--Develop System/Equipment/Plant Energy Mode1.

\subsubsection{Task 4.1--Define Dccupancy Pattern/Climate Interactions}

This task will build on ASHRAE SP 41 research (PNL 1983) on building response to occupancy and operation variability. The two activities to be performed as part of Task 4.1 are:

- Task 4.1.1--Define Climate Variables and Develop Data

- Task 4.1.2--Coordinate with ASHRAE TC 4.3 and TC 4.7

Task 4.1.1--Define Climate Variables and Develop Data

This task will build upon previous work (including SP 41 and Phase 1 of this project) by examining the climate variables used in previous work to reflect changes in climatic conditions from location to location. Also, for energy targets to be applicable over the full range of climatic conditions encountered in building design, the development process will consider extremes in the climate variables used. While it may be possible to interpolate for intermediate locations, extrapolation beyond the range of climates examined is inappropriate. The climates tested in Phase 2 will be selected carefully to provide necessary information on climate variation with a minimum number of computer simulations.

In this task, methods of compressing weather data for hourly energy simulation tools will be considered as an alternative to developing climate variables for regression equations. Past work on climate compression will be reviewed as a starting point for this alternative approach.

\section{Task 4.1.2--Coordinate with ASHRAE TC 4.3 and TC 4.7}

The project team will coordinate the research into climate, operation, and occupancy variables for the Targets Model with two ASHRAE Technical Committees: TC 4.3 and TC 4.7. This coordination will ensure that the design professionais 
involved in this area are aware of the ongoing research and can provide timely review of the overall work in this area.

\subsubsection{Task 4.2--Space-Function Characteristics Analysis}

The space-function-based methodology outlined as a result of Phase 1 is intended to be integrated into the design process to provide information early enough to be usefut in making design decisions. The tasks of Phase 2 propose a more complete and detailed examination of the elements of building design and the algorithms for defining the energy impact of decisions in each area. The primary function of this work is to refine, or perhaps even redefine, these algorithms and test their application over a much broader range of conditions than were addressed in Phase 1. Two activities will be performed in Task 4.2:

- Task 4.2.1--Define Space-Function Characteristics

- Task 4.2.2--Define Ranges for Space-Function Characteristics

\section{Task 4.2.1--Define-Space Function Characteristics}

This task will develop the first of the four components of the Targets Mode1. Phase 1 has provided a general catalog of functions commonly encountered in the design of commercial buildings and an initial attempt at defining the range of variation of those characteristics that influence the use of energy to serve the needs of each function. The primary objective of this task is to identify, and to accommodate, those factors for each space function that impact energy use but are not wholly within the control of the designer, including:

- specification of comfort and illumination conditions required by the function of the space

- operating schedules

- occupancy densities and ventilation requirements

- receptacle Toads and equipment-use schedules

- building configuration and orientation constraints imposed by the site 
- user/occupant glazing specifications

- domestic hot-water needs.

Variations in these characteristics may cause large differences in energy requirements from one building design to another. Precisely because these characteristics are largely outside the direct control of both the building designer and owner, they form inputs to any target setting procedure. The product of this task will be detailed specifications of these characteristics, the information required to identify them, and the data for each characteristic that will be used by other components of the Targets Model. This task will be coordinated with Task 6--Develop Characteristics-Selection Procedure.

Task 4.2.2--Define Ranges for Space-Function Characteristics

The expected range of variation of each space-function characteristic developed in Phase 1 will be reviewed prior to initiation of the Phase 2 analysis. Then, this task will develop ranges for each characteristic for each space function to be analyzed. Once an appropriate range for each characteristic has been defined, specific values or combinations of values to be examined in the development process will be selected to ensure that the analyses are valid over the entire domain of interest. The ranges proposed from this task for each space-function characteristic will be reviewed thoroughly, both within the Phase 2 project team and with the BIRP and TRP (formed and operating as described in Task 2).

\subsubsection{Iask 4.3--Deve?op Space-Function Loads Mode1}

Tasks $4.1,4.2,4.3$, and 4.4 together will produce the second major component of the Targets Model; Task 4.3 is related to the second major component of the Targets Model--the space-function energy model. Data will be compiled for climate variables in Task 4.1. In Task 4.2, the space-function characteristics will be developed. In Task 4.3 , the space-function loads model will be developed and in Task 4.4, the space-function energy model will be developed. They have been separated into three tasks because of the magnitude of the effort involved. Developing the space-function energy-use model is a complex 
and difficult undertaking and will require a major portion of Phase 2 resources to accomplish. In developing a space function loads model in Task 4.3, nine subtasks will be completed:

- Task 4.3.1--Evaluate Loads-Model Options

- Task 4.3.2--Define Schedule Impacts on the Space-Loads Mode1

- Task 4.3.3--Define Ventilation/Infiltration Component of Loads Model

- Task 4.3.4--Define Envelope Component of Loads Model

- Task 4.3.5--Define Lighting Component of Loads Model

- Task 4.3.6--Define Daylighting/Fenestration Component of Loads Mode1

- Task 4.3.7--Define Interna1-Loads Component of Loads Model

- Task 4.3.8--Define Latent/Sensible/Controls Component of Loads Model

- Task 4.3.9--Test and Verify Space-Loads Model

Task 4.3.1---Evaluate Loads-Mode] Options

Considerable work on a space-loads model has already been accomplished in research prior to the targets project - most notably research for development. of the proposed revision to ANSI/ASHRAE/IES Standard 90.1P. An important aspect of that research was the effort to define variation in annual space loads in terms of occupant density and ventilation requirements, lighting and equipment power density, and building envelope characteristics.

This task will consider two alternative approaches to a space function loads model (as discussed in Task 1.3): a correlation approach, and a compacted simulation approach. Results of the examination of the two approaches in this task will help inform the decision to be made in Task 1.3 on which method to use in final development of the Targets Model. Activities involved in assessing and developing each approach are discussed below.

Correlation Approach. A regression analysis, based on computer simulation data, resulted in the definition of correlation coefficients that relate annual heating and cooling loads to the thermal characteristics of the envelope, solar gain, and internal loads.

A version of this space/envelope load relationship was included in the first public review draft of ANSI/ASHRAE/IES Standard 90.1P, dated June 10 , 1985. During the public review of ANSI/ASHRAE/IES Standard 90.1P, a reviewer 
commented that the regression coefficients presented did not appear to be sufficiently responsive to variations in energy use at extremes in the range of envelope parameters and climate conditions considered.

A second public review has just been completed of a revised model that responded to the those comments. The revised model includes additional climate factors and the interactions among the variables and/or other envelope parameters.

In this Phase 2 task, the form of the model will be refined so that it can be applied to the space function approach. These modifications will be examined and tested briefly in the Phase 2 effort to verify their feasibility and applicability to the space function loads model. Also, an examination will done to see if the space-loads model can be more firmly grounded on a conceptual development from "first principles." The objective is to develop a means of establishing the loads for spaces that serve a specific function with a particular orientation and in a given climate. It is expected that part of this task will produce one of two potential products:

- a significant refinement of the current regression-based space-loads mode.

- a complete reworking of the model based upon a development from first principles.

Compacted Simulation. In this alternative approach, the primary focus is to develop a means to radically reduce computation time in one or more stateof-the-art annual hourly simulation programs with a minimum sacrifice in accuracy through the use of compaction techniques. It is assumed here that computations for a space function loads model do not need all of the algorithmic components of a full-energy simulation. For example, sufficient accuracy for purposes of the Targets Model may be attainable using far less than the 8760 hours of calculations per year in hourly simulation programs. This is just one example of compaction techniques that should be examined in this task. If this alternative is selected for final development of the Targets Model, the product will be a computational approach using compaction techniques to radically reduce computation time for a Targets Model assessment. 
A major element of this task is to assess the relative merits of the alternative approaches, correlation versus compacted simulation, and to select one or more approaches to pursue to completion in Phase 2.

\section{Task 4.3.2--Define Schedule Impacts on the Space-Loads Model}

For the correlation approach, earlier research indicates that varying occupancy, lighting, and HVAC operating schedules can be accommodated in the space-loads model by using schedule modification factors. However, tests of this concept to date have been limited and the issues related to operating schedules must be examined in more detail in Phase 2. This task will include further tests of schedule modification and the development of specific algorithms for incorporating the results into the space-ioads model.

For the compacted simulation approach, this task will involve incorporating schedules of occupancy, lighting, and HVAC operation as explicit spacefunction characteristics, with boundary conditions on operations defined by space function and sets of default conditions defined by ranges of typical operation. This would be a departure from previous approaches that usually have defined a single set of operating schedules and conditions for a space function or more typicaliy, for a building type.

Task 4.3.3--Define Ventilation/Infiltration Component of Loads Model

In the earlier SP 41 (PNL 1983) and Standard 90.1P research, the ventilation and infiltration component of the space-function-loads model has been treated as a constant, default value. In this task, the approach for simulating the ventilation and infiltration components of the loads model will be defined.

\section{Task 4.3.4--Define Envelope Component of Loads Model}

In this task, the opaque portion of the building envelope system, including insulating value and time-lag effects, will be investigated to develop a set of appropriate variables and an approach for use in the loads model.

Task 4.3.5--Define Lighting Component of Loads Mode 1

The energy component and design implications of the building lighting system will be investigated in this task. An approach for simulating the 
lighting system, including energy consumption and heat gains will be developed. An important aspect of this task is to define illumination aspects by space function as well as installed lighting power characteristics.

\section{Task 4.3.6--Define Daylighting/Fenestration Component of Loads Model}

The implications of the fenestration assemblies on the Targets Model will be investigated in this task. An approach for simulating the thermal and visual components of the fenestration assembly will be developed for vertical and horizontal fenestration assemblies.

Task 4.3.7--Define Interna 1-Loads Component of Loads Mode!

The load and energy characteristics of a given space function can vary greatly simply as a function of the magnitude and diversity of use for internal loads. In this task, ranges for both magnitude and diversity of internal loads for each space function will be identified. Multiple sets of values will also be identified for each space function for typical ranges of internal load values.

\section{Task 4.3.8--Define Latent/Sensible/Controls Component of Loads Model}

In Phase 1, three generic HVAC systems were examined. The results demonstrated a remarkable degree of similarity in the performance of the distinctly different systems when expressed in terms of the space loads imposed. However, the space-load variations examined in Phase 1 were the result of varying only the thermal transmission and shading characteristics of the glazing. The Phase 2 analysis must verify that the same relationships exist with variations in other sensible load factors. Based on the fact that the Phase 1 work showed a linear relationship between space loads and energy use it is expected that any sensible load will contribute in an additive manner to the energy use target.

However, an important issue, the effects of latent load variations on energy use, was not covered in Phase 1. These effects will be examined in Phase 2. Because it is difficult to sense the moisture content of the air within a space accurately, HVAC systems are controlled by sensing space temperature. However, since humidity is an important comfort criteria, this task 
will examine how systems controls respond to the latent loads imposed by occupants, infiltration, and other sources of moisture. This examination is based on the assumption that failure to incorporate latent load concerns into the Targets Model may limit its usefulness. Since the methods traditionally used to control humidity are often wasteful of energy, latent loads are an important issue.

Results of this task will be incorporated into either the correlation approach or the compacted simulation approach, depending upon which is selected for final development within the energy model. The same issues and variables apply to both approaches, but the techniques for inclusion in the Targets Model will differ depending upon the approach chosen.

\section{Task 4.3.9--Test and Verify Space-Loads Model}

A final but important task in developing the target space-loads model is to test the use of the space load coefficients over a broad range of parametric values to confirm that the space function approach correctly bounds the energy use characteristics of commercial buildings in the United States.

For the correlation approach, a large number of possible load-scheduleclimate combinations will be examined, and the tests will be structured carefully to minimize the number of computer runs required (and to minimize the related difficulties in managing resultant large data bases).

For both the correlation approach and the compacted simulation approach, this requires an extra measure of care in defining basic space characteristics and in analyzing the procedures used for defining climate and schedule impacts. Verification will be accomplished by comparing the results of the space-loads model with space loads calculated by D0E-2.1C, or another selected state-of-the-art simulation program, for the same range of parametric variations.

\subsubsection{Task 4.4--Develop System/Equipment/Plant Energy Model}

This task, along with Task 4.3, will produce the space-function energy-use model, the second major portion of the overall Targets Model. This task will 
use the results of Task 4.3 as input. To develop a complete space function energy model that incorporates the Task 4.3 Space Function Loads Model, the following subtasks will be completed:

- Task 4.4.1--Evaluate System/Equipment/Piant Energy-Model Options

- Task 4.4.2--Define System/Equipment Schedule Impacts on Energy Model

- Task 4.4.3--Define HVAC System and Control Component of Energy Model

- Task 4.4.4--Define HVAC Equipment Component of Energy Model

- Task 4.4.5--Test and Verify Energy Model.

For the correlation approach, this portion of the space-function energyuse model has not had the extensive foundation of research that the space loads model has had. Therefore, for the correlation approach, this portion of the Phase 2 effort will require considerable analysis and development effort. The proof-of-concept tests conducted in Phase 1 have begun to identify appropriate HVAC system factors which could translate space load estimates into estimates of energy use by means of a simple algorithm. Energy use would be determined separately for heating, cooling, and auxiliary devices.

The Phase 1 results indicated that it is possible to develop system load factors that relate space loads to the loads on the primary HVAC equipment (plant) in a straightforward way. However, this work must be extended in Phase 2 to clearly define the effects of system selection, sizing, and control on these system load factors and to assure that all factors that are fixed, and therefore not within the direct control of the designer, have been examined and can be accommodated within the targets model procedure. For a given building, design comfort criteria, operating schedules, and certain buildingconfiguration factors are fixed and may dictate some design features. For example a central VAV system would not be an option for a small-strip shopping center, nor would packaged rooftop units be an option for a 40-story office building.

For the compacted simulation approach, this task is in many ways much simpler. The task is to clearly define and implement ranges of system characteristics and load/system relationships for a wide variety of space functions. Information from elements of the correlation approach may prove helpful in guiding the development of specifics of the compacted simulation approach. 
Task 4.4.1--Evaluate System/Equipment/Plant Energy-Model Options

A major product of this task is the selection and final development for the Targets Model of the system/equipment/plant model. Whichever approach is selected, it will be necessary to define the expected outputs of the energy model. The evaluation of alternative models then becomes a comparison of the mode?s and their anticipated outputs.

If DOE-2.1C (or later version) is used as the foundation for generating the energy model, then an issue that must be resolved before beginning the development of the energy model is the differentiation of space loads from system effects in DOE-2.1C. The extraction rates given in the SS-F reports of DOE-2.1C seem to exhibit some system effects.

In the correlation approach, the process proposed for developing targets is based on being able to identify space loads in terms of space function characteristics independent of a particular thermal distribution system. The space loads are intended to reflect schedule and comfort conditions (thermostat settings) but not control features associated with a specific thermal distribution system.

It is therefore necessary to determine how best to define output from DOE-2.1C, or any model that is used, to provide an appropriate definition of the loads/system interface. Several possibilities will be considered, including, but not limited to, the use of the SYSTEMS SUM output option, selection of a simple reference system, or creation of a new intermediate output report.

Iask 4.4.2--Define System/Equipment Schedule Impacts on Energy Model

Schedules for system (pumps and fans) and equipment operation generaliy differ from those for occupancy and lighting and may include setback or setup control. To accurately characterize HVAC operation, the impact of the various control options for systems and equipment will be included in the energy model developed in Phase 2. This task will examine such schedule and control impacts and will develop appropriate methods for incorporating the impacts into the model. 
Task 4.4.3--Define HVAC System and Control Component of Energy Model

Phase 2 will extend the Phase 1 analysis to assure that all system and control factors have been examined and that the range of system options is sufficiently broad to cover all areas in which the designer might be constrained for a given set of space functions. This requires clearly stated descriptions of both the system and control characteristics that must be accommodated by the Targets Model. This, in turn, will require examining several additional systems and control strategies.

It is expected that the three generic HVAC system types considered in Phase 1 will, in fact, be suitable. However dual duct, hydronic heat pump, and fan coil system characteristics will also be examined to assure that the systems options provided for developing targets are appropriate for all circumstances.

Task 4.4.4--Define HVAC Equipment Component of Energy Model

A similar amount of effort must be invested in characterizing the appropriate factors for full- and partial-load operation of the primary HVAC equipment in the Targets Model. Most hourly energy analysis computer codes use generic performance curves to simulate equipment operation. Partial-load performance is an important (if not dominant) factor in defining equipment impact on annual energy use. For the correlation approach, the simulation procedures used to characterize the equipment factor will be carefulty examined and modified as necessary.

Task 4.4.5--Test and Verify Energy Model

A final but important task in developing the targets space function energy-use model is to test the use of the space-load coefficients, the system factors and the equipment factors over a broad range of parametric values to confirm that the space function approach correctly bounds the energy-use characteristics of commercial buildings in the United States.

For the correlation approach, there are a large number of possible loadsystem-equipment-schedule-climate combinations to be examined, and the tests 
will be structured carefully to minimize the number of computer runs required (and to minimize the related difficulties in manaing the resulting large data bases).

For both the correlation approach and the compacted simulation approach, testing and verifying the energy model require an extra measure of care in defining basic system characteristics and in analyzing the procedures used to model systems and equipment. Verification will be accomplished by comparing the results of the target-setting process developed with energy use calculated by DOE-2.1C, or another selected state-of-the-art simulation program, for the same range of parametric variations.

\subsection{TASK 5--DEVELOP ENERGY-COST AND BUILDING-COST MODEL}

In this task, the third major component of the Targets Model, the energy cost and building cost model, will be developed. This is the first of two tasks that will incorporate economic considerations into the Targets Model. This task will generate the cost models that will develop relative changes in building and energy costs based upon changes in the results of the loads and energy portions of the space function energy-use model. Then, Task 6 will incorporate economic considerations directly into the characteristics selection procedure, which is the fourth major component of the Targets Model.

There will be three activities dealing directly with costs in Task 5 for Phase 2 of the project:

- Task 5.1--Develop Building System and Component Cost Expressions

- Task 5.2--Devel op Energy-Cost Procedure

- Task 5.3--Test Energy-Cost and Building-Cost Model.

Economics provides an additional perspective and source of guidance in determining appropriate target levels, but incorporating economics in a quantitative way into the process (i.e., into the Targets Model) is complex. Therefore, several subtasks, Task 5 and Task 6 incorporate testing, along with development and implementation, in order to facilitate necessary mid-course corrections. Also, several tasks will be conducted simultaneously in order to enable early review of the performance of the integrated energy, cost, and economics procedures as a whole. Each task is described below in detail. 


\subsubsection{Task 5.1--Develop Building System and Component Cost Expressions}

Activities for this task include:

- gathering cost data

- generating preliminary arithmetic cost expressions

- implementing the cost expressions into the cost component of the overall Targets Model

- generating and distributing initial output and cost data for review

- revising the cost expressions

- regenerating output

- repeating the review process as necessary.

Building-cost expressions will be based on data from an on-line construction costs data base as well as from other sources of construction-cost information including manufacturers. In some cases, such as with electric lighting and building insulation, it will be necessary to assign costs to products based on their application in specific building spaces or in conjunction with actual building assemblies. Inherent in the process of developing cost expressions will be a process of defining appropriate materials and technologies to be costed for use in the Targets Mode1. The development of cost expressions for a full range of appropriate technologies will be important to the comprehensiveness of the full Targets Model. Therefore, the review activities in this task will focus on this aspect of the cost model.

\subsubsection{Task 5.2--Develop Energy-Cost Procedure}

In Phase 1, the analysis of alternative methods for addressing energy sources produced a ranking with two energy-cost procedures ranked highest. The TOOC method was ranked number one. This Phase 2 task has as its primary objective the further exploration of the TOOC method for use with the overall Targets Model. In addition, the task will also examine, at lower priority, the second and third ranked methods from phase 1.

The task will address the specific details and implications of incorporating and using the TOOC method (or one of the other two methods) as part of the 
overall Targets Model. This examination will include the level of detail and complexity of inputs, calculations, and outputs required, as well as the implications of the energy cost procedure on the rest of the Targets Model.

Since the TOOC method received a low rating in Phase 1 on ease of use, particular attention will be paid in this task to means of simplifying its application as part of the Targets Model. For example, using the compacted simulation approach, a life-cycle cost model could incorporate boundary conditions and sets of typical values for economic parameters to ease the application of the model.

The task will include a review of preliminary findings by both the BIRP and the TRP before a final selection of an approach to energy sources is made.

\subsubsection{Task 5.3--Test Energy-Cost and Building-Cost Model}

The objective of this task is to both test the buflding-cost and energycost model in isolation (third component of the Targets Model), and in conjunction with the space function energy use model (second component of the Targets Model). This test procedure will be designed and conducted to test the performance of the generalized building cost expressions and energy-cost procedure selected.

The specifics of the nature of the testing will depend upon the final selection of the method for addressing energy sources accomplished in the previous task. The precise details of the energy-cost procedure to be used will need to be developed in Phase 2. Part of such a determination will depend partiy on how the procedure would interact with the rest of the Targets Model.

The performance of the generalized cost expressions versus actual material selections from the building-cost data base will be tested to quantify the differences in results from basing characteristic selections on generalized costs rather than on particular costs. Small differences would indicate that the procedure works well. A planned test is to use a variety of space descriptions drawn from the SP 41 test buildings. 


\subsection{TASK 6--DEVELOP CHARACTERISTICS-SELECTION PROCEDURE}

This task will produce the fourth major component of the Targets Model-the characteristics-selection procedure, which will be an algorithmic model for generating target values, based upon input energy and economic criteria. The characteristics selection procedure is the integrating component of the model; it will use the results of the three components already described in Tasks 4 and 5. Economic criteria will also be developed for use as part of the characteristics-selection procedure. Once the economic criteria and characteristics selection procedures have been developed, they will be thoroughly tested, both in isolation and in conjunction with the other portions of the Targets Model.

There will be three tasks dealing directly with economics in Task 6 for Phase 2 of the project:

- Task 6.1--Develop Economic Criteria

- Task 6.2--Develop Characteristics-Selection Procedure Model

- Task 6.3--Test and Verify Target-Selection Procedure Mode1.

\subsubsection{Task 6.1--Develop Economic Criteria}

In this task, sets of economic criteria that define appropriate levels of economic performance will be defined for investments in building energy efficiency. Consideration of amenity, efficiency, or architectural values will be considered in the development of the economic parameters. Economic parameters will be defined initially and revised as necessary to achieve proper balance with project noneconomic objectives after initial Targets Model output has been reviewed.

The economic parameters may need to vary for different combinations of space-function type and target level, although it is likely that many of these combinations will use some of the same criteria. A small scale survey of both the BIRP and TRP will be performed to ensure that the economic assumptions on which the targets are based are well founded. A questionnaire will be developed for gathering input on appropriate building configurations and client objectives. For reasons of efficiency this questionnaire should request confirmation, modification, or replacement of specific economic parameters already 
tentatively proposed by project team members. The questionnaire will be distributed to the BIRP and TRP and preliminary consensus results will be assembled. Then, the economic criteria will be incorporated into the Targets Model to generate and distribute example target results for review. A review cycle of revised economic criteria, regeneration of example targets, and subsequent review will be repeated as necessary.

\subsubsection{Task 6.2--Develop Characteristics-Selection Procedure Model}

The characteristics selection procedure will use a combination of energy and economic criteria to select materials, systems, and technologies that will in essence define target levels for a single space function or for combinations of space functions. In combination with an energy-cost approach for address"ng energy sources, the characteristics selection procedure has the distinct advantage of explicitly incorporating economic considerations into a targets-determination procedure. In this case, the cost-effectiveness of a target level, for a particular economic perspective, would not need to be tested after-the-fact, but would be part and parcel of the target generation procedure.

This task will involve the detailed development of the specific logical and mathematical relationships for conducting the selection and/or adjustment of the appropriate space-function characteristics. Details of the specific energy and economic-input criteria needed to generate a specific set of target levels will also be defined. This task will use the results of the Phase 1 proof-of-concept selection model as a starting point. White the spreadsheet program developed in Phase 1 has performed adequately as a proof-of-concept test, it may be based on logical and mathematical techniques that are considerably less effective than others that might have been employed. Alternatives that might improve the speed of execution and the flexibility of the procedure will be considered before the final version is developed.

Specific activities for this task include reviewing the proof-of-concept model logic and revising it as necessary, programming the calculation procedures for the Targets Model, and debugging and verifying implementation of the model $\log i c$. 


\subsubsection{Task 6.3--Test and Verify Target-Selection Procedure Model}

Three objectives for testing the target selection procedure model in the Targets Model are listed below:

- test the accuracy of the material, system, and technology configurations generated by the characteristics-selection procedure

- test the accuracy of the combined performance of all four components of the Targets Model, including the space-function characteristics, the space function energy-use model, the building cost and energy cost model, and the characteristics selection procedure model itself

- assess the overall economic performance of any example target levels generated by the Target Model.

This task will first include the testing of the characteristics selection procedure by itself. The task will then test the combined performance of all four components of the Targets Model together. DOE-2.1C and existing input files that have been used for testing the SP 41 results will be used as a test vehicle.

The overall economic performance of alternative sets of example target levels can be examined once the accuracy of the configurations, cost expressions, and energy model have been established. In addition, testing activities from previous tasks should make it possible to quantitatively describe a confidence envelope around the performance of the characteristics selection procedure.

\subsection{TASK 7--DEVELOP EXAMPLE WHOLE-BUILDING ENERGY TARGETS}

The tasks related to Target Development require broad participation by members of the project team, the BIRP, and the TRP since the tasks rely heavily on professional judgment and require the knowledge from various disciplines involved in the building design process.

The task of developing demonstration target values for a range of typical situations using the Targets Model developed in the above tasks involves four major activities: 
- Task 7.1--Define Target Levels

- Task 7.2--Develop Example Space-Function Target Characteristics

- Task 7.3--Test and Refine Space-Function Target Characteristics and Assumptions

- Task 7.4--Aggregate Space Function Targets into Demonstration Case Study Whole-Building Energy Targets

- Task 7.5--Using Targets in Building Design.

\subsubsection{Task 7.1--Define Target Levels}

This task involves three main issues:

- The number of separate target performance levels that will be developed must be determined.

- Each target level must be precisely defined, including expectations for economic performance, attitude towards risk (innovative technologies), and tradeoffs between design flexibility, energy performance, and cost. Clear criteria for defining the demonstration target levels must be developed in this task to insure that individual decisions that go into the targets are made in a consistent way. Decisions about space characteristics for specific example functions will in each case be made in light of the definition of the particular target level.

- A demonstration target level must be defined that relates to ANSI/ASHRAE/IES Standard 90.1P. A number of questions must be resolved in order to develop this target level, including how the procedure will replicate ANSI/ASHRAE/IES Standard 90.1P, providing a technically equivalent performance-based version or would simplifications be used in the procedure? Also, several assumptions will need to be made about features not currently defined by ANSI/ASHRAE/IES Standard 90.1P, such as mechanical system selection. For example, would a target level be defined by the least efficient, the most efficient, or an average option? 


\subsubsection{Task 7.2--Devel op Example Space-Function Target Characteristics}

In this task, recommended values and any restrictions that will be applied to the space-function characteristics will be determined. This data will be used in the Targets Model as examples. Design constraints for the space-function characteristics will also be developed. These will be refined later as the performance implications of these values are reviewed.

\subsubsection{Task 7.3--Test and Refine Space-Function Target Characteristics and Assumptions}

The cost expressions developed in Task 5 will be reviewed so that a definition of the defining constraints on various target levels can be set. For example, should certain target levels be such that they can only be achieved cost-effectively using the most cost-effective selections or should they be set at levels that can be achieved cost-effectively using the least cost-effective material selections? If an intermediate position is appropriate how should it be defined? Resolutions of these issues would be applied in developing cost expressions for the building-cost data.

Cost expression definitions will probably need to vary with target level and may vary according to function characteristics. Once building-cost data have been compiled and tentative cost expressions have been developed, these cost expressions will be reviewed to determine their design implications.

Because many of the tasks that provide data and products for the final Targets Model must be conducted simultaneously, interrelated parts of the procedure will be developed as separate pieces and later merged. An initial review of the interaction of the various models will reveal any necessary revisions that must be made.

\subsubsection{Task 7.4--Aggregate Space-Function Targets into Demonstration Case Study Whole-Building Energy Targets}

A limited number of demonstration case study whole-building targets will be developed for several example buildings. These demonstration targets will be of value as a general reference and as a guide for very typical buildings within particular building-type categories. 
The number of demonstration whole-building targets to be developed will be determined based on the variation in building parameters known to exist for the building type and the sensitivity to the variation observed in Task 7.3. If natural categories exist for any building type and these categories are important in terms of energy use, they will be used as a basis for these example targets.

Demonstration whole-building targets will then be developed. In addition to an energy-use value (and a possible maximum-demand value), the range of each important parameter used in developing the target will be stated, including the mix of space functions, the characteristics for the example space functions, and the target levels (economic perspective) considered. Some sensitivity analysis will be conducted as part of this task.

\subsubsection{Task 7.5--Using Targets in Building Design}

This task will develop a description of how targets will be used as part of a building design process. A complete procedure will be developed for checking if a building design meets a target value. Tasks in this section will develop an integrated approach to the interface between the technical procedures and the user. The two major steps required in using customized, building-specific targets for an actual design are to generate a building-specific target value, and to calculate if the building design will meet the target.

The procedures assume that the user will use some form of computer-based analysis with the targets. At least three different types, or levels, of energy analysis tools can be used to determine if a building design meets the targets: Hourly computer-simulation tools, such as DOE-2 and BLAST; bin-based analysis tools, such as ASEAM2, that perform monthly temperature-bin calculations based on the ASHRAE TC 4.7 method; and regression-based procedures.

In this Phase 2 task a number of options will be examined as potential user interfaces during a building design. These options are as follows:

- Generate a target using the Targets Model and testing the performance of a building using a regression, bin, or hourly-based procedure of the user's choice against this value. 
- Generate a target using the Targets Model and test the design using this value using the same analysis procedure. When another type of procedure is to be used to test the building's performance, the characteristics generated by the Targets Model would be input into the procedure used for testing performance in order to generate a target that would be consistent with the testing procedure results.

- Create the input file for the Targets Model testing procedure automatically for some widely used bin and hourly procedures (such as ASEAM2 and DOE-2). Input file creation would be performed by a microcomputer-based procedure that would be distributed along with the target-generating procedure.

- Generate Targets Model inputs from an existing input file for a binbased and an hourly-based procedure using a computer program. This program would run on a microcomputer and would eliminate the need to input a description of the building being tested into the targets model provided that an input file describing that building already existed for the building being tested. 



\section{REFERENCES}

ANSI / ASHRAE/IES 90A-1980. Energy Conservation in New Building Design, Sections 1-9. Cosponsored by the American Society of Heating, Refrigerating and Air-Conditioning Engineers and the Illuminating Engineering Society, New York.

ANSI/ASHRAE/IES 90.1P. 1986. Public Review Draft of Energy Efficient Design of New Buildings Except Low-Rise Residential Buildings. Cosponsored by the American Society of Heating, Refrigerating, and Air-Conditioning Engineers and the Illuminating Engineering Society, Atlanta.

ASHRAE/IES 90-75. Energy Conservation in New Building Design, Sections 10 and 11, ASHRAE/IES 90B-1975. Cosponsored by the American Society of Heating, Refrigerating, and Air-Conditioning Engineers and the Illuminating Engineering Society, New York.

Pacific Northwest Laboratory (PNL). 1983. Recommendations for Energy Conservation Standards and Guidelines for New Commercial Buildings. PNL4870, Volumes 1-40, prepared for the U.S. Department of Energy by Pacific Northwest Laboratory, Richland, Washington. 

APPENDIX A

LIST OF BUILDING SYSTEM INTEGRATION RESEARCH REPORTS 
APPENDIX A

LIST OF BUILDING SYSTEM INTEGRATION RESEARCH REPORTS

\begin{abstract}
PNL-4358 Project Plan, Development of Recommendations to Upgrade ASHRAE/IES Standard 90A-1980 Energy Conservation in New Building Design, Pacific Northwest Laboratory, Richland, WA. June 1982 .

PNL-4435 W. M. Bowen, S. Moreno, A. R. 01sen, Climate Selection and Development of $\mathrm{Cl}$ imate Indicators, Pacific Northwest Laboratory, Richland, WA. September 1982.

PNL-5123 J. L. Stoops, J. J. Deringer, S. Moreno, H. P. Misuriel1o, Summary Report: The BEPS Redesign of 168 Commercial Buildings, Pacific Northwest Laboratory, Richland, WA. May 1984.

PNL-5143 Vol. I Weather Data for Simplified Energy Calculation Volume I. Eastern United States: TRY Data, Pacific Northwest Laboratory, Richland, WA. August 1984.

PNL-5143 Vol. II Weather Data for Simplified Energy Calculation Volume II. Middle United States: TRY Oata, Pacific Northwest Laboratory, Richland, WA. August 1984.

PNL-5143 Vol. III Weather Data for Simplified Energy Calculation Volume III. Western United States: TRY Data, Pacific Northwest Laboratory, Richland, WA. August 1984.

PNL-5143 Vol. IV Weather Data for Simplified Energy Calculation Volume IV. United States: WYEC Data, Pacific Northwest Laboratory, Richland, WA. August 1984.

PNL $-4870-1$

through 40

R. W. Reilly, Recommendations for Energy Conservations Standards and Guidelines for New Cormercial Buildings, Pacific Northwest Laboratory, Richland, WA. October 1984.

PNL-5027

J. A. Heide17, Commercial Building End-Use Energy Metering Inventory, Pacific Northwest Laboratory, Richland, WA. ApriT 1985.

PNL -5462

C. Claar, R. P. Mazzucchi, J. A. Heidell, Project on Restaurant Energy Performance End-Use Monitoring, Pacific Northwest Laboratory, Richiand, WA. June 1985.
\end{abstract}


PNL -5462

Appendices

PNL -5709

PNL -5696

PNL -5966

DOE /CE-0166

PNL -5854-1

UC-95d

PNL $-5854-2$

UC $-95 d$
C. Claar, R. P. Mazzucchi, J. A. Heide11, Project on Restaurant Energy Performance End-Use Monitoring, Pacific Northwest Laboratory, Richland, WA. June 1985.

J. A. Heidel1, J. J. Deringer, Fifth Generation Design Process Tools: Phase I Planning Report, Pacific

Northwest Laboratory, Richland, WA. November 1985.

R. W. Reilly, Recommendations for a Multi-Year Plan for Building Systems Integration Research, Pacific Northwest Laboratory, Richland, WA. January 1986.

National Association of Home Builders, Cutting Energy Costs in Mulitfamily Housing: Practical Case Studies for the Builder and Developer, Pacific Northwest Laboratory, Richland, WA. August 1986.

Volume 1 of 4. G. L. Wilfert, J. W. Callaway, Environmental Assessment: Proposed Interim Energy Conservation Standard for Design of New Federal Commercial Buildings. U. S. Department of Energy, Washington, DC. November 1986.

Volume 2 of 4 . J. M. Roop, Economic Analysis: Proposed Interim Energy Conservation Standard for Design of New Federal Commercial Buildings. U. S. Department of Energy, Washington, DC. November 1986.

Volume 3 of 4. D. B. Crawley, P. D. Gilbride, Envelope System Performance Compliance Calculation Program Documentation - Version 1.0. U. S. Department of Energy, Washington, DC. November 1986.

Volume 4 of 4. 0. B. Crawley, E. G. Stephan, Lighting Prescription and System Performance Compliance Calculation Program Documentation - Version 1.0. U. S. Department of Energy, Washington, DC. November 1986.

D. R. Crawley, R. S. Rriggs, J.W. Jones, W. W. Seaton, J. E. Kaufman, J. J. Deringer, E. W. Kennett, Development of Whole-Building Energy Design Targets for Commercial Buildings -- Phase 1 Planning, Volume 1: Final Report, Pacific Northwest Laboratory, Richland, WA. February 1987.

D. B. Crawley, R. S. Briggs, J. W. Jones, W. W. Seaton, J. E. Kaufman, J. J. Deringer, E. W. Kennett, Development of Whole-Building Energy Design Targets for Comnercial Buildings -- Phase 1 Planning, Volume 2: Technical Report, Pacific Northwest Laboratory, Richland, WA. February 1987. 
Research reports are available from:

Nationat Technical Information Service

U.S. Department of Commerce

5285 Port Royal Road

Springfield, VA 22161

A. 3 



\section{DISTRIBUTION}

No. of

Copies

OFFSITE

30

DOE Technical Information

Center

Mr. Marlin Addison

Arizona State University

Architecture and Environment Design

Tempe, AZ 85281

Mr. Charles Achilles

Inst. of Real Estate Management

$430 \mathrm{~N}$. Michigan Ave, 6th Floor

Chicago, IL 60611

Mr. John Anderson

Anderson, Mason, Dale

1615 17th Street

Denver, CO 80202

Mr. Gifford H. Albright

National Science Foundation

$1800 \mathrm{G}$ Street, NW

Washington, DC 20550

Mr. George Alexander

Veterans Administration

810 Vermont Ave, NW

Washington, DC 20420

Mr. Raymond G. Alvine

Raymond G. Alvine and Associates

1102 Douglas Street

Omaha, NE 68102

Mr. Henry R. Amistadi

Cornerstones

54 Cumberland Street

Brunswick, ME 04011
No. of

Copies

Mr. Gregg D. Ander

Southern California Edison $\mathrm{Co}$.

P.0. Box 800

Rosemead, CA 91770

Mr. Anthony A. Armstrong

Office of Energy Resources

Station 53, State House

Augusta, ME 04330

Mr. George Arnold

City of Austin Texas

3000 South I-H35

Austin, TX 78704

Mr. Donald A. Bahnfleth

ZBA, Inc.

23 East Seventh Street

Cincinnati, OH 45202

Mr. Erv Bales

Nu Institute of Technology

Bldg. Engr, and Arch. Research Ctr.

Newark, NJ 07102

Ms. Sue Balistocky

938 N. Croft

Beverly Hills, CA 90069

Mr. Chip Barnaby

Berkeley Solar Group

3140 Mart in Luther King Jr. Way

Berkeley, CA 94730

Mr. Will Beaton

TRB Hawaii, Ltd.

1001 Bishop Street

Honolulu, HI 96813

Mr. Robert Beirner

Inter. Masonry Institute

823 15th Street, NW

Washington DC 20005 
No. of

Copies

Ms. Lynn G. Rellenger

Donald McGeddy, P.E., P.C.

890 Westfall Road

Rochester, NY 14618

Mr. Dwight A. Beranek

U.S. Army Corps of Engineers

P.0. Box 103, Downtown Station

Omaho, NE 68101

$\mathrm{Mr}$. Bill Bethea

U.S. Department of Energy, CE-116

1000 Independence Ave. SW

Washington, DC 20585

Mr. Larry Bickle

Bick le Group

1177 West Loop South

Suite 240

Houston, TX 77027

Mr. James Binkley

U.S. Postal Service

Washington, DC 22060

Mr. Bruce Birdsall

Lawrence Berkeley Laboratory

1 Cyclotron Road, Building 90

Berkeley, CA 94720

Mr. Bill Bobenhausen

Energy Design Collaborative

529 Central Avenue

Scarsdale, NY 10583

5 Mr. Jean Boulin

Office of Buildings and Community Systems

U.S. Department of Energy

1000 Independence Ave., SW

Washington, DC 20585

Mr. Robert H. Braun

Charles and Braun

121 2nd Street

San Francisco, CA 94105
No. of

Copies

Mr. Gene Brewer

National Inst. of Building

Sciences

1015 15th Street, NW, Suite 700

Washington, DC 20005

Dr. James Brodrick

Gas Research Institute, Inc.

8600 West Bryn Mawr

Chicago, IL 60631

Mr. Kurt Brandle

Architectural Research Lab

College of Architecture \& Urban Planning

University of Michigan

Ann Harbor, MI 48109

Mr. Steven F. Bruning

Newcomb and Boyd Consulting

Engr.

One Northside 75

Atlanta, GA 30318

Mr. Harvey J. Bryan

Harvard University

48 Quincy Street

Cambridge, MA 02138

Mr. Fred Bueh1

Lawrence Berkeley Laboratory

1 Cyclotron Road, Bldg. 90

Berkeley, CA 94720

Mr. Huber H. Buehrer

Buehrer Group

122 East Dudley

Maumee, $\mathrm{OH} 43537$

Mr. Dave Bullen

American Institute of Architecture

1735 New York Avenue, NW

Washington, DC 20006 
No. of

Copies

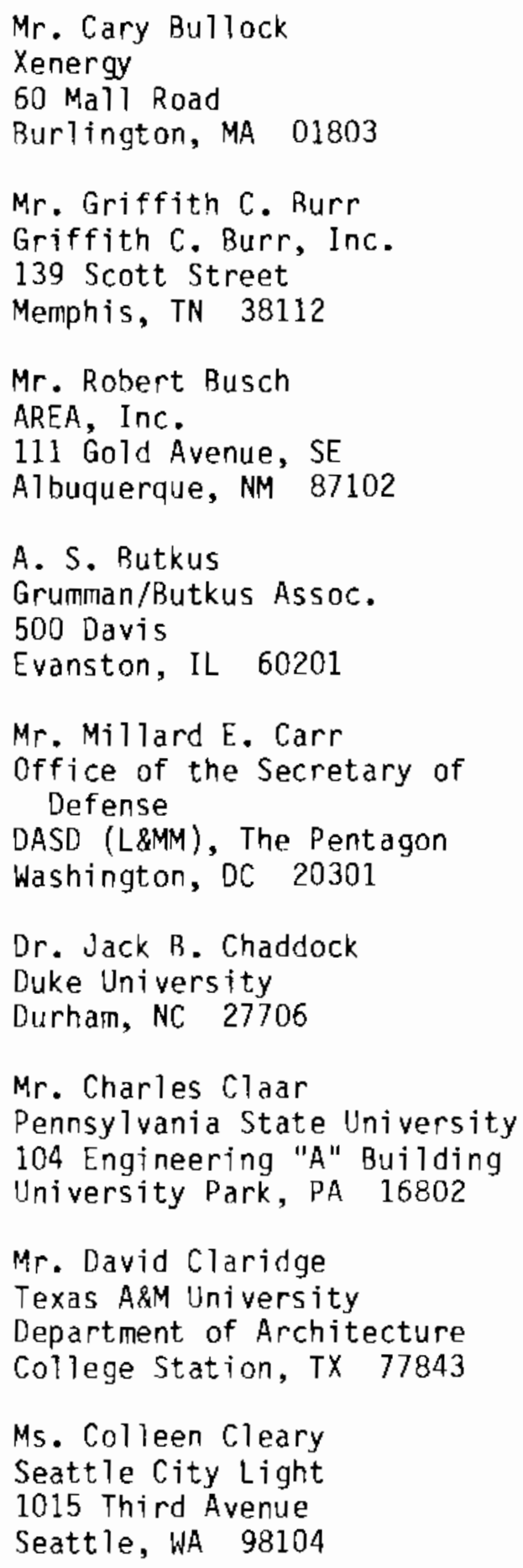

No. of

Copies

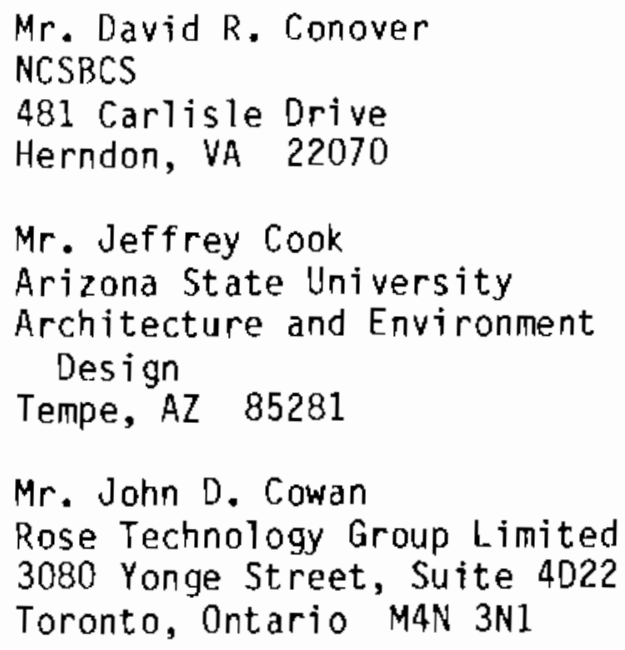


No. of

Copies

Mr. David L. DiLaura

Lighting Technologies

3060 Walnut Street, \#209

Boutder, C0 80301

Richard W. Dixon

Florida Department of

Community Affairs

2571 Executive Center

Circle, East

Tallahassee, F1 32399

Mr. Barry Donaidson

Tishman Research Corporation

666 Fifth Avenue

New York, NY 10103

Mr. Charles Eley

Charles Eley Associates

142 Minna Street

San Francisco, CA 94105

Mr. Scott Ellinwood

Scott Ellinwood and Associates

3639 Harbor Blvd.

Ventura, CA 93001

Ms. Mary Fagerson

University of Minnesota

110 Architecture

Minneapolis, MN 55455

Mr. Charles P. Farnham

LTI

P.0. Box 3532

Bellevue, WA 98009

Mr. Don Fe1ts

Don Felts and Associates

514 Second Street, NW

Albuquerque, NM 87103

$\mathrm{Mr}$. Francis Fereira

Fereira and Kalasinsky

Associates

4 Renwick Drive

Norton, MA 02766
No. of

Copies

Mr. Chico Fernandez

HQ USAF/LEEEU Bldg. 516

Bolling Air Force Base

Washington, DC 20332

Mr. Will S. Fisher

Genera1 Electric Company

Nela Park

Cleveland, $\mathrm{OH} 44112$

Mr. Bernard Fleury

E.N.T.P.E.

1 Rue Audin

69120 Vauix

en Velin, France

$\mathrm{Mr}$. Jeff Floyd

Sizemore/FToyd

1 Piedmont Center, \$200

At lanta, GA 30505

Mr. Robert N. Floyd

$A R C$ Incorporated

1004 West Avenue

Austin, TX 78701

Mr. Harrison S. Fraker

University of Minnesota

School of Architecture

Minneapolis, MN 55455

Mr. Greg Franta

ENSAR Group

66 S. Van Gordon Street, \#107

Lakewood, C0 80228

Mr. Emil Friberg

Fribert Associates

P.0. Box 2080

Forth Worth, TX 76113

Ms. Carol Gardner

Office of Buildings and Community Systems

U.S. Department of Energy

1000 Independence Ave., S.W.

Washington, DC 20585 
No. of

Copies

Mr. Sheldon B. Glickman

Lightolier, Inc.

346 Claremont Avenue

Jersey City, NJ 07305

Mr. Frank W. Godsey

Texas State Tech. Inst. - WACO

Physical Plant Department

Waco, TX 76705

Mr. David B. Goldstein

Natural Resources Defense

Council

25 Kearny Street, Suite 200

San Francisco, CA 94108

Mr. Harry Gordon

Burt, $\mathrm{Hill}$, Kosar, Rittelman

Assoc.

440 1st St. NW, Suite 500

Washington, DC 20001

Mr. James W. Griffith

James W. Griffith, Inc.

3921 Caruth Blvd.

Dallas, TX 75225

Mr. Gerald C. Groff

Carrier Corporation

P.0. Box 4800

Syracuse, NY 13221

Mr. David L. Grumman

Grumman/Butkus Associates

500 Davis Street

Evanston, IL 60201

Mr. Jeff S. Haberl

University of Colorado

CEAE Dept., Campus Box 42B

Boulder, CO 80309

Mr. J. Michael Haggans

University of Missouri

\#6 Clark Hall

Columbia, MO 65211
No. of

Copies

Mr. Roger W. Haines

908-P Ronda Sevilla

Laguna Hilis, CA 92653

Mr. Jay Hall

The Deringer Group

335 Cove Road

Riva, MD 21140

Mr. Nicholas P. Hall

Illinois Department of Energy

325 W. Adams, Room 300

Springfield, IL 62704

Mr. Jeffrey P. Harris

Lawrence Berkeley Laboratory

1 Cyclotron Road, B1dg. $90 \mathrm{H}$

Berkeley, CA 94720

Mr. David T. Harrji

Princeton University

CEES/EQUAD

Princeton, No 08544

G. Kimball Hart

Hart, McMurphy and Parks

102 W. Washington Street

Middleburg, VA 22117

Mr. Robert Hastings

EMPA-KWH

$\mathrm{CH} 8600$ - Dubendorf

Switzerland

$\mathrm{Mr}$. Volker Hartkopf

Dept. of Public Works Canada

700 Industrial Blvd. No. 5

Ottawa, Ontario Canada KIC OYg

$\mathrm{Mr}$. James A. Heidell

Synergic Resources Corporation

1511 Third Ave., Suite 1018

Seattle, WA 98103 
No. of

Copies
No. of

Copies

\begin{tabular}{|c|c|}
\hline \multirow[t]{2}{*}{$\begin{array}{l}\text { Mr. Jordan Heiman } \\
\text { J.L.H., Inc. } \\
110 \text { Stoneyside Lane } \\
\text { St. Louis, M0 } 63132\end{array}$} & $\begin{array}{l}\text { Mr. Robert Holzer } \\
\text { Holzer Energy Management Co. } \\
8332 \text { Snowden 0aks Place } \\
\text { Laure1, MD } 20708\end{array}$ \\
\hline & $\begin{array}{l}\text { Mr. Mark Hopkins } \\
\text { Ali iance to Save Energy } \\
1925 \text { K Street, NW, \#204 } \\
\text { Washington, DC } 20006\end{array}$ \\
\hline $\begin{array}{l}\text { Mr. James E. Hi } 11 \\
\text { National Bureau of Standards } \\
\text { Building } 226 \text {, Room } B 306 \\
\text { Gaithersburg, MD } 20899\end{array}$ & $\begin{array}{l}\text { Mr. Bion D. Howard } \\
\text { National Assoc. of Home } \\
\text { Builders } \\
\text { l15th M Street NW } \\
\text { Washington, DC } 20005\end{array}$ \\
\hline $\begin{array}{l}\text { Mr. Adam V. Hinge } \\
\text { New York State Energy Office } \\
\text { Two Rockefeller Plaza } \\
\text { Albany, NY } 12223\end{array}$ & $\begin{array}{l}\text { Mr. David Howe } \\
\text { Farmers Home Administration } \\
\text { l4th St. Independence Ave. SW } \\
\text { Washington, DC } 20250\end{array}$ \\
\hline $\begin{array}{l}\text { Mr. Jeff Hirsch } \\
2138 \text { Morongo Drive } \\
\text { Camarillo, CA } 93010\end{array}$ & $\begin{array}{l}\text { Mr. Jozek Hraska } \\
\text { Slovak Technica } 1 \text { University } \\
\text { Randinskeho ll }\end{array}$ \\
\hline $\begin{array}{l}\text { Mr. John Hogan } \\
\text { City of Seattle } \\
400 \text { Municipal Building }\end{array}$ & $\begin{array}{l}\text { Bratislavah, Czechos lovakia } \\
\quad 81368\end{array}$ \\
\hline Seattle, WA 98104 & $\begin{array}{l}\text { Gene Hughes } \\
\text { Sherlock, Smith and Adam }\end{array}$ \\
\hline $\begin{array}{l}\text { Mr. Mac Holder } \\
\text { L. M. Holder II I Incorporated } \\
4202 \text { Spicewood Springs Rd. }\end{array}$ & $\begin{array}{l}3047 \text { Carter Hill Rd. } \\
\text { Montgomery, AL } 36111\end{array}$ \\
\hline $\begin{array}{l}\text { Suite } 214 \\
\text { Austin, TX } 78759\end{array}$ & $\begin{array}{l}\text { Mr. Bruce Hunn } \\
\text { University of Texas at Austin } \\
10100 \text { Burnet Road }\end{array}$ \\
\hline $\begin{array}{l}\text { Mr. John Holton } \\
\text { Burt Hill Kosar Rittelman }\end{array}$ & Austin, TX 78758 \\
\hline $\begin{array}{l}440 \text { First Street, NW, } \# 500 \\
\text { Washington, DC } 20001\end{array}$ & $\begin{array}{l}\text { C. E. Janeke } \\
\text { Adaptive Resources, Inc. } \\
\text { P. } 0 \text {. Box } 187\end{array}$ \\
\hline $\begin{array}{l}\text { Mr. Mike Holtz } \\
\text { Architectural Energy Corp. } \\
8753 \text { Yates Drive, Suite } 105 \\
\text { Westminister, Co } 80301\end{array}$ & $\begin{array}{l}\text { Claremont, CA } 91711 \\
\text { Mr. John E. Janssen } \\
\text { HoneywelT TSC } \\
\text { 1000 Boone Avenue N } \\
\text { Golden Va1ley, MN } 55427\end{array}$ \\
\hline
\end{tabular}

\author{
$\mathrm{Mr}$. Robert Holzer \\ Holzer Energy Management $\mathrm{Co}$. \\ 8332 Snowden 0aks Place \\ Mr. Mark Hopkins \\ Alliance to Save Energy \\ 1925 X Street, NW, \#204 \\ Mr. Bion D. Howard \\ ational Assoc. of Home \\ 15 th M Street NW \\ Mr. David Howe \\ 14th St. Independence Ave. SW \\ Mr. Jozek Hraska \\ Slovak Technica1 University \\ Randinskeho 11 \\ ratislavah, Czechos lovakia \\ Gene Hughes \\ Sherlock, Smith and Adam \\ 047 Carter Hill Rd. \\ Mr. Bruce Hunn \\ 10100 Burnet Road \\ C. E. Janeke \\ Adaptive Resources, Inc. \\ P.0. Box 187 \\ Mr. John E. Janssen \\ 1000 Boone Avenue $\mathrm{N}$ \\ Dorley,
}


No. of

Copies

$5 \mathrm{Mr}$. Jerold Jones

University of Texas at Austin Engineering Teaching Center

Austin, TX 78712

Eino 0. Kainlauri

Iowa State University

290 College of Design

Ames, IA 55001

Jan Kalas

The Eggers Group

2 Park Avenue

New York, NY 10016

$\mathrm{Mr}$. Ron Kamerud

Lawrence Berkeley Laboratory

1 Cyclotron Road, Building 90

Berkeley, CA 94720

$5 \mathrm{Mr}$. John E. Kaufman

Il luminating Engineering Society

345 East 47 th Street

New York, NY 10017

Mr. Phil Keb

Hyatt Hotels Corporation

200 West Madison

Chicago, IL 60606

Mr. Doug Kelbaugh

University of Washington

Department of Architecture

Seattle, WA 98105

Mr. Richard M. Kelso

University of Tennessee

School of Architecture

Knoxville, TN 37916

5 Mr. Earle Kennett

AIA Foundation

1735 New York Avenue, NW

Washington, DC 20006
No. of

Copies

Mr. Steve Kimsey

Heery Energy Consultants, Inc. 880 West Peachtree St., NW

Atlanta, GA 30367

Mr. Ed Knipe

$\mathrm{B} \& \mathrm{C}$

P.0. Box 7103

Pasadena, CA 91109

Mr. Fred Kohlass

S. H. Kohlass and Associates

345 queens Street, \#401

Honolulu, HI 96813

Mr. Ted Kurkowski

U.S. Department of Energy

1000 Independence Ave., SW

Washington, DC 20585

Mr. Richard A. Kutina

American Gas Association

1515 Wilson Blvd.

Arlington, VA 22209

Ms. Linda Lawrie

U.S. Corps of Engineers

P.0. Box 4005

Champaign, IL 61820

Ms. Marlene Lee

Marlene Lee Lighting Design

153 Kearny Street

San Francisco, CA 94108

Mr. Richard C. LeVere

Manville Prod. Corp.

P.0. Box 5108

Denver, C0 80217

Mr. Harry Lobdell

Lithonia Lighting

Post Box "A"

Conyers, GA 30207 
No. of

Copies

Ms. Vivian Loftness

Carnegie-Mellon University

Department of Architecture

Pittsburg, PA 15213

Mr. John C. M. Lu

Tennessee Valley Authority

Signa T Place 35610

Chattanooga, TN 37402

Mr. Bruce T. Maeda

California Eneray Commission

1516 9th Street, MS-25

Sacramento, CA 95814

Mr. Scott Mathews

Howard Brandston Lighting

Design

141 West 24 Street

New York, NY 10011

Mr. Mike Maybaun

Cosentini

2 Pen Plaza

Suite 2750

New York, NY 10121

Mr. Edward Mazria

Mazria Associates

1700 Paseo De Peralta

Santa Fe, NM 87503

Mr. Merle McBride

Owens Corning Fiberglas

Technical Center

Granville, $\mathrm{OH} 43023$

Mr. Joe A. McCarty

U.S. Army Corps of Engineers, $\mathrm{HQ}$

20 Mass Avenue, Nw

Washington, OC 20314

Mr. Martin McCloskey

Lighting Technologies

1568 S. Bradley Drive

Boulder, C0 80303
No. of

Copies

Dr. Ross McCluney

Florida Solar Energy Center

300 State Road 401

Cape Canaveral, FL 32920

Dr. John F. McIntosh

Arizona State University

Architecture and Environment Design

Tempe, AZ 85287

5 Ms. Hayden N. Mckay

Howard Brandston Lighting Design

141 West 24th Street

New York, NY 10011

Faye C. McQuiston

Oklahoma State University

School of Mechanical Engr.

Stillwater, OK 74078

Ms. Karen L. Meadows

University of Colorado, Boulder

P.0. Box 428

Boulder, CO 80309

Laheri Mehta

Syska and Hennesey, Inc.

11 W. 42nd Street

New York, NY 10036

Mr. Alan Meier

Lawrence Berkeley Laboratory

1 Cyclotron Road

Berkeley, CA 94720

Mr. Tim Michels

Londe, Parker, Michels, Inc.

5050 0akland Avenue

St. Louis, M0 63110

Mr. John Millhone

Office of Buildings and

Community Systems

U.S. Department of Energy

1000 Independence Ave., SW

Washington, DC 20585 
No. of

Copies

Mr. Harry P. Misuriello

W.S. Fleming and Associates, Inc.

P.0. Box 15442

Washington, DC 20003

Collins P. Mitchell, Jr.

Tennessee Valley Authority

3S64D Signal Place

Chattanooga, TN 37402

Sam Mitchell

Federation of American Hospitals

1111 19th Street, NW, Suite 402

Washington, DC 20036

Mr. Gerard C. Murphy

514 Flying Dutchman

Crosby, TX 77532

Mr. Daniel Hugh Nal?

Jones, Nall and Davis

84 Peachtree St., Suite 900

Atlanta, GA 30303

Manny Nicholaides

Hufsey-Nicholaides Assoc., Inc.

2900 SW 28th Lane

Miami, FL 33133

Mr. Eric C. Nohle

New York State Energy Office

2 Rockefeller Plaza

Albany, NY 12223

$\mathrm{Mr}$. George R. Owens

The Rouse Company

10275 Little Patuzent Parkway

Columbia, MD 21044

Mr. Larry Palmiter

Ecotope, Inc.

2812 East Madison

Seattle, WA 98112
No. of

Copies

R. J. Pearson

P.0. Box 752

Madison, WI 53701

Mr. Neil R. Patterson

The Trane Company

3600 Pammel Creek Road

La Crosse, WI 54601

Mr. Bill Pennington

California Energy Commission

1516 9th Street, Mail

Station 24

Sacramento, CA 95814

$\mathrm{Mr}$. Alton Pentz

Building Owners and Managers Association

1250 Eye Street, NW

Washington, OC 20005

Ms. Norma Perry

National Association of Theater Owners

1560 Broadway, Suite 714

New York, NY 10036

Mr. John Peterson

University of Texas at Austin

10100 Burnet Road

Austin, TX 78758

Mr. Peter Pfister

Pfister Architects

2123 rd Ave North - Suite 302

Minneapolis, MN 55401

Mr. Don Prowler

2302 Locust Street

Philadelphia, PA 19140

Mr. Ted Rauh

California Energy Commission

15169 th Street

Sacramento, CA 95814 
No. of

Copies

Mr. Raymond D. Reed

Texas A\&M University

Department of Architecture

College Station, TX 77843

Mr. Gilbert H. Reiling

General Electric Company

Nelan Park

Cleveland, $\mathrm{OH} 44112$

Mr. Ronald L. Ritschard

Lawrence Berkeley Laboratory

1 Cyclotron Road

Berkeley, CA 94720

Mr. Richard Rittelman

Burt Hill Kosar Rittleman

Assoc.

400 Morgan Center

Butier, PA 16001

Mr. Scott J. Rohr

John Weidt Associates

110 W. Second Street

Chaska, MN 55318

Mr. Arthur H. Rosenfeld

Lawrence Berkeley Laboratory

1 Cyclotron Road

Berkeley, CA 94720

Mr. Robert A. Rundquist

R.A. Rundquist Associates

56 Ward Avenue

Northampton, MA 01060

$\mathrm{Mr}$. Tom Sayre

Sizemore/Floyd

1 Piedmont Center, Suite 200

At lanta, GA 30305

5 Mr. William W. Seaton

ASHRAE, Inc.

1791 Tullie Circle

At lanta, GA 30329
No. of

Copies

Mr. Scott Silver

University of Texas at Austin

10100 Burnet Road

Austin, TX 78758

Mr. Mike Sizemore

Sizemore/Floyd

1 Piedmont Center, Suite 200

Atlanta, GA 30305

Mr. James Smith

office of Buildings and Community Systems

U.S. Department of Energy, CE-131

1000 Independence Avenue, SW

Washington, DC 20585

Mr. James A. Smith

U.S. Department of Energy

1000 Independence Ave SW, CE-131

Washington, DC 20585

Mr. Fredric J. Smothers

$F$. Smothers and Associates

575 Mission Street, Suite 302

San Francisco, CA 94105

Mr. Robert H. Socolow

Princeton University

Center for Energy and Environ. Study

Princeton, NJ 08544

Mr. Rohert Sonderegger

Morgan Systems Corporation

1654 Solano Avenue

Berkeley, CA 94707

Mr. Lawrence G. Spielvogel

Lawrence G. Spielvogel, Inc. Wyncote House

Wyncote, PA 19095 
No. of

Copies

Mr. Tim Steele

Bonneville Power Administration

P.0. Box 3621

Portland, OR 97208

Mr. William K. Tao

William K. Tao and Associates

2357 - 59th Street

St. Lou is, MO 63110

Mr. Steven T. Taylor

Linford Engineering Company

P.0. Box 449

Oakland, CA 94604

Mr. Kevin Teichman

U.S. Department of Energy 1000 Independence Ave, SW

Washington, DC 20585

Mr. Albert Thumann

Association of Energy Engr.

4025 Pleasantdale Rd., $\$ 340$

At lanta, GA 30340

Mr. Tom Todd

Engineering Sciences, Inc.

2701 Union Ave., Extd,

Suite 200

Memphis, TN 38112

Mr. Nat Treadway

Public Utility Comm. of Texas

7800 Shozl Creek BIvd.,

Suite 400N

Austin, TX 78757

Mr. Tony Usibelli

Washington State Energy Office

$400 \mathrm{E}$. Union

$01 y m p i a, W A 98504$

Mr. A. Joseph Van den Berg

Edison Electric Institute

1111 Nineteenth Street, NW

Washington, DC 20036
No. of

Copies

Mr. Thomas Vonier

Thomas Vonier Associates, Inc. 3741 W. Street, NW, Suite 200 Washington, DC 20007

Tim Vrabel

Office of Energy Resources

Station 53

Augusta, ME 04333

Mr. David W. Ware

California Energy Commission

1516 9th Street, MS-25

Sacramento, CA 95814

Mr. Jack R. Warner

ACEC R\&D Foundation

1015 15th St., NW, Suite 802

Washington, DC 20005

Mr. Kellogg L. Warner

Pacific Gas and Electric Co.

77 Beale Street, Room 1113

San Francisco, CA 94106

Mr. Ernie Watkins

U.S. Navy - EP03A

200 Stovall Street

Alexandria, VA 22332

Mr. Donald Watson

P.0. Box 401

Guilford, CT 06437

Mr. Jerry $W$. White

Engineering Consultants, Inc. 6605 East State Blvd., Suite 16 Fort Wayne, IN 46815

Mr. Bruce Wilcox

Berkeley Solar Group

3140 Martin Luther King Jr. Way

Berkeley, CA 94703 
No of

Copies

Mr. Alexander Willman

ACEC/Research and Management

Foundation

1015 15th Street, NW, Suite 802

Washington, DC 20005

Fredrick Winkelmann

Lawrence Berkeley Laboratory

1 Cyclotron Road, B1dg. 90 Room 3145

Berkeley, CA 94720

Mr. Hofu Wu

Arizona State University

Architecture and Environment Design

Tempe, AZ 85287

\section{ONSITE}

DOE Richland Operations Office

J. J. Sutey

D. R. Segna
No of

Copies

\section{Pacific Northwest Laboratory}

P. K. Alley

W. B. Ashton

R. S. Briggs

D. B. Crawley (25)

R. S. Crowder

E. S. Edin

C. A. Geffen

B. M. Johnson

A. D. Lee

R. W. Reitiy

T. J. Secrest

G. M. Stokes

K. R. Taylor

R. P. Wallin

Publishing Coordination MH (2)

Technical Report Files (5) 